\title{
Lockerbie Academy: \\ Neolithic and Early Historic timber halls, a Bronze Age cemetery, an undated enclosure and a post-medieval corn-drying kiln in south-west Scotland
}

by Magnus Kirby

CFA Archaeology Ltd, Old Engine House, Eskmills Park, Station Road, Musselburgh EH21 7PQ

with contributions by

S Anderson, M Hastie, A Jackson, M Johnson, R McBride, D McLaren, P Northover, A Sheridan, J Thoms \& G Warren Illustrations prepared by L Whitelaw, K Clarke, C Evenden \& M O’Neil

Scottish Archaeological Internet Report 46, 2011 www.sair.org.uk 
Published by the Society of Antiquaries of Scotland, www.socantscot.org.uk with Historic Scotland, www.historic-scotland.gov.uk

and the Council for British Archaeology, www.britarch.ac.uk

Editor Helen Bleck

Produced by Archetype Information Technology Ltd, www.archetype-it.com

ISBN: 9780903903530

ISSN: $1773-3803$

Requests for permission to reproduce material from a $S A I R$ report should be sent to the Director of the Society of Antiquaries of Scotland, as well as to the author, illustrator, photographer or other copyright holder.

Copyright in any of the Scottish Archaeological Internet Reports series rests with the SAIR Consortium and the individual authors.

The maps are reproduced from Ordnance Survey material with the permission of Ordnance Survey on behalf of The Controller of Her Majesty's Stationery Office. (C) Crown copyright 2001. Any unauthorised reproduction infringes Crown copyright and may lead to prosecution or civil proceedings. Historic Scotland Licence No. GD 03032G, 2002.

The consent does not extend to copying for general distribution, advertising or promotional purposes, the creation of new collective works or resale. 


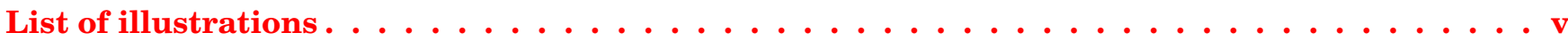

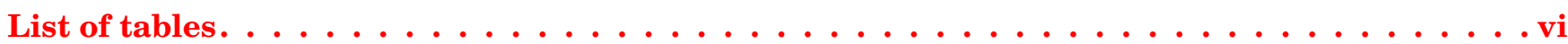

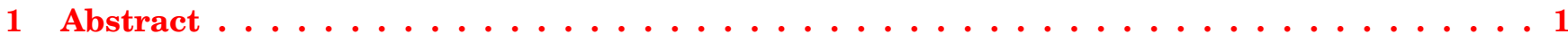

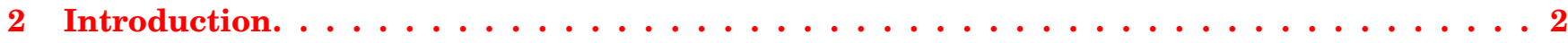

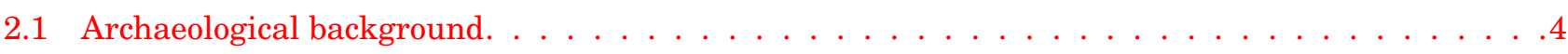

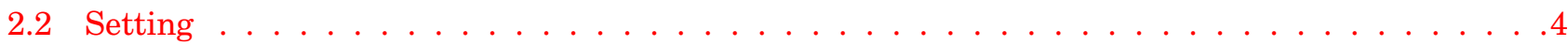

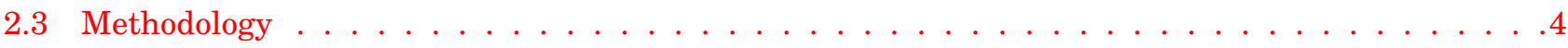

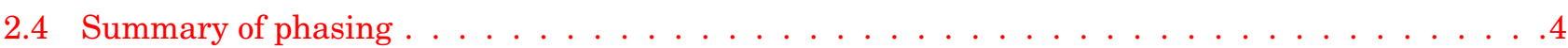

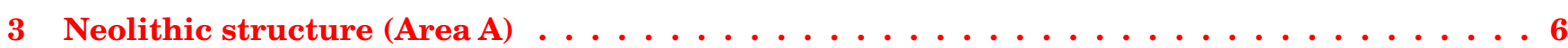

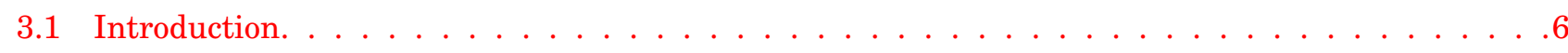

3.2 Description of the structure/structures $\ldots \ldots \ldots \ldots \ldots \ldots \ldots \ldots$

3.3 Radiocarbon dates . . . . . . . . . . . . . . . . . . . . . . . 12

3.4 Prehistoric pottery, by Alison Sheridan . . . . . . . . . . . . . . . . . . . . . . . . . 12

3.5 Fired clay, by Sue Anderson . . . . . . . . . . . . . . . . . . . . . . 18

3.6 Flint, by Graeme Warren . . . . . . . . . . . . . . . . . . . . . . . . . . . . . . . . . . . . . . . 19

3.7 Bone, by Sue Anderson . . . . . . . . . . . . . . . . . . . . . . . . . . . . 20

3.8 Charred plant remains, by Mhairi Hastie . . . . . . . . . . . . . . . . . . . . . . . 20

3.9 Discussion of the Neolithic structure . . . . . . . . . . . . . . . . . . . . . . 23

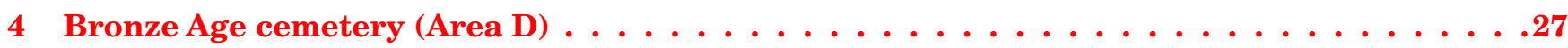

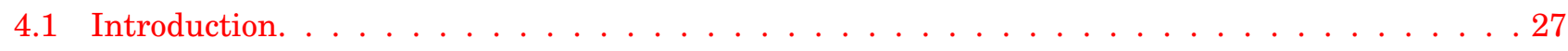

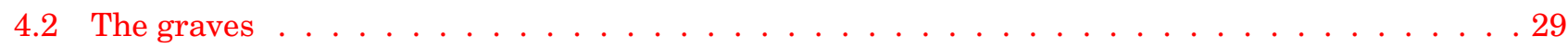

4.3 Radiocarbon dates . . . . . . . . . . . . . . . . . . . . . . . 30

4.4 Collared urn, by Melanie Johnson . . . . . . . . . . . . . . . . . . . . . . . . 30

4.5 Chipped stone, by Graeme Warren . . . . . . . . . . . . . . . . . . . . . . . . . . . . . . 31

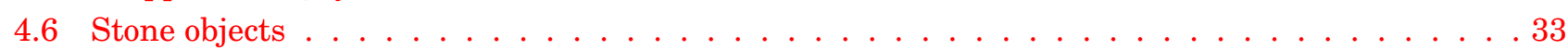

4.7 The antler pin, by Dawn McLaren . . . . . . . . . . . . . . . . . . . . . . . . . . . 34

4.8 The bronze dagger from the central grave (F33), by Alison Sheridan and Peter Northover. . . . . 35

4.9 Cremated bone, by Sue Anderson . . . . . . . . . . . . . . . . . . . . 38

4.10 Discussion of the Bronze Age funerary features, with Alison Sheridan . . . . . . . . . . . . . . 41

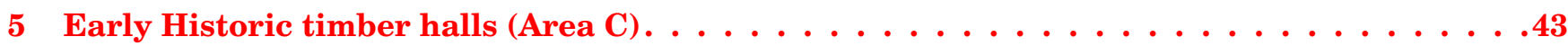

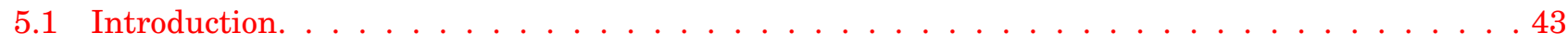

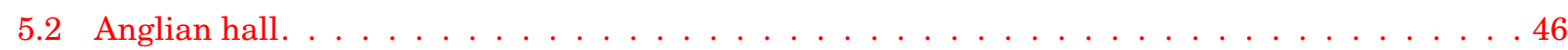

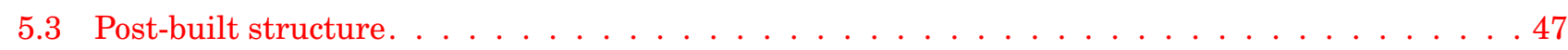

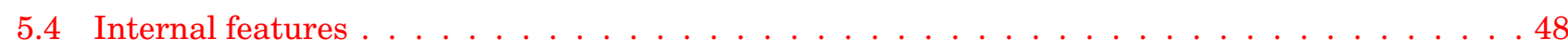

5.5 Radiocarbon dates $\ldots \ldots \ldots \ldots \ldots \ldots \ldots \ldots \ldots$ 


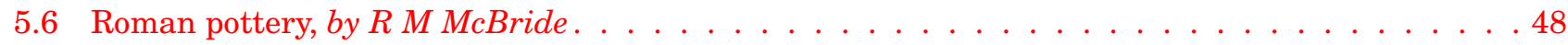

5.7 Fired clay, by Sue Anderson . . . . . . . . . . . . . . . . . . . . . . . . 48

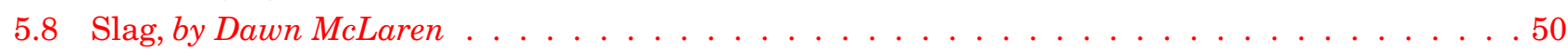

5.9 Bone, by Sue Anderson . . . . . . . . . . . . . . . . . . . . . . . . . . . . . . 50

5.10 Charred plant remains, by Mhairi Hastie . . . . . . . . . . . . . . . . . . . . . 50

5.11 Discussion of the Anglian hall and earlier structure . . . . . . . . . . . . . . . 51

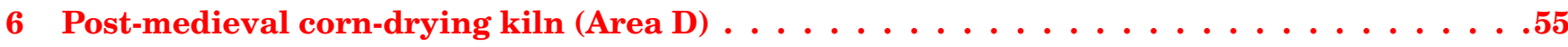

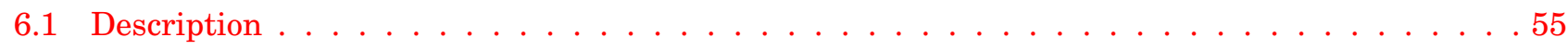

6.2 Slag, by Dawn McLaren . . . . . . . . . . . . . . . . . . . . . . . . . . . 55

6.3 Other finds, by Sue Anderson . . . . . . . . . . . . . . . . . . . . . . . . . 55

6.4 Animal bone, by Jennifer Thoms . . . . . . . . . . . . . . . . . . . . . . . . . 55

6.5 Charred plant remains, by Mhairi Hastie . . . . . . . . . . . . . . . . . . . 57

6.6 Discussion of the corn-drying kiln, by Mhairi Hastie . . . . . . . . . . . . . . . . . . . . 57

7 Segmented ditched enclosure $($ Area B) $\ldots \ldots \ldots \ldots \ldots \ldots \ldots \ldots$

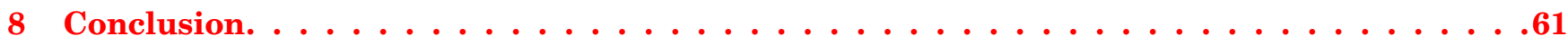

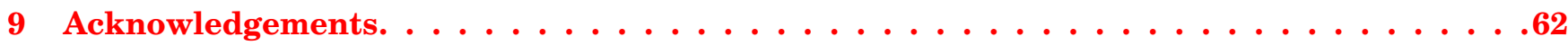

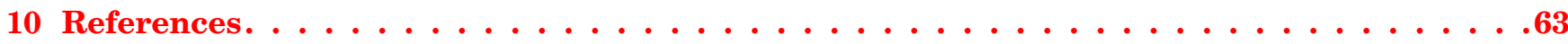




\section{LIST OF ILLUSTRATIONS}

Site location map. . . . . . . . . . . . . . . . . . . . . . . . . . 2

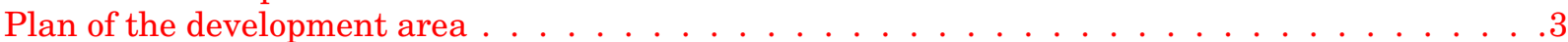

Plan of Area A: Neolithic structure and other features. . . . . . . . . . . . . . . . . . . .6

Possible interpretations of the structure . . . . . . . . . . . . . . . . . . . .

The excavated structure from the north . . . . . . . . . . . . . . . . . . . 8

The excavated structure from the south . . . . . . . . . . . . . . . . . . . .8

Selected sections of post-holes and construction trenches . . . . . . . . . . . . . . .

Distribution of the pottery and the lithics . . . . . . . . . . . . . . . . . . . 13

Neolithic pottery. . . . . . . . . . . . . . . . . . . . . . 16

Neolithic pottery . . . . . . . . . . . . . . . . . . . . . . . 17

Lithics . . . . . . . . . . . . . . . . . . . . . . . . . . 19

Plan of Area D: funerary features and medieval corn-drying kiln . . . . . . . . . . . . . . . . 27

Selected sections of graves. . . . . . . . . . . . . . . . . . . . . . . . . . 28

Area D collared urn (F35) . . . . . . . . . . . . . . . . . . . . . . . . . . . . 31

Area D finds from F34 and arrowhead No. 10 from F33 . . . . . . . . . . . . . . . . . . 32

Dagger from F33 . . . . . . . . . . . . . . . . . . . . . . . . . . . . 35

Dagger: microscope photographs . . . . . . . . . . . . . . . . . . . 36

Plan of Area C: Anglian hall and earlier structure . . . . . . . . . . . . . . . . . . . . . . 43

Separated plans of the Anglian hall and earlier structure. . . . . . . . . . . . . . . . . . . 44

Anglian hall and earlier structure from north . . . . . . . . . . . . . . . . . . . . . 45

Anglian hall and earlier structure from east . . . . . . . . . . . . . . . . . . . . . . . 45

Anglian hall, selected sections of post-holes and construction trenches. . . . . . . . . . . . . 46

Fired clay. . . . . . . . . . . . . . . . . . . . . . . . . . . . 49

Section of corn-drying kiln. . . . . . . . . . . . . . . . . . . . . . . . . 56

Area B: segmented ditched enclosure . . . . . . . . . . . . . . . . . . . . . . 59 


\section{LIST OF TABLES}

1 Radiocarbon dates from the Neolithic structure . . . . . . . . . . . . . . . . . 5

2 Composition of primary lithic technology . . . . . . . . . . . . . . . . . . . 19

3 Neolithic timber hall: summary of carbonised cereal remains by feature type . . . . . . . . 21

4 Radiocarbon dates from the Bronze Age cemetery . . . . . . . . . . . . . . . . . . 30

5 Element analysis of samples from the dagger blade . . . . . . . . . . . . . . . 38

6 Percentages of identified fragments out of total identified to area of skeleton . . . . . . . 38

7 Summary of EBA cremation burials . . . . . . . . . . . . . . . . . . . . . 39

8 Radiocarbon dates for the post-built and Anglian structures . . . . . . . . . . . . . . 48

9 Anglian hall: summary of carbonised cereal remains by feature type. . . . . . . . . . . . 50

10 Radiocarbon dates from corn-drying kiln . . . . . . . . . . . . . . . . . . . 55

11 Summary of plant remains recovered from the corn-drying kiln . . . . . . . . . . . . . 57 


\section{ABSTRACT}

Trial trenching carried out by CFA Archaeology Ltd in 2006 to the north of Lockerbie Academy identified four areas of archaeological significance covering a timescale from early Neolithic to postmedieval periods. The earliest site identified was the remains of a Neolithic timber hall, which was situated on top of the flat plateau towards the northwest end of the site (Area A). Pottery recovered from the Neolithic structure was of the Carinated Bowl ceramic tradition.

At the summit of the rounded knoll in the centre of the area (Area D) a Bronze Age phase consisting of a cremation and inhumation cemetery enclosed by a possible ring-cairn was identified. The Bronze Age cemetery included a Collared Urn and a copper alloy dagger of Butterwick type.

At the base of the rounded knoll, the remains of an Early Historic timber hall were identified (Area
C). This Anglian timber hall reoccupied the site of a post-built structure, which was interpreted as a timber hall, possibly belonging to an earlier British tradition. Radiocarbon dates taken from the primary fill of two of the post-holes of the earlier structure gave dates which are broadly contemporary with the dates obtained for the Anglian hall, suggesting that the post-built structure immediately preceded it.

A corn-drying kiln was identified cut into the same knoll as the Bronze Age cemetery (Area D) and has been dated to the late medieval or early post-medieval period.

A segmented ditched enclosure was located towards the north-east end of the site (Area B), but the poor survival of this feature combined with a lack of finds and palaeobotanical evidence means that it remains undated and poorly understood. 


\section{INTRODUCTION}

In January 2006, CFA Archaeology Ltd (CFA) was commissioned by Dumfries \& Galloway Council to undertake archaeological trial trenching in an area earmarked for the construction of a new primary and secondary school for the Lockerbie area. The area lay to the north of the existing Lockerbie Academy on agricultural land bordering the West Coast Mainline Railway (NGR: NY 1339 8273 ; illus 1), within a broad valley that serves the vital role of permitting easy access between the central belt of Scotland and the north of England. Located on what would probably have been an important trade route stretching back for many millennia and situated within Dryfedale, $c 200 \mathrm{~m}$ to the east of the Kirk Burn at an altitude of $c 70 \mathrm{~m} \mathrm{OD}$, this area was considered to have excellent archaeological potential. The topography of the area consists of gently rolling fields with a flat plateau towards the northern end of the site and a low rounded knoll towards the centre. This knoll (SMR No. DG 21026) had been identified in the $1960 \mathrm{~s}$, by local archaeologist William F Cormack, as a site of archaeological potential but no invasive fieldwork had previously been carried out. Trial trenching carried out by CFA identified four areas of archaeological significance (illus 2) covering a time scale from early Neolithic to postmedieval periods.
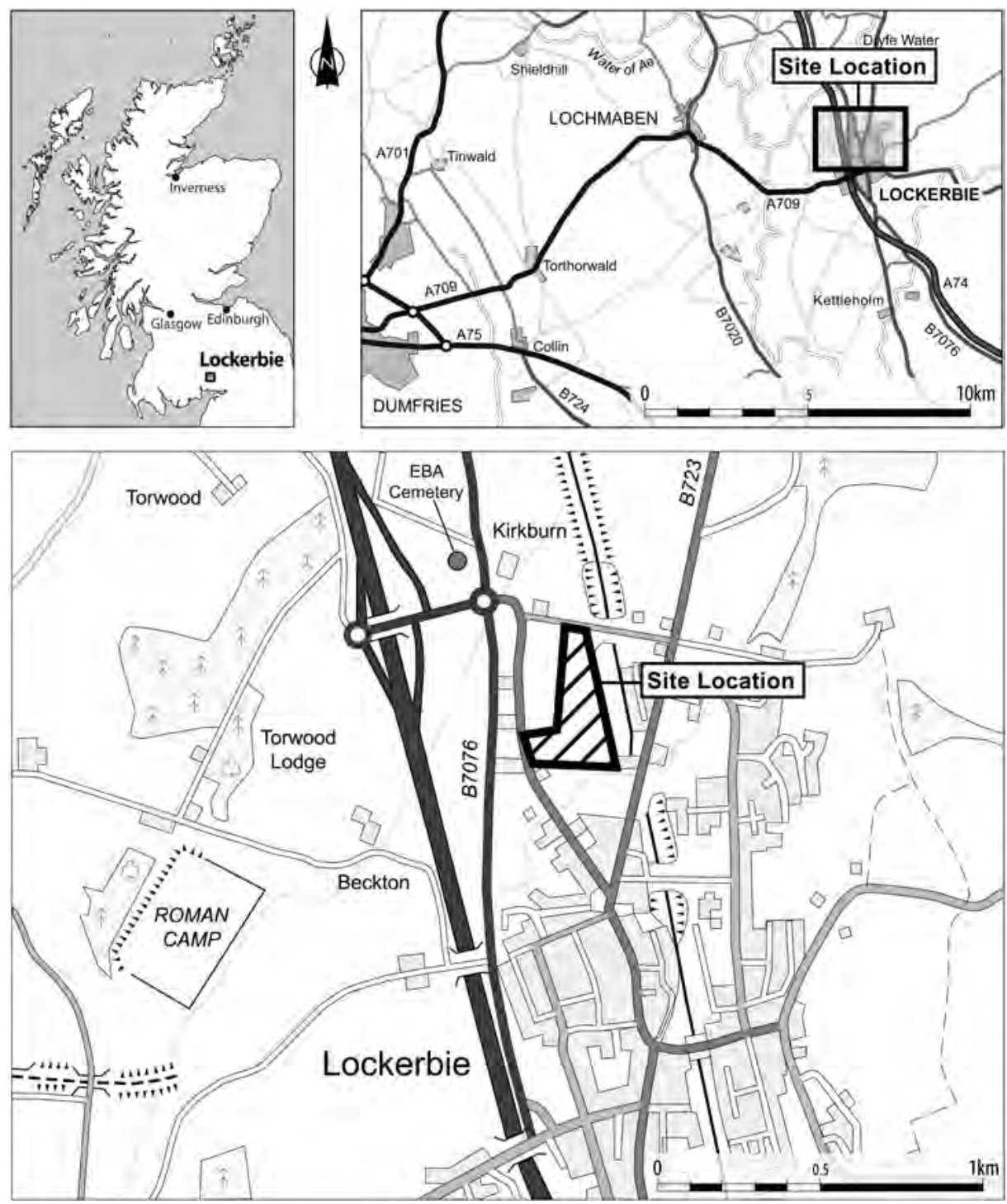

Illus 1 Site location map 

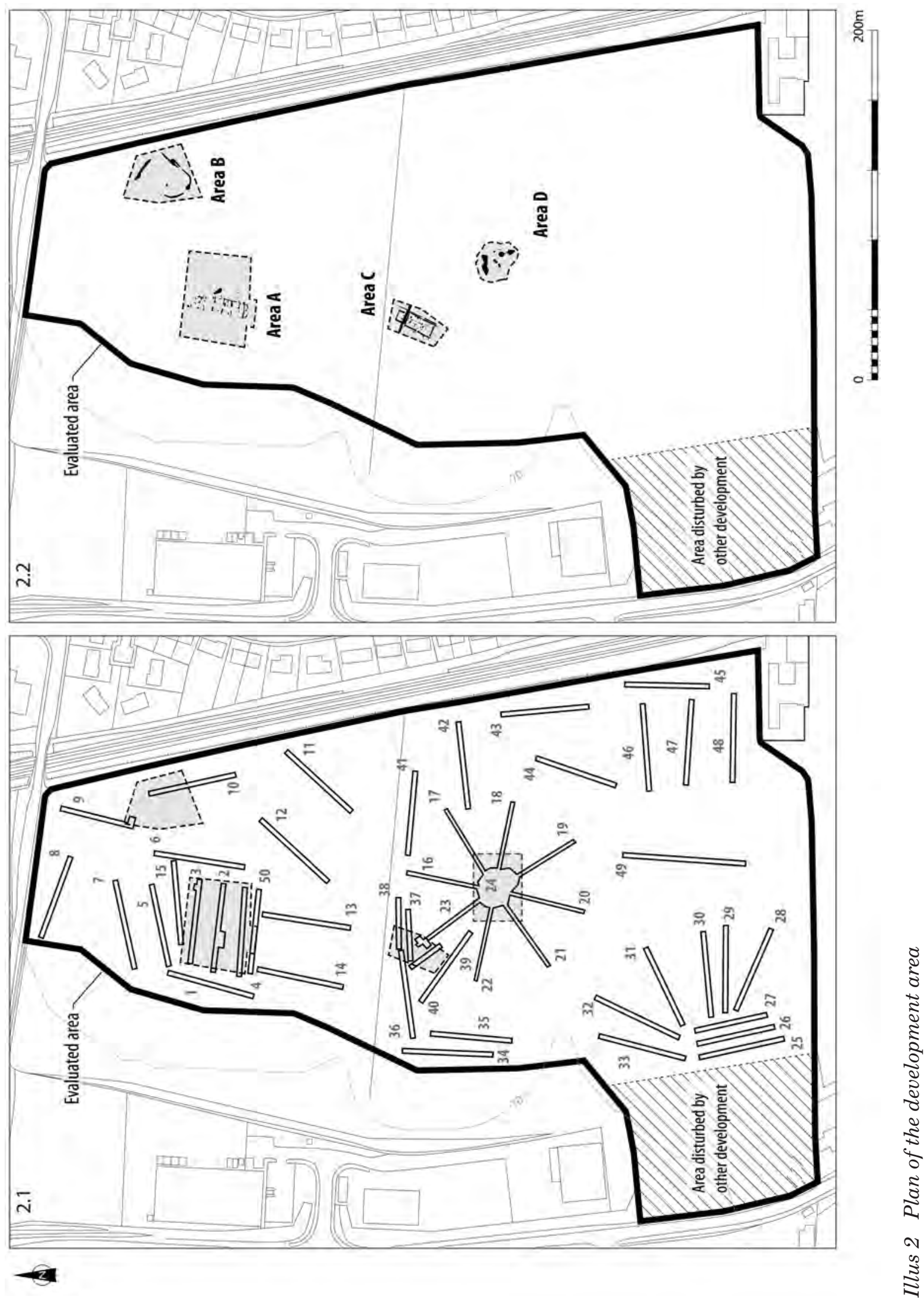


\subsection{Archaeological background}

The fertile plains of Dryfedale have been well suited for the purpose of settlement since prehistory and this is reflected in the quantity of archaeological sites within close proximity to the Lockerbie Academy site. Of particular note are the Late Neolithic/ Early Bronze Age cemetery at Kirkburn (NMRS ref NY18SW 16; Cormack 1963) and a Neolithic lithicworking, ritual and settlement site at Beckton Farm (NY18SW 95; Pollard 1997). Other sites within the vicinity include a palisaded enclosure at Harthill (NY18SW 15), a burnt mound at Muirhead (NY18SW 100), an enclosure at Torwood (NY18SW 62) and a polished stone axe (NY18SW 21) found at nearby Broomhouse Farm.

The recognition of the Lockerbie Academy site as an area of archaeological potential can be credited to the late William F Cormack, who identified an area of oyster shell and stone at the summit of the low knoll towards the centre of the proposed development area. Having excavated the cremation cemetery at Kirkburn in 1961 (Cormack 1963), Cormack considered that this knoll had the potential to be a site of a similar nature. It is also largely thanks to the quantities of lithics recovered by Cormack during his fieldwalking exploits that the Neolithic settlement and ritual complex at Beckton Farm were identified and subsequently excavated by GUARD (Pollard 1997). Given the archaeological potential of the knoll, combined with the fact that Kirkburn and Beckton Farm lie only $c 300 \mathrm{~m}$ to the north-west and $400 \mathrm{~m}$ to the west respectively, a planning condition requiring a programme of archaeological trialtrenching was applied to the proposed development by Dumfries \& Galloway Council.

\subsection{Setting}

The Lockerbie Academy site was situated on the eastern edge of an expanse of open farmland close to the confluence of the Dryfe Water and the Annan Water. As well as being fertile and containing a plentiful supply of water, this location would potentially have had contacts with other areas via the rivers of the Dryfe Water, the Annan Water, the Kinnel Water and the Water of Ae. The site itself was positioned on the edge of higher ground that sloped eastward to a height of $223 \mathrm{~m}$. This area is likely to have been better draining than the lowerlying ground containing the major rivers, and a fast-flowing watercourse that ran down from the southern flank of the Hass would have provided a reliable source of clean drinking water.

\subsection{Methodology}

In agreement with the Dumfries \& Galloway Council Archaeologist, fifty trial trenches were excavated amounting to $5000 \mathrm{~m}^{2}$ (illus 2.1). The greatest con- centration of trenches was placed on the flat plateau towards the northern end of the area and on the rounded knoll in the centre. Fewer trenches were placed on the low-lying ground because it was considered to be of lower archaeological potential.

Four concentrations (Areas A-D; illus 2.2) of archaeological features were identified and soilstripping within these areas was extended; intensive hand-cleaning was undertaken to reveal the full extent of the features. The resultant open area excavations had the following maximum dimensions: Area A 50m $\times 50 \mathrm{~m}$; Area B $35 \mathrm{~m} \times 35 \mathrm{~m}$; Area C $30 \mathrm{~m} \times 20 \mathrm{~m}$; Area D $25 \mathrm{~m} \times 25 \mathrm{~m}$. The extent of the subsequent mitigation measures was decided by the Dumfries \& Galloway Council Archaeologist.

\subsection{Summary of phasing}

The earliest site identified was the remains of a Neolithic timber hall, which was situated on top of the flat plateau towards the north-west end of the site (Area A). Pottery recovered from the Neolithic structure was of the Carinated Bowl ceramic tradition, suggesting a date of $3950 \mathrm{BC}$ to $3700 \mathrm{BC}$. These dates have been backed up by radiocarbon dating taken from grains of charred emmer wheat, hazelnut shell and willow, which produced an earliest date of 3950-3700 cal $\mathrm{BC}(2 \sigma)$ and a latest date of 3770-3630 cal $\mathrm{BC}(2 \sigma)$ (Table 1). They are broadly contemporary with the dates obtained from the Neolithic timber halls excavated at Balbridie Farm, Aberdeenshire (Ralston 1982; Fairweather \& Ralston 1993), Claish, Stirling (Barclay et al 2002) and Warren Field (also known as Crathes), Aberdeenshire (Murray \& Murray 2004).

At the summit of the rounded knoll in the centre of the area (Area D) a Bronze Age phase consisting of a cremation and inhumation cemetery enclosed by a possible ring-cairn was identified. The Bronze Age cemetery was initially dated by the presence of a Collared Urn of a type generally dating between $1900 \mathrm{BC}$ and $1600 \mathrm{BC}$ and a copper alloy dagger of Butterwick type, of which comparable examples have been dated to between $2200 \mathrm{BC}$ and $1950 \mathrm{BC}$. Radiocarbon analysis produced an earliest date of 2140-1910 cal $\mathrm{BC}$ and a latest date of $1910-1690 \mathrm{cal} \mathrm{BC}(2 \sigma)$.

At the base of the rounded knoll, the remains of an Early Historic timber hall were identified (Area C). The interpretation of this structure as belonging to the Anglian period was initially based on the ground plan, which closely resembled examples from Yeavering, Northumberland (Hope-Taylor 1977), Sprouston, Borders (known from cropmarks only) and Doon Hill, East Lothian (Hope-Taylor 1980). This interpretation is supported by radiocarbon dates taken from charred barley, which give an earliest date of 430-620 cal $\mathrm{AD}(2 \sigma)$ and a latest

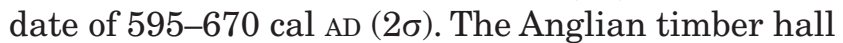
reoccupied the site of a post-built structure, which was interpreted as a timber hall, possibly belonging to an earlier British tradition. Radiocarbon dates 
Table 1 Radiocarbon dates from the Neolithic structure

\begin{tabular}{|c|c|c|c|c|c|c|}
\hline $\begin{array}{l}\text { SUERC Lab } \\
\text { No. }\end{array}$ & Context & Type & Species & Date BP & $\begin{array}{c}\text { Calibrated } \\
1 \sigma \mathrm{BC} \\
\end{array}$ & $\begin{array}{c}\text { Calibrated } \\
2 \sigma \text { BC }\end{array}$ \\
\hline 19247 & F114/02 & Charred grain & Emmer wheat & $4950 \pm 35$ & $3770-3660$ & $3800-3650$ \\
\hline 19248 & F114/02 & Charred grain & Emmer wheat & $4920 \pm 30$ & 3710-3655 & $3770-3640$ \\
\hline 19249 & F17/02 & Charred grain & Emmer wheat & $4990 \pm 40$ & $3900-3700$ & $3940-3650$ \\
\hline 19250 & F17/02 & Charred grain & Emmer wheat & $5020 \pm 30$ & $3940-3710$ & $3950-3700$ \\
\hline 19254 & F144/02 & Charred grain & Emmer wheat & $4925 \pm 30$ & $3715-3650$ & $3770-3640$ \\
\hline 19255 & F144/02 & Charred grain & Emmer wheat & $4915 \pm 30$ & $3705-3655$ & 3770-3640 \\
\hline 19256 & F149/02 & Charred grain & Emmer wheat & $4955 \pm 35$ & $3775-3690$ & $3800-3650$ \\
\hline 19257 & F149/02 & Charred grain & Emmer wheat & $4915 \pm 25$ & $3705-3655$ & $3760-3640$ \\
\hline 19258 & F117/02 & Charred grain & Emmer wheat & $4980 \pm 30$ & 3780-3705 & $3920-3660$ \\
\hline 19259 & F117/02 & Charred grain & Emmer wheat & $4890 \pm 30$ & 3695-3645 & $3720-3630$ \\
\hline
\end{tabular}

taken from the primary fill of two of the post-holes of the earlier structure gave dates of 550-660 cal $\mathrm{AD}$ and $600-675$ cal $\mathrm{AD}(2 \sigma)$, which is broadly contemporary with the dates obtained for the Anglian hall, suggesting that the post-built structure immediately preceded it.

A corn-drying kiln was identified cut into the same knoll as the Bronze Age cemetery (Area D). Corn-drying kilns have been in use in the northwest of the British Isles since Roman times (Scott 1951), but the vast majority of those recorded are post-medieval in date (Cormack 1981). Radiocarbon dating on charred oats taken from the fire-pit of the Lockerbie Academy kiln gave an earlier date of 1450-1640 cal AD and a later date of 1510-1800 cal $\mathrm{AD}(2 \sigma)$. The Hearth Tax Lists of 1692 indicate that corn-drying kilns were relatively rare in Dumfriesshire (Adamson 1970-72), but were comparatively common in Wigtonshire, with perhaps one for every half-dozen households (Cormack 1981).

A segmented ditched enclosure was located towards the north-east end of the site (Area B), but the poor survival of this feature combined with a lack of finds and palaeobotanical evidence means that it remains undated and poorly understood. 


\section{NEOLITHIC STRUCTURE (Area A)}

\subsection{Introduction}

The Neolithic timber structure (illus 3-7) was situated in a prominent raised position at the top of a flat plateau and its foundations had been cut into free-draining sandy gravel subsoil. Overall, the structure appeared to measure up to $c 27 \mathrm{~m}$ north-to-south by $c 8 \mathrm{~m}$ east-to-west, giving it a ratio of almost 3.5:1. Ian Ralston (pers comm) has suggested that the broadly east-west alignment of the Neolithic structures excavated at Balbridie, Claish and Warren Field related to the direction of

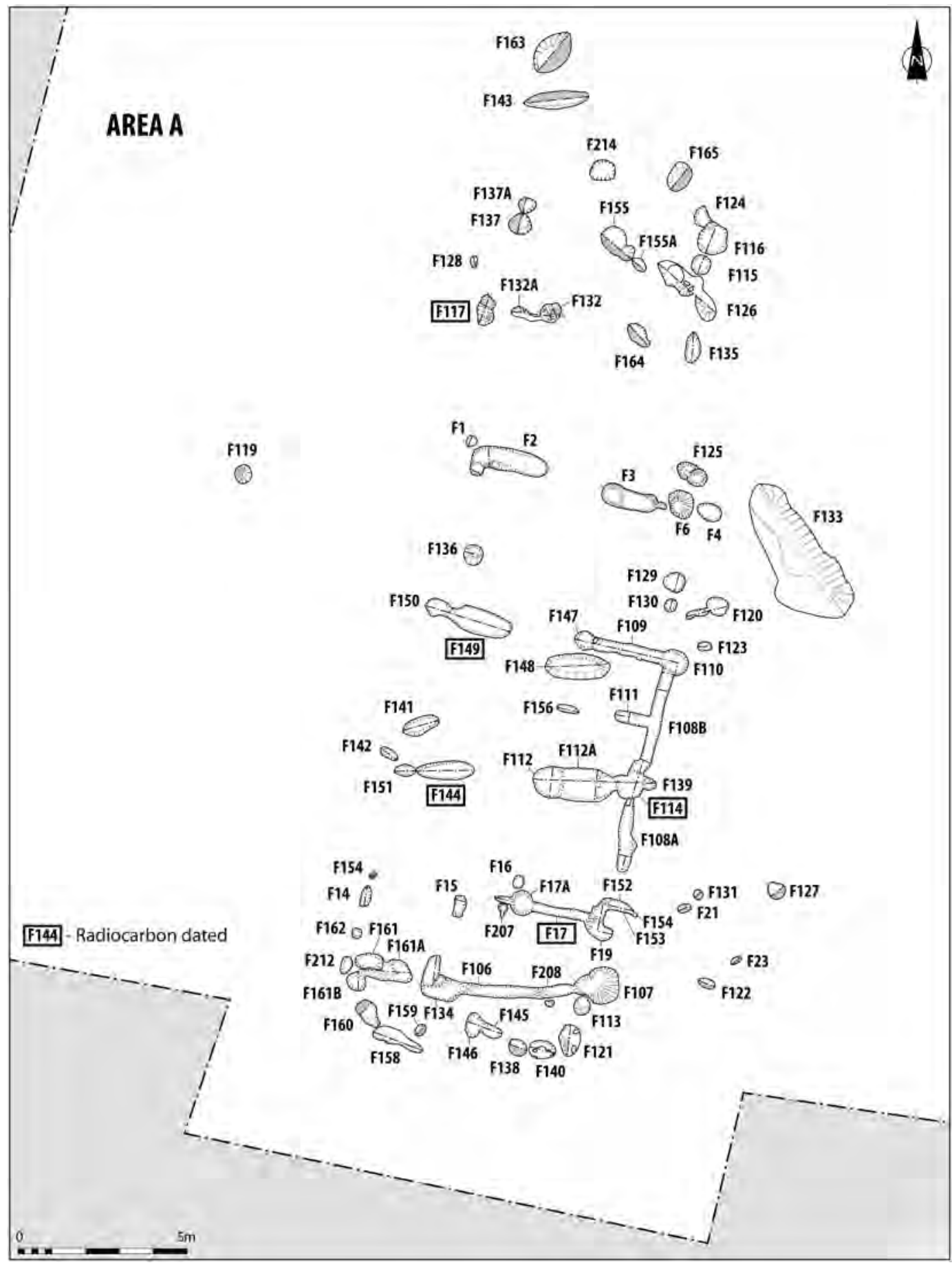

Illus 3 Plan of Area A: Neolithic structure and other features 


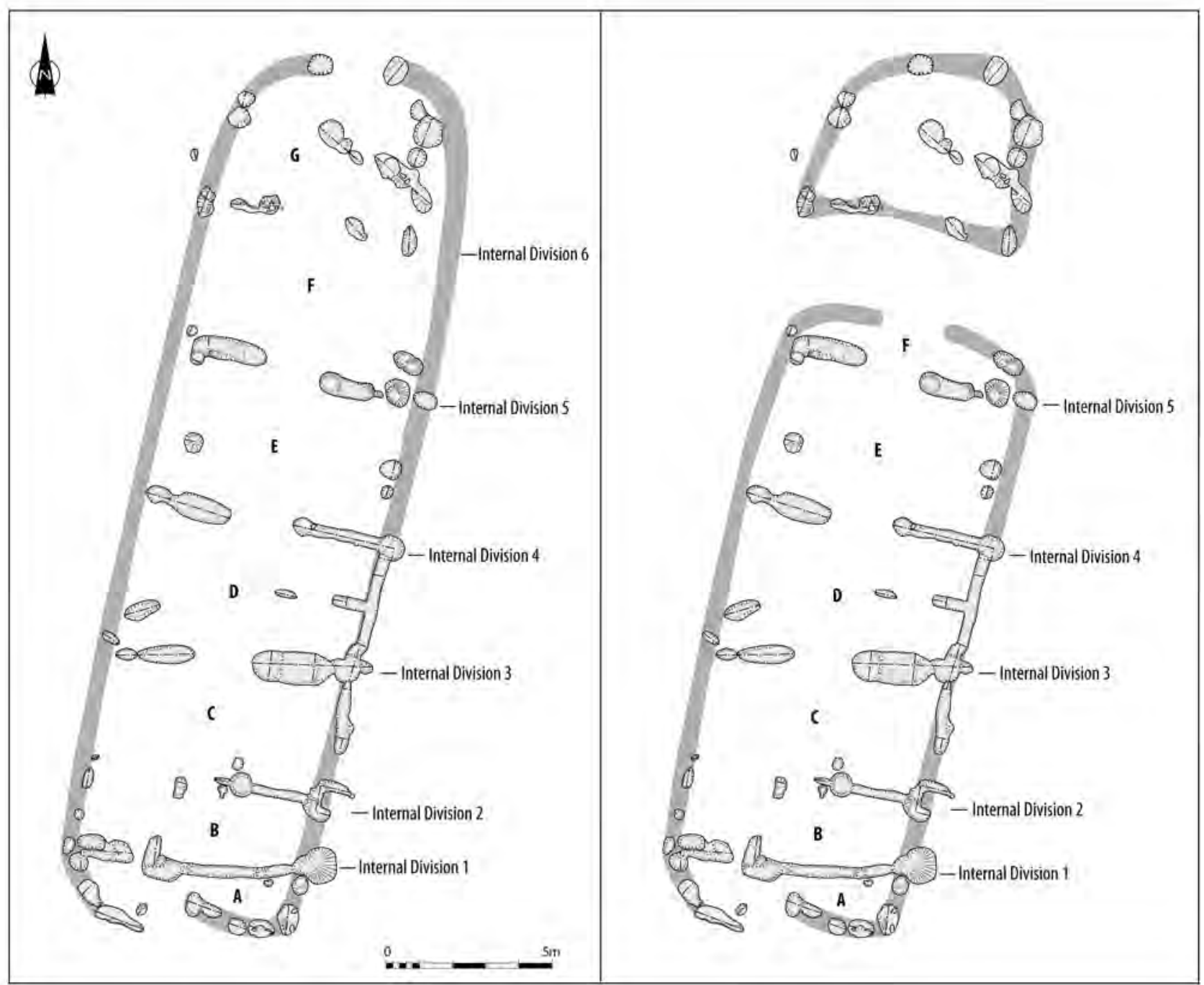

Illus 4 Possible interpretations of the structure

the prevailing wind in their respective valleys and the north-south alignment of the Lockerbie Academy hall might relate to northerly winds being funnelled through Dryfedale where it narrows to the north. The northern end of the structure was slightly offset from the southern end, meaning that an alternative interpretation of these features as two separate structures measuring $c 19 \mathrm{~m} \times 8 \mathrm{~m}$ and $7.5 \mathrm{~m} \times 5.5 \mathrm{~m}$ respectively is possible. The excavators consider it to be possible that the offset nature of this part of the structure may have been the result of structural features having been removed by plough truncation. However, it was not clear why the degree of truncation should have been more severe within certain parts of the structure than it was in others. Both interpretations of the remains, that they constituted a single structure or two juxtaposed ones, will be considered in the following text (illus 4).

The walls of the structure, where they survived and could clearly be identified, were defined by a combination of construction trenches, post-pits, and separate post-holes, which were of varying sizes and had been cut to varying depths into the subsoil.
These features appear to have represented a single phase of construction. Some of the post-holes showed evidence of having been re-cut, but it is thought that this is most likely to represent the replacement of single posts after they had started to rot. The fill of the features predominantly consisted of silty sand, with the ratio of sand to silt increasing towards the base.

Internally, the building appeared to be divided into compartments by walls that ran at right angles from the external western and eastern walls towards the centre of the building, creating a wide central aisle running much of the length of the building from north to south. The internal divisions comprised substantial post-holes, suggesting that this was a roofed structure. Slight reddening of the subsoil within the interior of the building, which is visible on some of the site photographs, and charcoal from within some of the post-holes, suggests that the building may have burnt down. Pottery and lithics recovered from the structure also showed evidence of burning.

All features thought to be associated with the 


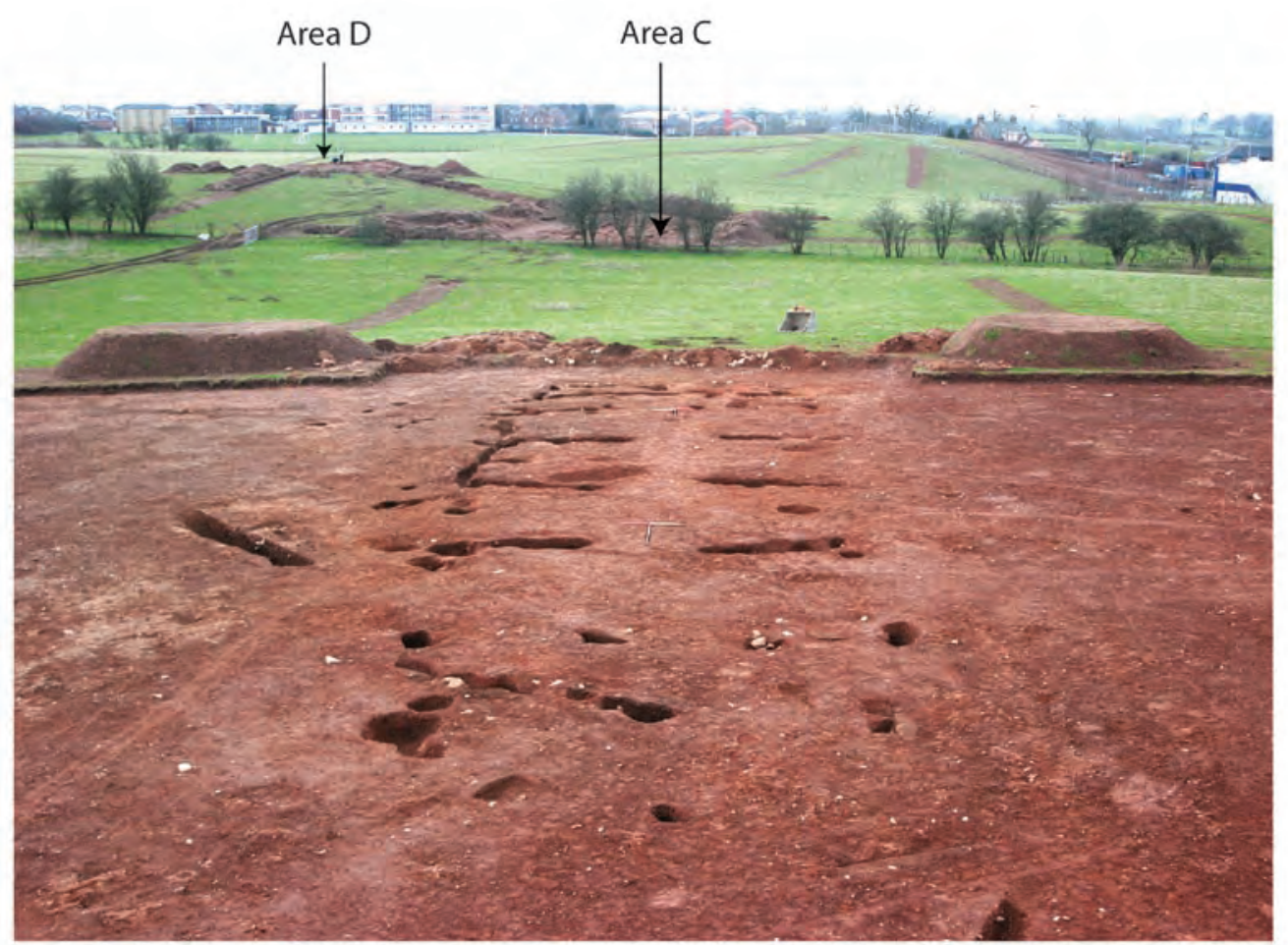

Illus 5 The excavated structure from the north

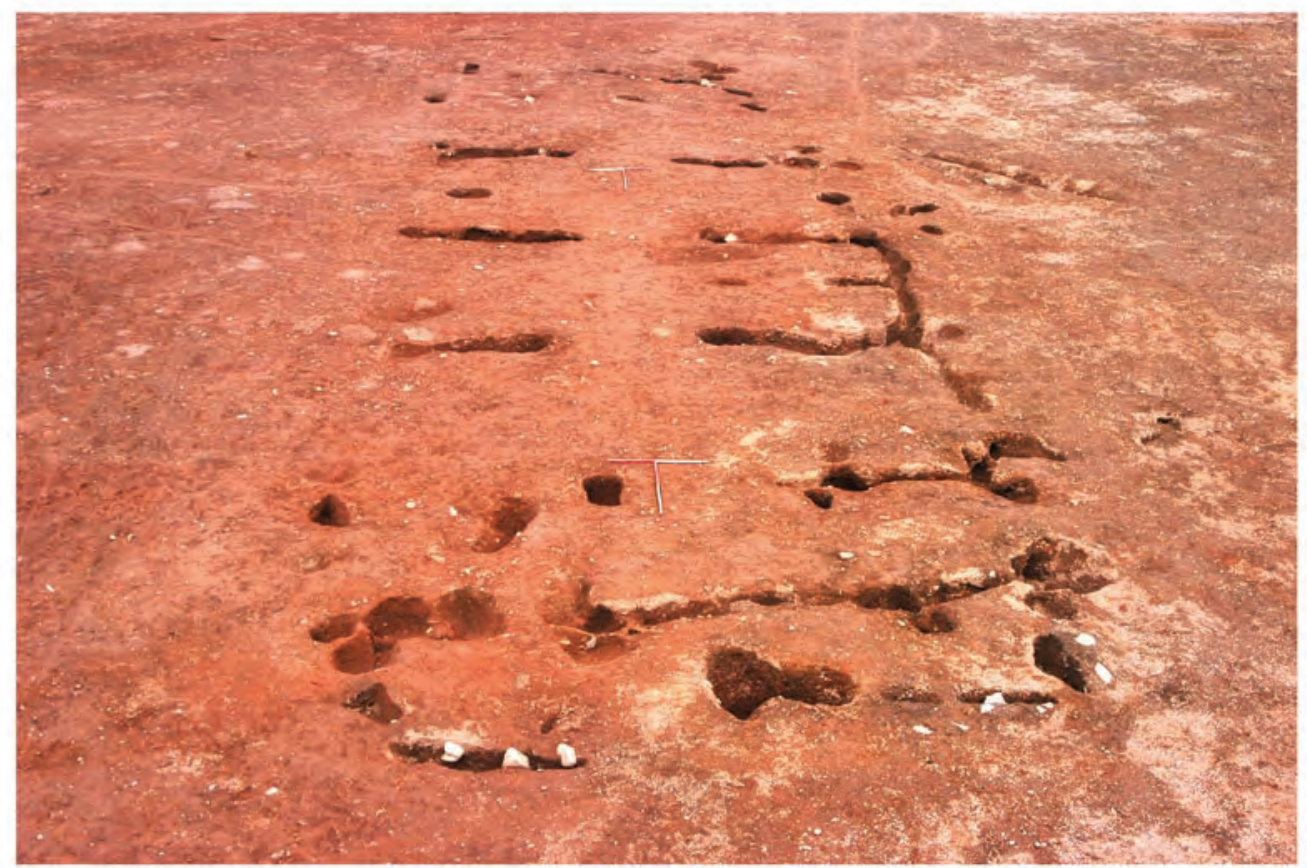

Illus 6 The excavated structure from the south

structure of the hall were $100 \%$ excavated with the exception of F137A, F137B, F138, F155, F155A, F159, F160, F164 and F165 which, due to time constraints, were $50 \%$ excavated. Samples were taken from $c 50 \%$ of the features, giving good spatial coverage from throughout the structure, and from all charcoal-rich deposits for environmental sampling.

\subsection{Description of the structure / structures}

\subsubsection{The terminals}

The southern terminal of the structure (or southernmost of the two structures, depending on whether it is interpreted as a single structure or two separate structures) was defined by eight post-holes (from 


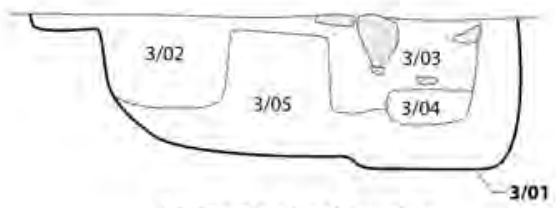

F3, longitudinal section

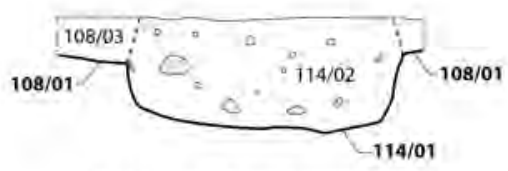

F114, west-facing section

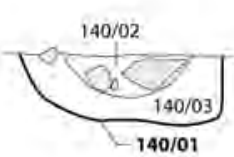

F140, north-facing section

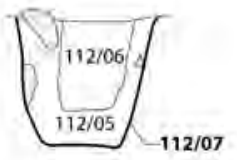

F112, west-facing section

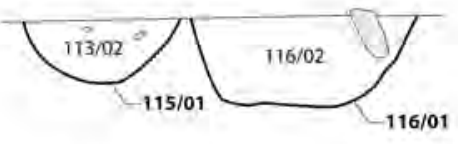

F115 \& F116, east-facing section

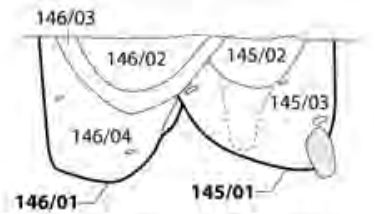

F145 \& F146, south-facing section

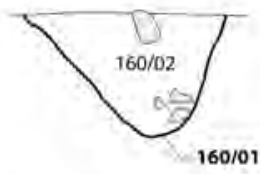

F160, south-east-facing section

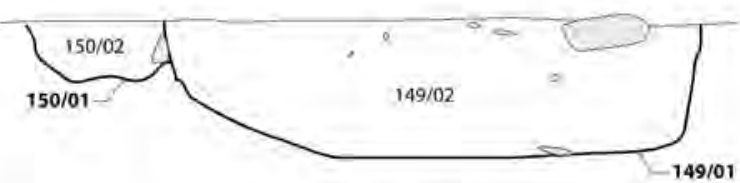

F149 \& F150, longitudinal section

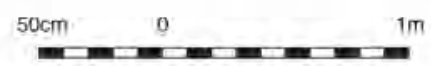

Illus 7 Selected sections of post-holes and construction trenches

east to west: F161B, F160, F158, F146/F145, F138, F140, F121 and F113). Post-holes F161B, F160, F158, F138, F140, F121 and F113 curved inward from the external sidewalls, with post-hole F145, of which post-hole F146 is a re-cut (illus 7), being slightly inset from a straight line drawn between post-hole F158 and F138. A gap between post-holes F158 and F145/F146 may have been an entranceway, which was slightly offset from the centre towards the western side of the structure. Packing stones were identified in post-holes F121, F140, F145, F146 and F158 and Neolithic pottery was recovered from post-holes F158 and F160 (illus 7).

Based on the assumption that that the ground plan identified represented a single structure, the northern terminal consisted of post-holes F137A, F214, F165, F124 and F116. This part of the structure had suffered from a considerably greater level of truncation than the southern terminal, with one post-hole (F165) only surviving to a depth of $0.12 \mathrm{~m}$. The curvature of the arc of this end-wall thus appeared to be considerably tighter than that displayed at the southern terminal, with the northern end of the building thus being slightly narrower than the southern as well as appearing slightly offset from it. However, it is possible that there were further post-holes to the east of F115 that had been totally removed by truncation, and the hypothetical existence of additional features could be postulated to allow for a much more symmetrical arrangement, bringing it into line in both scale and form with the southern end of the structure. No Neolithic pottery was recovered from the terminal post-holes, but sherds were recovered from F115, which lay immediately to the south of F116 (illus 7).

Based on the alternative interpretation that this was two separate structures, the description just given would relate to the northern wall of a smaller structure, set north of and separate from the main building. In this hypothesis, its southern end is most likely to be represented by post-holes F117, F132A, F132, F164 and F135. In this case, the northern terminal of the main hall would probably have consisted of an arc of posts, again largely removed by truncation, to the north of F2/F3, and is likely to have incorporated $\mathrm{F} 1$ and F125. 


\subsubsection{The side walls}

The southern part of the eastern wall was represented by post-holes F107, F19, F152/F153, construction trench F108A, post-hole F114 (illus 7), construction trench F108B and post-hole F110. To the north of F110, the continuation of the line of this wall appeared to have been largely removed by plough truncation, with F4 being the only surviving post-hole. Projecting a straight line through F107/ F110/F4 would place the eastern side wall slightly to the east of F116, the easternmost feature of the northern terminal of the building as it survived at the time of excavation, but as already mentioned the heavily truncated nature of the terminal means that it is possible that the arc of post-holes may have extended to the east of F116.

The better-preserved southern part of the eastern side wall consisted of a combination of post-holes and construction trenches. A line of carbonised wood running along the base of the construction trenches suggests that they contained closely positioned squared-off timber planking uprights measuring $c 0.4 \mathrm{~m} \times 0.4 \mathrm{~m}$ at the base. Features of this nature were also noted at Balbridie (I Ralston, pers comm). Post-holes F107, F114 and F110 appear to have contained substantial timbers, suggesting that they served a major structural function. Charred emmer wheat recovered from $\mathrm{F} 114$ produced radiocarbon dates of 3800-3650 cal BC and 3770-3640 cal BC $(2 \sigma)$.

The western side of the structure appears to have suffered from an even more considerable degree of plough truncation, which had almost completely removed this part of the structure. This is not easy to explain, for there are no noteworthy changes of gradient in the vicinity which might explain why truncation should have been locally more severe here. The line of this wall is thought to be represented by post-holes F212, F162, F14, F154, F142 and F117. Post-holes F212, F162 and F14 survived to a maximum depth of $0.3 \mathrm{~m}$ and post-holes F154, F142 and F117 only survived to a maximum depth of $0.13 \mathrm{~m}$. There was no evidence for construction trenches of the type that formed part of the eastern wall, but on that side of the building these were up to $c 0.2 \mathrm{~m}$ shallower than the neighbouring post-holes, suggesting that more severe plough truncation seen on the western side of the structure could have removed any equivalent slots completely. Radiocarbon dates on paired samples of charred emmer wheat taken from F117 produced dates of $3920-3660 \mathrm{cal} \mathrm{BC}$ and $3720-3630 \mathrm{cal} \mathrm{BC}(2 \sigma)$.

The alternative interpretation based on two separate structures would suggest that the walls followed the same alignment, but as already mentioned, they started to turn inwards at F4 and opposite F2 to form a curved terminal. F117 would then have become the south-western corner of the smaller northern structure. This would have given the main structure an overall length of $c 19 \mathrm{~m}$ and the smaller structure a length of $c 7 \mathrm{~m}$ (east-west).

\subsubsection{Internal structural elements}

Based on the assumption that this was a single structure, it appears to have had six possible internal transversal divisions (Internal Divisions 1-6 from south to north) dividing it into seven possible compartments (Internal Compartments A-G from south to north), broadly paralleling the internal arrangement identified at Claish (Barclay et al 2002).

Interpreting these features as two separate structures would reduce the number of internal divisions within the main building to five, creating six compartments. The smaller northern structure would thus have consisted of a single compartment with a possible centre post (F155).

The southernmost internal division (Internal Division 1) consisted of two suites of features. To the east lay a linear construction trench (F106), which extended from external post-hole F107 and terminated at internal post-hole F134. The aisle here comprised a narrow gap measuring only $c 0.3 \mathrm{~m}$ wide, which divided post-hole F134 from post-hole F161. This last feature was part of the western part of this arrangement, and was conjoined to post-holes 161A and 161B. Three post-pipes were identified within construction trench F106. In common with all the internal construction trenches, it is envisaged that construction trench F106 may have contained a line of posts of decreasing height in relation to the pitch of the roof. It is noteworthy that this transversal arrangement is set obliquely to those further north within the building.

Internal Division 2, again better preserved to the east, consisted of a linear construction trench (F17), which extended from post-hole F152, suggested to have lain on the eastern longitudinal wall line, and terminated at internal post-hole F17A. Post-hole F17A measured $0.62 \mathrm{~m}$ in diameter and contained several packing stones, suggesting that it held a substantial timber upright. A gap of $0.7 \mathrm{~m}$ divided post-hole F17A from post-hole F15, which was separated by $2.3 \mathrm{~m}$ from the western side wall marked by F14. Again, this postulated traverse lacks internal symmetry. A construction trench similar to F17 may originally have run between F15 and F14/F154, but if it did, it had been entirely removed by plough truncation before this intervention. A sherd of Iron Age pottery was recovered from the upper fill of post-hole F15, but it is thought that it was intrusive and it is not considered to constitute reliable dating evidence for this feature. Radiocarbon dates on paired samples of charred emmer wheat taken from $\mathrm{F} 17$ produced dates of 3940-3650 cal BC and 3950-3700 cal BC $(2 \sigma)$.

The eastern portion of Internal Division 3 consisted of a substantial 1m-wide construction trench (F112A), which extended from external posthole F114 and terminated at internal post-hole F112. A gap of $1.6 \mathrm{~m}$ divided F112 from construction trench F144, which was conjoined to post-hole F51. Post-hole F112 measured $c 1 \mathrm{~m}$ in diameter by $0.52 \mathrm{~m}$ deep and contained a post-pipe measuring $0.38 \mathrm{~m}$ in 
diameter by $0.4 \mathrm{~m}$ deep (illus 7 ). The post had been held in place by packing stones. Construction trench F144 measured $1.5 \mathrm{~m}$ by $0.6 \mathrm{~m}$ by $0.48 \mathrm{~m}$ deep, but post-hole F151 had a depth of only $0.1 \mathrm{~m}$, suggesting that the substantial holes immediately on either side of the central aisle held the main structural timbers, again an arrangement readily paralleled at Balbridie. Radiocarbon dates on paired samples of charred emmer wheat taken from F144 produced two dates of 3770-3640 cal BC $(2 \sigma)$.

Internal Division 4 consisted on the eastern side of a construction trench (F109) measuring $1.7 \mathrm{~m}$ long by $0.2 \mathrm{~m}$ wide by $0.18 \mathrm{~m}$ deep, which extended from external post-hole F110 and terminated at internal post-hole F147. Post-hole F147 measured $0.75 \mathrm{~m}$ in diameter by $0.4 \mathrm{~m}$ deep and contained some fairly large packing stones, again suggesting the presence of a substantial timber upright. A gap of $1.8 \mathrm{~m}$ divided post-hole F147 from the western portion of this traverse, which consisted of construction trench F149, which cut post-hole F150 (illus 7). F149 contained Neolithic pottery, burnt worked flint and charcoal. Again, these two halves are not symmetrical, and are on slightly different alignments. The eastern side of the compartment between Internal Divisions 3 and 4 may have been further subdivided by F111 and F156, but both these features were less than $0.2 \mathrm{~m}$ deep, suggesting that they had been heavily truncated, or that they formed a less solid sub-division within the structure. Radiocarbon dates on paired samples of charred emmer wheat taken from F149 produced dates of 3800-3650 cal BC and $3760-3640 \mathrm{cal} \mathrm{BC}(2 \sigma)$.

As it survived, the eastern part of Internal Division 5 consisted of one individual post-hole (F6) and a construction trench (F3). Construction trench F3 itself contained two post-holes (illus 7). The western post-hole, which was the larger of the two, measured $0.66 \mathrm{~m}$ in diameter by $0.56 \mathrm{~m}$ in depth and contained a number of packing stones. A possible post-pipe was identified in post-hole F6. To the west of the central aisle, packing stones were also identified at the eastern end of F2, suggesting that it held a substantial timber upright here. A possible subdivision of the compartment, or further individual roof supports is/are represented by post-holes F129 and F136, which are directly positioned on opposite sides of the structure.

Internal Division 6 consisted of a line of four differently-sized post-holes (F132A, F132A, F164 and F135) measuring between $0.19 \mathrm{~m}$ diameter by $0.08 \mathrm{~m}$ deep and $0.78 \mathrm{~m}$ by $0.72 \mathrm{~m}$ by $0.48 \mathrm{~m}$ deep. Post-hole F164 contained large quantities of charcoal. If the separate structures interpretation is preferred, this would have been the external southern wall of the northern structure.

The evidence for axial posts is somewhat ambiguous, but two post-holes (F155 and F134) that may have served this function have been identified. At the northern end of the structure, post-hole F155 measured $0.92 \mathrm{~m}$ from east to west by $0.63 \mathrm{~m}$ from north to south and had a depth of $0.42 \mathrm{~m}$. Large packing stones within the primary fill suggest that it held a substantial timber upright. Post-hole F134 at the southern end of the building is rather more problematic when viewed as an axial post. This feature was positioned closer to the western side of the building, and even though the post appears to have been positioned at the eastern end of the posthole where it adjoins F106, this would have placed the axial line to the west of centre when projected directly to post-hole F155. However, it is considered likely that the axial beam consisted of a series of short lengths of timber supported by the internal divisions rather than a single continuous length, and a slight zig-zagging of the timbers would probably have allowed them to track the axial line without compromising the integrity of the structure. Posthole F146 was also briefly considered as a possible candidate for the axial post, but this appears to have been a re-cut of F145, which is on the same alignment as F17A, F112, F147 and F3.

There was no evidence of a possible axial post within the vicinity of $\mathrm{F} 2 / \mathrm{F} 3$, which is where it is likely to have been positioned if this had been the northern end of the main structure. Given that F2 and F3 survived to depths of $0.44 \mathrm{~m}$ and $0.67 \mathrm{~m}$ respectively, it seems unlikely that an axial posthole within this location would have been removed completely. However, it has been noted by Ian Ralston (pers comm) that the probable axial posts at Balbridie were some of the least substantial identified and this post may have been of a similar nature. It could also be that the substantial nature of F2/F3 removed the need for an axial post.

\subsubsection{Internal features}

There were no features that were considered to be non-structural identified within the Neolithic structure. The lack of occupation layers, surfaces or hearths is a further indication of the degree of plough truncation that has been inflicted on this site.

\subsubsection{External features}

Several additional features were identified outwith the structure. Of particular note was a large pit (F133) that was situated immediately to the east of the structure. The pit was rather irregular in shape and measured $4.6 \mathrm{~m}$ long by $2 \mathrm{~m}$ wide by $0.5 \mathrm{~m}$ deep. A quantity of Neolithic pottery recovered from the primary fill of the pit all proved to belong to the same vessel (Pot 31, Sheridan below). This feature may have been a borrow pit for the procurement of sand.

Features F120, F123, F131, F21, E127, F23 and F122 were situated close in to the eastern wall of the structure and may relate to structural repairs (F120 and F123) or to external features such as animal pens. Other scattered pits included F119, 
F143, F163 and F10. Pit F119 contained charcoal and burnt bone, but there were no finds from the other pits and their relationship to the structure is unclear.

A pit (F12) containing a large quantity of firecracked stone was situated $c 25 \mathrm{~m}$ to the east of the structure (not illustrated). It measured $1.1 \mathrm{~m}$ in diameter by $0.32 \mathrm{~m}$ deep. The quantity of fire-cracked stone suggests that it may have been a cooking pit. It is unclear if this pit related to the Neolithic activity on the site, as it was not dated.

\subsubsection{Modern feature}

The level of root action within F148, combined with the presence of modern pottery at the base, suggests that this was a recent feature, possibly a tree bole.

\subsection{Radiocarbon dates}

Five pairs of samples were submitted for dating, all of which were charred emmer wheat. The samples were selected to give good spatial coverage across the structure and to determine whether the smaller northern group of features relating to the possible separate northern structure dated to the same period as the southern group of features constituting the main hall or the southern end of a single hall. An earliest date of 3950-3700 cal $\mathrm{BC}(2 \sigma)(5020 \mathrm{BP})$ came from $\mathrm{F} 17$ and a latest date of 3720-3630 cal $\mathrm{BC}(2 \sigma)$ (4890 BP) came from F117. Although the latest date was obtained from the northern group of features, the other paired sample from F117 produced a date of 3920-3660 cal $\mathrm{BC}(2 \sigma)$, which is earlier than the majority of dates obtained for the southern group of features. The spread of dates suggests that they relate to the ongoing usage of the structure rather than a single burning episode.

The dates obtained for the Lockerbie Academy Neolithic hall $(5020 \pm 30-4890 \pm 30$ BP) are broadly contemporary with those obtained for Claish $(5080 \pm 40-4845 \pm 40$ BP), Balbridie (5010 $\pm 125-4745$ \pm 135 BP) and Warren Field (5200 $\pm 35-4975 \pm 45$ вP).

\subsection{Prehistoric pottery, by Alison Sheridan}

\subsubsection{Introduction}

The Area A ceramic assemblage comprises 146 sherds and 63 fragments (pieces smaller than $10 \mathrm{~mm}$ across) weighing just over $0.8 \mathrm{~kg}$ overall. With the exception of one sherd of Early Iron Age pottery (described below), the assemblage is of Early Neolithic date, and belongs to the early part of the Carinated Bowl tradition (Sheridan 2007a). Full details of each pot are presented in the archive; general characteristics are described here.

\subsubsection{Early Neolithic pottery}

The Early Neolithic assemblage comprises small parts from a large number of vessels: a minimum of 46 pots have been identified, but the total may have been slightly higher. Sherd size is small, with the largest single sherd (from Pot 14) measuring $c$ 66 by $48 \mathrm{~mm}$. In most cases, no more than $5 \%$ of any individual pot is represented. With the exception of the sherds from Pot 31 that were found in pit F133, all the pottery came from the fills of the pits, post-holes and wall slots inside the structure (illus $8 \mathrm{a}$ ); where found in post-hole fills, the sherds were mostly towards the edge of the fill, indicating the deposition of these sherds while the posts were standing. The pottery was fairly evenly distributed along the length of the structure, and spatial scattering of sherds from individual pots was minimal: three sherds, from three neighbouring features (F106, F140 and F208; Internal Division 1 and end wall), conjoin to form the rim and neck of Pot 1 . Most sherds show no or minimal sign of abrasion, suggesting that they had not lain around for long before being incorporated in these fills. A plausible explanation for their presence in the fills in this condition is that as pots broke during the use of the structure, smallish sherds were swept towards the walls.

There is a high incidence of burnt sherds, and also of spalling, which can be a sign of heat damage. In most cases, this damage probably occurred during the burning down of the structure, and the effects were localised, with some sherds from the same pot or context being burnt, while others were unaffected (eg in F19). Similarly, the intensity of the burning varied, with the heavily burnt sherds (comprising a third of the assemblage) being oxidised throughout. Burning had also softened some of these sherds, making them prone to subsequent abrasion (eg Pots 18 and 36 ).

A narrow range of vessel forms is represented, with carinated and sinuous-profiled bowls dominating the assemblage. Twenty-one such vessels are attested from sherds from the rim, neck or neck-belly junction (illus 9-10), and a further two are suggested by the flattish base sherds of Pots 22 and 23: carinated and sinuous-profiled bowls often have slightly flattish, yet still rounded, bases. The sherds representing Pots 24-45 - almost all belly sherds - could equally well have come from bowls of these shapes, as their curvature, wall thickness (6.1-12.5mm) and fabric fall within the range seen for such vessels. The only pot that is demonstrably not of carinated or sinuous-profiled form is Pot 46 , a roughly hemispherical, thick-walled vessel (illus 10). This will be described below.

The reconstruction drawings, shown in illus 9 and 10 , show the range of carinated and sinuousprofiled vessel forms present in the assemblage. These drawings have been based on diameter measurements using a standard diameter estimation chart; the angle of the neck has been assessed by examining details of its shape, in particular the 

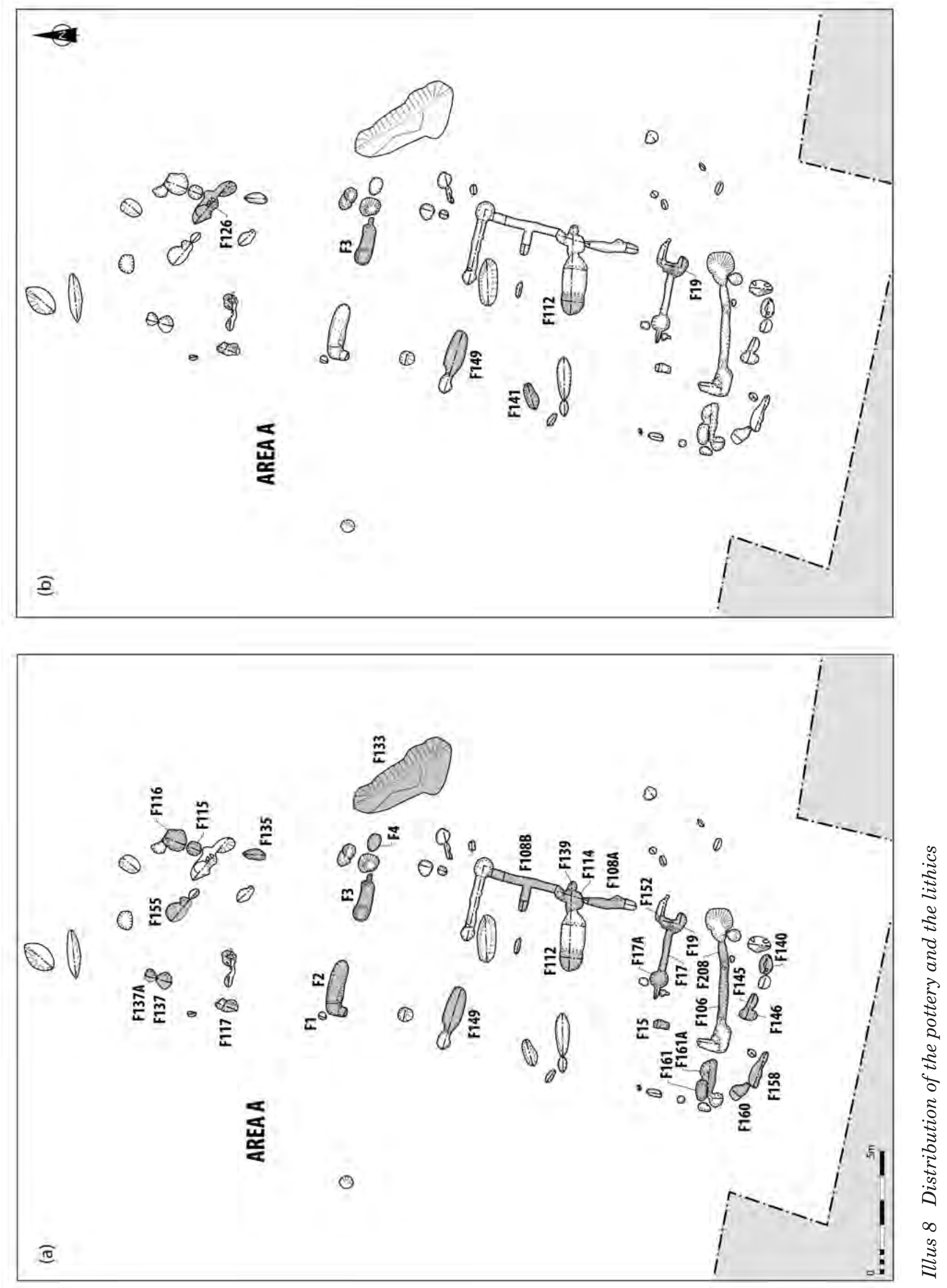
relative curvature (if present) of the inner and outer surfaces. The angle of the neck-belly junction has similarly been assessed by comparing the curvature of the inner and outer surfaces (which also provides clues as to whether the neck had been upright and straight or curved, and whether the belly had been shallow or deep). Breakage patterns along ring joint lines also provide clues as to the original angle of the neck and neck-belly junction. Rim and carination shapes, where absent, have been extrapolated from the forms represented elsewhere in the assemblage.

Eight bowls (Pots 1-8) - and possibly a ninth, represented only by a small rim sherd (Pot 9) - have widely splaying necks and generally shallow bellies. These include three exceptionally large vessels, with rim diameters estimated at 396,390 and $366 \mathrm{~mm}$ respectively; the smallest example has an estimated rim diameter of $215 \mathrm{~mm}$. Despite their considerable size, Pots 1-3 are thin-walled: at its narrowest, the Pot 5 neck is only $4.85 \mathrm{~mm}$ thick, for example, making this the thinnest-walled pot in the assemblage. The rim on Pot 1 is rounded and neatly rolled over to form a beading, while that on Pot 9 (too small to allow a reconstruction, but probably from this shape of bowl) is rounded and gently everted. The necks, generally long, are either straight or virtually so (as in Pots 1 and 2), or else slightly concave (Pots 5 and 7). That on Pot 2 is more curved on its inner surface and increases in thickness towards the rim, lending the bowl a top-heavy appearance. The neck-belly junction is either sinuous (Pots 4 and 8) or very gently carinated (Pot 7).

The other reconstructible carinated or sinuousprofiled vessels (Pots 10-18, and probably also Pots 19-21, represented only by small sherds) have upright or slightly everted necks and shallow to deep bellies. The largest of these (Pot 10) has an estimated rim diameter of $290 \mathrm{~mm}$; the smallest (Pot 18), 178mm. With the exception of the relatively thick-walled Pot 21 , which is at least $14.3 \mathrm{~mm}$ thick, all these bowls have wall thicknesses (away from rims and carinations) of less than $10 \mathrm{~mm}$. Rims are rounded, everted and gently hooked (Pots 14, 19) or else partly rounded and partly flattish, and minimally everted (Pots 16, 20). Necks are straight (Pots 11-15, 17, 18) or concave (Pot 16). The neckbelly junction is either sinuous (Pot 15) or carinated, gently so in the case of Pots 10, 11 and 21 and more markedly so in Pot 13.

Regarding manufacture, these pots were all made by adding successive clay rings to a basal pad, flattening each one before adding the next. Breaks along ring joint lines are relatively common and indicate that in some areas the constituent flattened rings had been fairly narrow, especially around the neckbelly junction (as in Pot 10) and near the base (in Pot 23, where burning has caused the pot to crack along joint lines: illus 10). The prominent carination on Pot 13 had been made by adding a strip to the outside of the body. Before building the pots, the clay had probably, in most cases, been refined by levigation; crushed stone was added to all pots as a filler, to prevent cracking during drying and firing.

The size of these lithic inclusions varies within and between pots, but none is larger than $7 \times 4 \mathrm{~mm}$. The density also varies, from very sparse (below $3 \%$ ) to $7-10 \%$, and while the thin-walled pots $(<10 \mathrm{~mm}$ thick) tend to contain few and small inclusions, this is not always the case (as seen in Pot 24, for instance). The most frequently used type of stone is micaceous quartz, featuring large, golden-coloured mica platelets: this occurs as the sole or main inclusion in 33 pots. In a further six pots, its place is taken by non-micaceous quartz; and in six more, by a speckly, black and white granitic stone. The fact that small fragments of all these stone types are also present in the Iron Age sherd suggests that they were probably obtained locally. Only one pot (Pot 3) does not contain these types of stone, instead having various kinds of grey, fine-grained stone.

Surface finish varies, but in every case an attempt was made to achieve a smooth surface. Wet-smoothing, using a soft material such as an animal-skin pad, has created a thin, slip-like effect that is visible on most sherds. This would have been undertaken when the vessel was leather-hard, and in many cases it has created very smooth surfaces (although on the interior of Pot 3, a piece of grit on the pad has left scratches on the surface). Additional treatment is visible on some pots: the fairly high sheen on both surfaces of Pot 1 may have been achieved by polishing with a pad, while on other pots, a pebble or some other blunt tool had been used to smooth the surface to a matte finish in some cases (as on the outside of Pots 14 and 45), to a low sheen (as on the outside of Pot 3 and the inside of Pot 14), a medium sheen (outside of Pot 4, both surfaces of Pots 11 and 13) or a fairly high sheen (Pot 2, both surfaces). The tool had been rubbed horizontally around the pots. Some of the bowls with splaying necks have particularly fine surface finishes, on their interior as well as exterior, emphasising their role as display objects as well as functioning pots. With the other pots, the thicker-walled examples $(>10 \mathrm{~mm})$ are generally less carefully finished than those with walls less than $10 \mathrm{~mm}$ thick. There is no trace of decoration on any of the pots.

The colour of the sherds varies, not least because some have been heat-altered, but with eleven vessels (Pots 1, 3, 7, 9, 11-13, 15, 16 and 28) a deliberate attempt has been made to create black pots (or pots with one black surface and one black-brown surface). This suggests good control over the firing process. With these pots, the core is the same colour as one or both of the surfaces. With some other pots, the core is darker than one or both of the surfaces, suggesting a rapid firing.

Regarding the function of these bowls, the presence of a thin black encrustation on the interior and/or exterior of ten vessels suggests their use as cooking pots. These include the largest bowl (Pot 1), which has a patch of encrustation just below the rim on the exterior, and Pot 31, from F133, where 
many of the belly sherds have encrustation on their interior. Whether other pots had also been used for cooking would require analysis for absorbed lipids to be undertaken. To judge from the size and shape of the other carinated and sinuous-profile pots, they were probably used for serving foodstuffs; they are not an ideal shape or size for storage, unless small quantities of material are concerned.

Finally, the globular pot (Pot 46) stands out in several respects as being different from the rest of the assemblage. It is a thick-walled (up to $14.4 \mathrm{~mm}$ thick), roughly hemispherical bowl with a simple rounded, slightly inturned rim; the estimated rim diameter is $c 210 \mathrm{~mm}$ and the estimated height of the pot, $139 \mathrm{~mm}$. The surfaces were probably wetsmoothed but are slightly uneven. Inclusions are fairly abundant ( $c 7 \%$ density), in some cases large (up to 8.3 by $6.5 \mathrm{~mm}$ ), and consist of quartz. One of the three constituent sherds was heavily burnt. The other two have pale exteriors and black interiors, and while no organic encrustation is visible, it is possible that this pot was used for cooking.

\subsubsection{Early Iron Age pottery}

The Early Iron Age sherd, which was found at a high level in F15, differs from the Neolithic pottery in its form and fabric; it is also noticeably harder. It is a rim and upper body sherd from a flat-based, bucketlike vessel with a slightly inturned rim $(c 200 \mathrm{~mm}$ in estimated diameter) and a steep internal bevel immediately below the rim. Extensive burnt-on organic residues on the exterior and interior indicate its use as a cooking pot. Inclusions are sparse $(<3 \%)$ and comprise a few small fragments of the micaceous quartz and granitic stone as seen in the Neolithic pottery, along with some dull grey fine-grained stone fragments. The edges of this sherd are not abraded, indicating that it had not lain around long before being buried. Comparanda (eg from Traprain Law, East Lothian) suggest a mid to late first millennium $\mathrm{BC}$ date (F Hunter pers comm). The presence of a single intrusive late sherd in an otherwise entirely Early Neolithic structure is puzzling, but given the degree of truncation of the site, it is impossible to tell whether there had once been more extensive evidence for an Early Iron Age presence there.

\subsubsection{Summary description of the illustrated vessels (illus 9-10)}

Note: 'open' = profile descriptor where rim diameter exceeds carination diameter by more than a few $\mathrm{mm}$; 'neutral' = rim and carination diameter roughly the same. Inclusion density: very sparse $=3 \%$ or less; fairly sparse $=c 5 \%$; medium-density $=7-10 \%$. All inclusions are of stone.

1. Sherds from the rim and neck of a large open gently carinated bowl with fairly shallow belly.
Very sparse angular inclusions. Contexts 106/02, 140/02, 208/2.

2. Sherds from neck of a large open gently carinated bowl with shallow belly. Very sparse angular inclusions. Context 19/02.

3. Neck sherd from large, open carinated bowl with widely splaying neck and shallow to medium-depth belly. Very sparse angular and sub-angular inclusions. Context 115/02.

4. Two conjoining sherds spanning the neck-belly junction of a large open carinated/S-profiled bowl with widely splaying neck, gentle sinuous carination and shallow belly. Very sparse angular and sub-angular inclusions. Context 114/02.

5. Neck sherd from open carinated bowl with splaying neck and shallow belly. Very sparse angular inclusions. Context 115/02.

6. Sherds from the rim, neck and (not shown) belly of a medium-sized open carinated/S-profiled bowl with splaying neck and medium to deep belly. Fairly sparse angular and rounded inclusions. Heavily burnt. Context 17/02.

7. Sherds from the neck, neck-belly junction and (not shown) belly of a medium-sized open carinated/S-profiled bowl with splaying neck, very gentle sinuous carination and medium-deep belly. Medium-density angular and sub-angular inclusions. Context 116/02.

8. Sherds from the neck-belly 'junction', belly and possibly the neck (of which only the sinuous 'carination' at the neck-belly junction is shown) of what had probably been a medium-sized, open S-profiled bowl with medium-depth belly. Fairly sparse angular, sub-angular and rounded inclusions. Twelve of the sixteen constituent sherds are heavily burnt. Context 152/02.

9. Small rimsherd from medium-sized to large open carinated or S-profiled bowl. Very sparse angular and sub-angular inclusions. Context $161 / 02$.

10. Sherds from the carination and (not shown) belly of a medium-sized to large neutral carinated bowl with medium-depth belly. Fairly sparse angular and sub-angular inclusions. Belly sherd (which might possibly belong to a different pot) burnt. Context 155/02.

11. Sherds from the carination and (not shown) belly of a medium-sized neutral carinated bowl with medium-depth belly. Fairly sparse angular inclusions. Context 146/04.

12. Two conjoining neck sherds from medium-sized neutral carinated bowl with medium-depth belly. Very sparse angular and sub-angular inclusions. Context 1/02.

13. Carination sherd of a medium-sized open carinated bowl with medium to deep belly. Medium-density angular and sub-angular inclusions. Context 149/02.

14. Sherd from the rim and neck of a medium-sized, neutral carinated bowl with deep belly. Very sparse angular and rounded inclusions. Outside of sherd probably scorched. Context 15/02. 


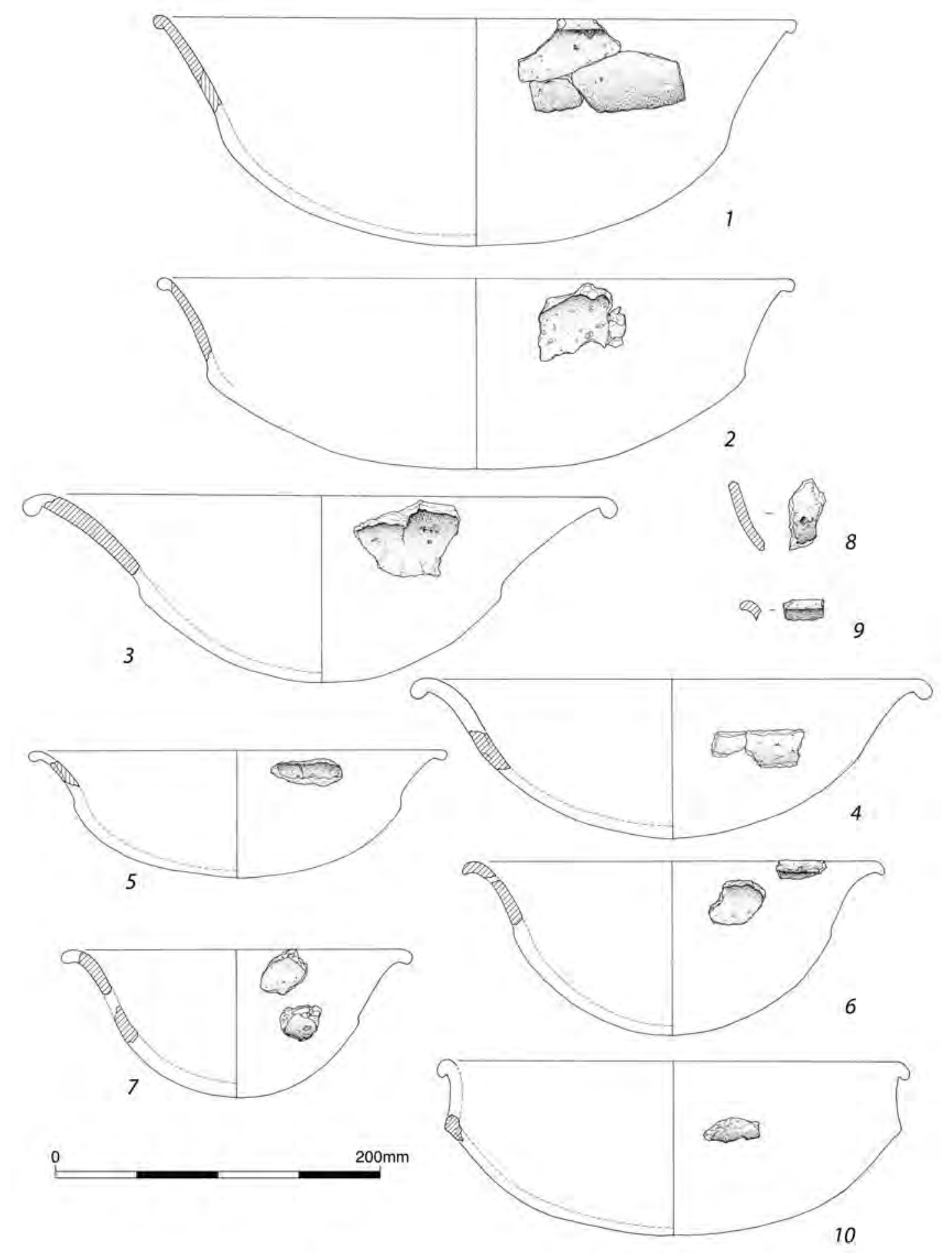

Illus 9 Neolithic pottery

15. Sherd from the neck-belly junction of a medium-sized neutral S-profiled bowl with deep belly. Fairly sparse angular inclusions. Context $158 / 02$.

16. Sherd from the rim of a medium-sized neutral carinated bowl with deep belly. Mostly angular inclusions, one rounded, 5-7\%. Context $146 / 02$.
17. Sherds from the rim, neck and belly of a mediumsized neutral carinated bowl with deep belly. Fairly sparse angular and sub-angular inclusions. Heavily burnt. Context 114/02.

18. Two conjoining neck sherds from a mediumsized neutral carinated bowl with deep belly. Fairly sparse angular and sub-angular inclusions. Heavily burnt. Context 112/04. 

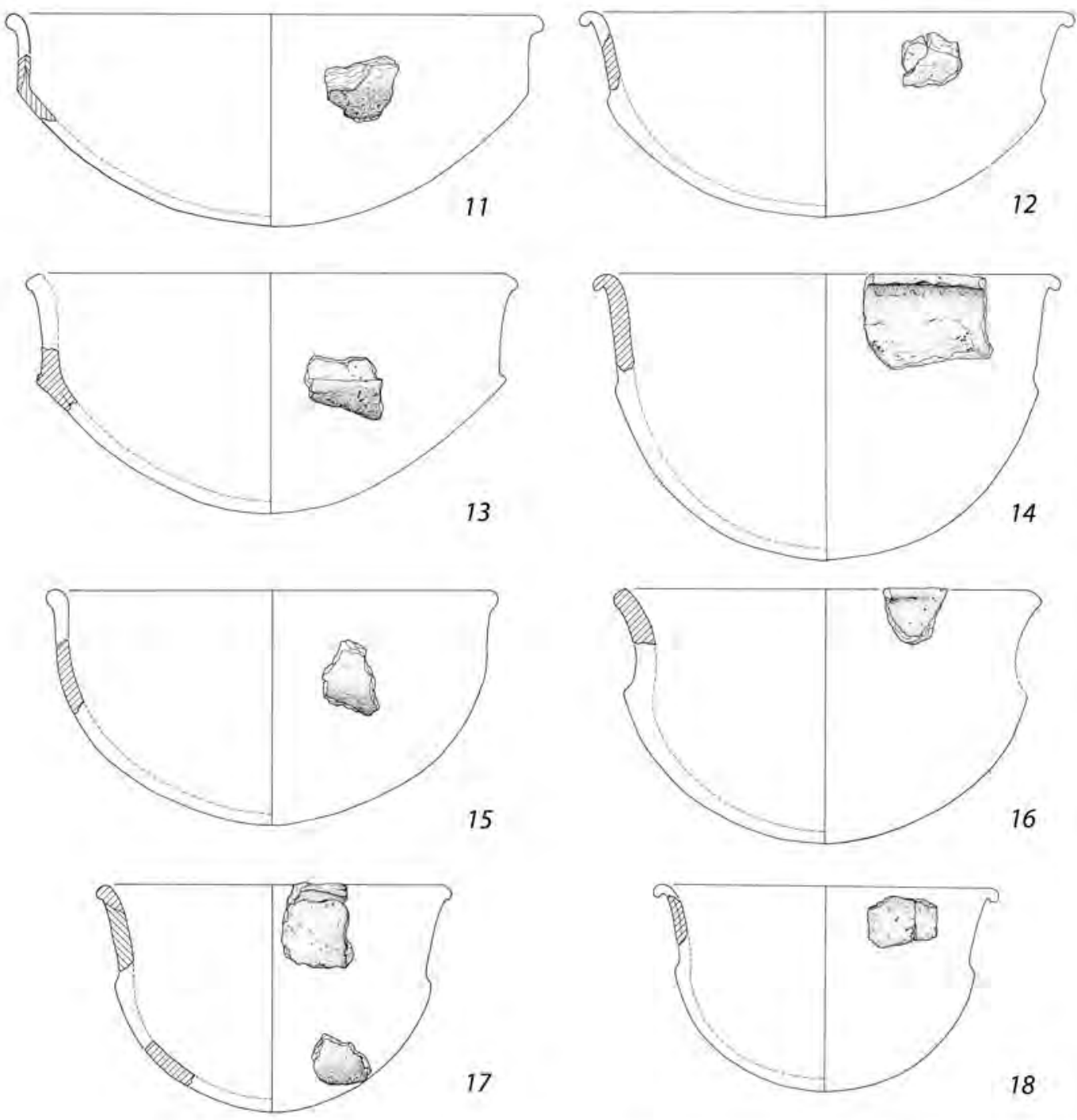

17

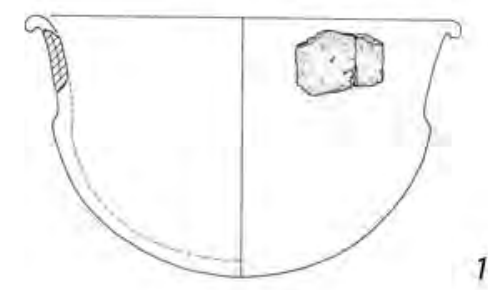

18
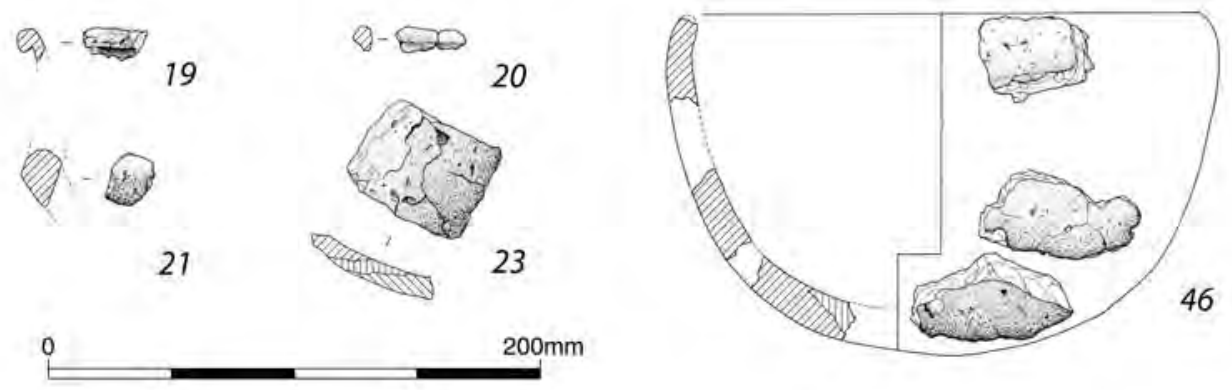

Illus 10 Neolithic pottery

19. Small rimsherd from carinated or S-profiled bowl, probably with an upright or slightly everted neck. Too small for reliable diameter estimation, but could have been as large as very to fairly sparse $(3-5 \%)$ inclusions, mostly angular. Context 112/05.

20. Even smaller rimsherd from carinated or Sprofiled bowl, probably with an upright or slightly everted neck. Too small for reliable

diameter estimation. Very sparse angular inclusions. Heavily burnt. Context 3/02.

21. Carination sherd from large, thick-walled carinated bowl with gentle carination and probably deep belly. Very sparse angular inclusions. Heavily burnt. Context 117/02.

23. Sherds from the gently curving base and (not illustrated) belly of a large, probably carinated or S-profiled bowl. Very sparse angular and 
sub-angular inclusions. Heavily burnt, and has cracked along coil joint lines, showing clearly how the base was built up. Context 117/02 and $117 / 05$

46. Sherds from the rim and belly of a mediumsized, uncarinated, roughly hemispherical coarseware bowl with a minimally inturned rounded rim. Medium-density but large angular and sub-angular inclusions, up to $c 8.3$ by 6.5 , just quartz. One sherd heavily burnt. Context $161 \mathrm{~A} / 02$

\subsubsection{Discussion of the pottery}

The Early Neolithic assemblage is instantly recognisable as belonging to the Carinated Bowl (henceforth 'CB') tradition, in its earliest, 'traditional', form (see Sheridan 2007a for the most recent discussion of CB pottery). This is characterised by a predominance of carinated and sinuous-profiled bowls of various sizes, mostly thin-walled, with simple rounded and everted rims. The fabric of these pots ranges from very fine, with small and sparse lithic inclusions, to relatively coarse, and the range of surface finishes seen in the Lockerbie Academy assemblage is typical (although the occasional decorative use of fingertip fluting, seen on some other traditional CB assemblages, is absent here). Simple hemispherical bowls and cups - smaller and finer than the large Pot 46 - are usually present as a minor element in $\mathrm{CB}$ assemblages, and occasionally collared jars are found (as at Biggar Common in South Lanarkshire: Sheridan 1997, Fig. 17.3, and at Claish, Stirling: Sheridan 2002); this form is absent from the Lockerbie Academy assemblage. The consistency of the earliest CB tradition is reflected not only in vessel form, fabric and finish, but also in such characteristics as the thickening of the neck towards the rim in some shallow-bellied bowls (as, for example, at Pencraig Hill, East Lothian: Sheridan 2007b; MacGregor \& McLellan 2007, Fig. 2.24, V3).

The CB assemblage at Lockerbie Academy is closely comparable with that found at the other large Early Neolithic house structures in Scotland at Claish, Stirling and at Crathes Warren Field, Aberdeenshire (Sheridan 2009); the assemblage at the other excavated structure of this kind, at Balbridie in Aberdeenshire, represents an early modification of the $\mathrm{CB}$ canon. The similarity extends to the nature of the assemblage, with small amounts of a large number of vessels being present. The similarity is also echoed in the radiocarbon dates obtained for the Lockerbie Academy structure, which are very closely comparable with those obtained from short-lived species samples from Claish and Crathes (Sheridan 2007a, Fig. 7 and appendix). Recent Bayesian analysis of the Claish and Crathes dates indicate that use of both of these structures was short-lived (with $68 \%$ probability values of $1-50$ years' use, dating between $3720-3670$ and $3680-3640$ cal BC for Claish, and of 1-65 years' use, between 3800-3740 and 3750-3695 cal BC, for Crathes: A Bayliss pers comm). Given the dates obtained for the Lockerbie structure (see above), it is very likely that Bayesian analysis would reveal a similarly short use life for the Lockerbie Academy structure.

As discussed elsewhere (eg Sheridan 2007a), the ceramic and dating evidence - not just from these large rectangular structures, but also from various domestic and funerary sites elsewhere in Britain and Ireland - points towards the introduction of a well-established Continental tradition of pottery manufacture to Britain and Ireland early in the fourth millennium BC. As far as its presence in Dumfries \& Galloway is concerned, the closest findspot to the Lockerbie Academy structure is at Kirkburn, also in Lockerbie, where CB pottery was found in several pits (Cormack 1963, eg fig. 6, pits 14 and 54). This site is less than a kilometre from the Lockerbie Academy structure/s. Further afield, a pit at Carzield, Kirkton produced parts of two traditional $\mathrm{CB}$ vessels and radiocarbon dates of $5010 \pm 70$ BP (Beta-68480,3966-3649 cal BC at 2 $\sigma$, from hazelnut shells plus short-lived tree charcoal) and $4920 \pm 110$ BP (Beta-68481, 3962-3383 cal BC at $2 \sigma$, from hazelnut shells: Maynard 1993). Similar pottery was found sealed on the old land surface at Pict's Knowe, on the other side of Dumfries (Peterson \& Roberts 2007, 132-3 and Fig. 14.1.1), and further examples were found at the long cairns excavated by Lionel Masters at Lochhill and Slewcairn (Masters 1973), and, further along the coast, at the simple megalithic monument at Cairnholy 1 (Piggott \& Powell 1949, Fig. 7.1). As for the CB pottery found at the two cursus monuments at Holywood near Dumfries, that from Holywood South represents what has been described elsewhere as 'modified CB pottery' (Sheridan 2002; 2007a) - a type developed from 'traditional CB' pottery - while that from Holywood North is closer to traditional CB in form (Peterson \& Roberts 2007, 221-2). The Holywood South pottery came from a pit (undated) that is believed by the excavator to pre-date the cursus bank (Thomas 2007, 241). The Holywood North pottery is believed to relate to the first phase of cursus construction, and is associated with a radiocarbon date (from burnt hazelnut shell) of $4960 \pm 35$ вP (SUERC-2115, $3890-3650$ cal BC at $2 \sigma$ ); while subsequent phases of cursus construction there post-date this (Ashmore $2007 \mathrm{a} \& \mathrm{~b}$ ), this date is comparable with those obtained for the Lockerbie Academy structure/s.

\subsection{Fired clay, by Sue Anderson}

Ten small fragments $(9 \mathrm{~g})$ of abraded fired clay in very fine pink and buff fabrics were found in two post-holes and a beam slot related to the Neolithic structure, F17A, F108 and F152. A fragment of very friable ?lime mortar with a flat surface, pinkish in colour and containing coarse quartz sand and pebbles, was found in post-hole F145. The latter is likely to be intrusive. 


\subsection{Flint, by Graeme Warren}

Twelve flint artefacts were recovered. The material is fragmentary, with $42 \%$ broken and $75 \%$ edgedamaged; in many cases this edge damage clearly does not relate to use of the artefacts. Material was recovered from a variety of pit, post-hole and construction trench fills (illus 8b). Notably, ten were found within the central compartments of the structure, with only a single flake being recovered from an irregular pit (F126) at the northern end, and a blade fragment (14) (illus 11) was recovered from F152 towards the southern end (illus 8b). Given the evidence of spatial patterning to the stone tools recovered from Warren Field indicating particular areas where stone tools were produced (Warren 2009), this pattern is of some interest, and should be compared to the distribution of other material, especially ceramics, at Lockerbie Academy.

Two-thirds of the flints were burnt, in some cases badly, and in all cases evidently after flaking. The deposit of three unburnt flints, two flakes and a blade in the primary fills of F3 is notable as the only concentration of material not affected by burning: this included a fragment of a polished flint object. These artefacts, from a primary phase of construction, are likely to be chronologically separate from the other artefacts, associated with use or destruction. However, technologically the assemblage is broadly homogeneous, and observations from other halls indicate that treating an assemblage
Table 2 Composition of primary lithic technology

\begin{tabular}{lcc}
\hline Blank & Total & No. retouched \\
\hline Blade & 4 & 1 \\
Chunk & 1 & 0 \\
Flake - regular & 3 & 2 \\
Flake - indeterminate & 3 & 0 \\
fragment & & 1 \\
Frag of polished object & 1 & \\
\hline
\end{tabular}

from the hall as a unit is legitimate. As such, this assemblage is very much in keeping with other hall sites in Scotland. Assemblages from Balbridie and Warren Field are both larger, but include significant numbers of finds from topsoil. The assemblage from Claish did not include recovery from topsoil, and totalled only seven struck pieces (Barclay et al 2002).

With one exception, the fragment of a polished object noted above, the assemblage consists entirely of debitage sensu stricto (Table 2). No cores are present. Evidence for primary technology on site is therefore limited to information gained from these flakes and blades, which are often fragmentary. They indicate the production of broad and narrow blades, and some broader flakes. In some cases these display strong evidence of platform lipping, and are likely to result from 'soft hammer' production. A single flake probably results from bipolar

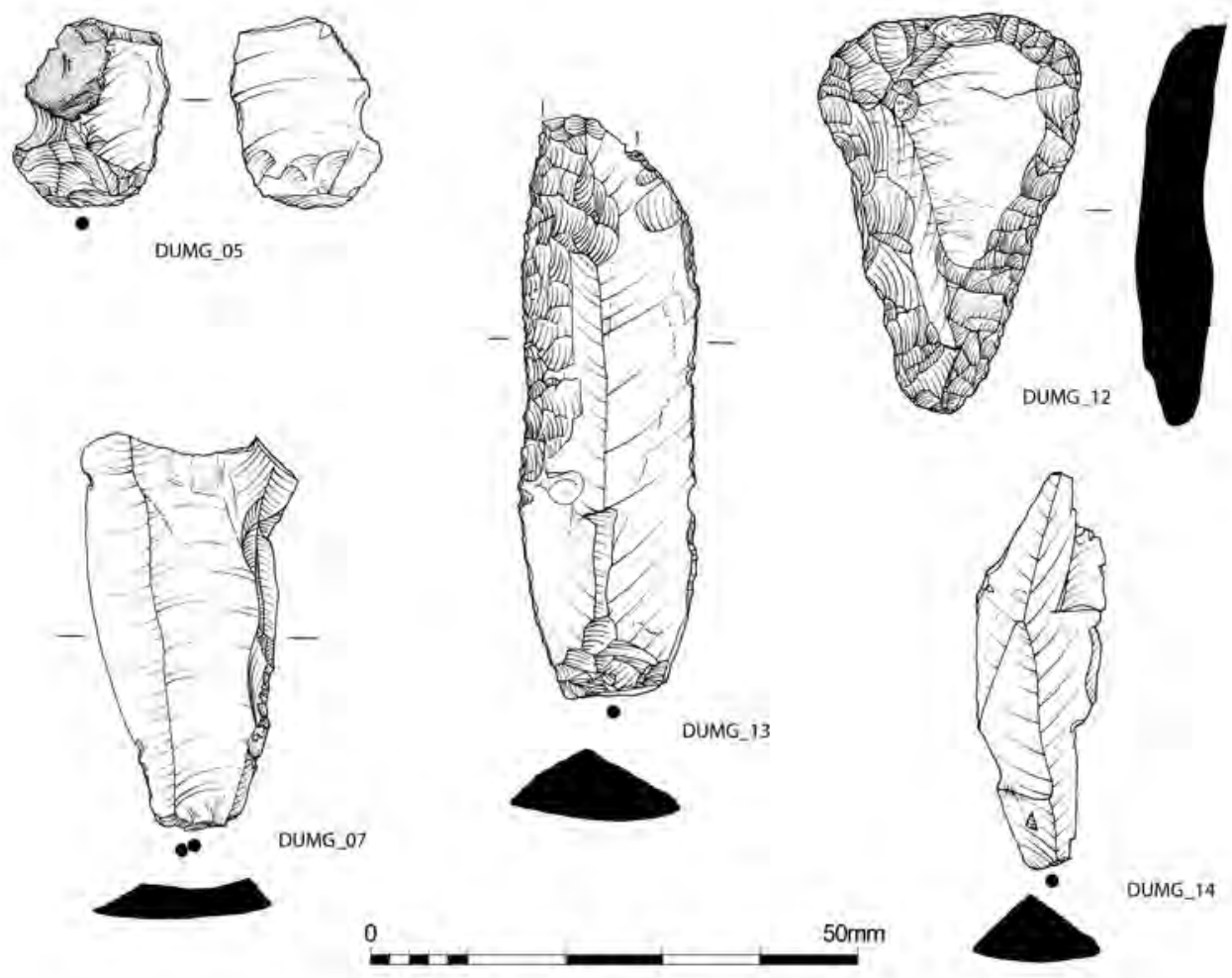

Illus 11 Lithics 
working. The characteristic forms of working, and the debitage-dominated structure to the assemblage is very much in keeping with halls from elsewhere in Scotland, and indeed with the characteristics of early Neolithic stone working in this region more generally (Warren 2007a). Assemblages, probably mainly later Neolithic, although with potential for mixing, from Beckton, within a few hundred metres of the current site (Pollard 1997), also include very few cores, although bipolar examples are present. A total of four items are retouched (illus 11).

5. Lightly and irregularly retouched flake.

This may be 'spontaneous' retouch resulting from use, sometimes described as 'nibbled' retouch (F3/04).

9. Small spall of a polished honey-coloured flint object removed from the working edge of that object.

Fine polishing striae are clearly visible under magnification. It is not possible to classify the parent object based on this spall (F3/05). (Not illustrated.)

12. A formal end of flake convex scraper.

A convex working edge has been created at the distal, and extensive modification of both laterals tapers to the platform, which has been removed. The artefact is both heavily abraded, possibly from use, and later burnt (F112/04).

13. Edge-retouched knife on a fine long blade of flint, presumably imported.

Acute light retouch characterises one lateral, with the distal receiving more invasive treatment. At the distal, this approaches a planoconvex knife in treatment and a fragment may have been classified as such (F149/02).

Two blades are also illustrated (illus 11, nos 5 and 14).

The range of retouched pieces is broadly in keeping with timber halls in other parts of Scotland, with the presence of convex scrapers, a variety of edge retouched forms and ill-defined knives and edgeretouched forms (Warren 2007a). The presence of elongated plano-convex knives, arguably on blade blanks of imported flint, is also well attested in the region. The presence of a fragment of a polished artefact is much more unusual, with Warren (2007a, 42) commenting on the absence of polished stone axes from secure early Neolithic contexts in the region.

The small assemblage from the timber hall at LockerbieAcademy is therefore very much in keeping with the characteristics from such halls elsewhere in Scotland, and more broadly, with earlier Neolithic industries in the east of Scotland, which themselves are broadly comparable with industries in other parts of Britain and Ireland.

Our understanding of the structure of Neolithic stone working in the south of Scotland is weak, and the influence of different raw material regimes on stone working is difficult to assess. The south of Scotland is characterised by the 'superabundant' (Wickham-Jones \& Collins 1978) presence of a blue/grey chert in primary and secondary geological contexts (one piece of this material was recovered from Area D, below). Most Mesolithic assemblages across the central and eastern parts of the Southern Uplands in general are often characterised by extensive use of this stone, which outcrops within 40 miles of Lockerbie, and was demonstrably quarried in early prehistory, probably in the Mesolithic (Warren 2007b). The local use of chert in the Mesolithic is also demonstrated at Star and Smittons (Finlayson 1990) whilst Ward and colleagues have identified Mesolithic activity at Daer Reservoir (c 8550-7950 cal BC) within 20 miles of Lockerbie, again relying on a variety of raw materials (Ward 1995; Ward 1997; Ward 1998). Small lithic assemblages from Beckton, Lockerbie, broadly associated with later Neolithic activity (Pollard 1997), are dominated by flint, but chert, pitchstone, mudstone and quartz are also present in significant proportions. In this broader context, the exclusive reliance on flint of the Early Neolithic industry at Lockerbie Academy is unusual, although the small sample size, and the absence of more detailed chronological modelling of changes in raw material use over time means that caution is needed in interpretation.

\subsection{Bone, by Sue Anderson}

Thirteen features (fourteen contexts) produced small quantities of burnt and calcined bone from samples or hand-collection, much of it chalky and abraded. Most groups weighed less than $5 \mathrm{~g}$ and consisted of tiny fragments too small to identify to species. Most were identified as possibly or probably animal. Fragments from F13 were identified as possibly human. Two unburnt fragments of small mammal bone from F208 may be intrusive.

\subsection{Charred plant remains, by Mhairi Hastie}

\subsubsection{Methods and results}

Sixty-six samples were retained from deposits associated with the Neolithic timber hall. Fifty-two of these samples were processed for the retrieval of palaeobotanical remains and artefacts. No floor surfaces were preserved and all of the plant remains were recovered from negative features such as postholes and pits.

Twenty-nine samples contained some carbonised plant remains including cereal grain, nutshell and seeds of wild taxa. The plant remains were generally spread throughout the structure, although the largest concentrations of cereal grain and hazelnut shell were observed to come from features located at the southern end of the timber hall. The grains were extremely abraded, indicated by the large number 
Table 3 Neolithic timber hall: summary of carbonised cereal remains by feature type

\begin{tabular}{|c|c|c|c|c|c|c|c|c|c|c|c|}
\hline Latin name & Plant part & $\begin{array}{l}\text { Feature type } \\
\text { Common name }\end{array}$ & SW & EW & WW & PIT & T1 & T2 & T3 & $\mathbf{T 4}$ & T5 \\
\hline \multicolumn{12}{|l|}{ Wild taxa } \\
\hline Corylus avellana & nutshell & hazel & + & +++ & + & + & ++ & +++ & ++ & ++ & + \\
\hline Rumex sp. & seed & dock & & & & & 1 & & & & 1 \\
\hline Bud indet & bud & indeterminate & & & 1 & & & & & & \\
\hline Seed indet & seed & indeterminate & & 1 & 1 & & & & & & \\
\hline $\begin{array}{l}\text { Monocotyledon } \\
\text { rhizomes }\end{array}$ & & & + & + & & & + & + & & & + \\
\hline \multicolumn{12}{|l|}{ Other plant remains } \\
\hline Linum utatissimum & seed & cultivated flax & 6 & 14 & 18 & & 1 & & 2 & & \\
\hline Linum cf. utatissimum & seed & cultivated flax & & & & & 1 & & 1 & & \\
\hline \multicolumn{12}{|l|}{ Cereal indet } \\
\hline Triticum sp. & caryopsis & wheat & & 8 & 5 & 13 & 2 & 2 & 2 & 9 & \\
\hline cf. Triticum sp. & caryopsis & wheat & & 2 & & & 1 & & & & \\
\hline Triticum dicoccum $\mathrm{L}$. & caryopsis & emmer wheat & & 9 & 2 & 10 & & 2 & 5 & 19 & \\
\hline Triticum cf. dicoccum & caryopsis & emmer wheat & & 2 & & & & & & 1 & \\
\hline Triticum sp. & spikelet fork & wheat & 1 & & & 1 & & & & & \\
\hline Triticum dicoccum $\mathrm{L}$. & glume base & emmer wheat & & & & & & 1 & & & \\
\hline $\begin{array}{l}\text { Triticum cf. } \\
\text { aestivo-compactum }\end{array}$ & caryopsis & bread/club wheat & & 1 & & & & & & & \\
\hline Hordeum sp. & caryopsis & barley & & 7 & & 3 & 3 & 1 & 1 & 3 & 1 \\
\hline cf. Hordeum sp. & caryopsis & barley & & & & 1 & & & & & \\
\hline Hordeum naked & caryopsis & naked barley & & 2 & & & & & 1 & 1 & \\
\hline Hordeum naked (ST) & caryopsis & naked barley & & & & & & 1 & & & \\
\hline Avena sp. & caryopsis & oat & & 1 & & & & & & 1 & \\
\hline cf. Avena sp. & caryopsis & oat & & & & 1 & & & 1 & & \\
\hline Cereal indet & caryopsis & indeterminate & 4 & 33 & 11 & 49 & 3 & 7 & 6 & 10 & 2 \\
\hline
\end{tabular}

Key: SW = south wall, EW = east wall, WW = west wall, PIT = pits, T1-T5 = Transverse I-V, + = rare, ++ = occasional, +++ = common and $++++=$ abundant

of grains that could not be identified to species level (highlighted in the 'cereal indet' row in Table 3).

The cereal grain was dominated by wheat (Triticum sp.), a small number of which were identified as emmer wheat (Triticum dicoccum) and one possible bread/club wheat (Triticum aestivo-compactum). In addition, small quantities of naked barley (Hordeum sp.) and grains of oat (Avena sp.) were recovered. None of the oat had palea and lemma attached, and it was not possible to distinguish between the wild and cultivated species. A small assemblage of wheat chaff was recovered, comprising glume bases and spikelet fork fragments. One of the chaff remains was sufficiently preserved to be identified as emmer.

Small burnt fragments of hazelnut shell (Corylus avellana) were recovered from twenty-five samples, and cultivated flax seeds were present in seven of the samples. In addition, small fragments of charred rhizomes (underground stems) and what may be culm bases were recovered from a small number of the samples.
Low concentrations of charcoal were recovered from all of the processed samples; thirty-six samples containing charcoal fragments suitable for species identifications ( $4 \mathrm{~mm}$ or greater). The charcoal was dominated by plate-like fragments of oak with large concentrations of oak charcoal recovered from features F112, F117, F125, F149 and F161. Occasional small amorphous fragments of alder (Alnus sp.) and hazel (Corylus sp.) were also recovered. One particularly small fragment of possible willow (cf. Salix sp.) was present in the fill of a post-hole (F114) forming part of the eastern wall of the hall.

\subsubsection{Cereal processing and collection of wild resources}

The Neolithic plant assemblage was dominated by wheat along with small quantities of naked barley. Although the quantity of the grain recovered is small it does correlate with a repeated pattern throughout Britain, with emmer often the most 
abundant species identified, along with barley. The small quantity of oat grains recovered is likely to be the wild variety (Avena fatua) growing as weeds in arable fields.

The small cereal assemblage recovered from the timber hall contrasts markedly with the high concentrations of grain found at other similar structures, for instance at Hambledon Hill, Dorset (Robinson 2000), Lismore Fields, Derbyshire (Jones forthcoming) and Balbridie, Aberdeenshire (Fairweather \& Ralston 1993). The recovery of carbonised grain from numerous internal features does indicate that like the other sites, grain was being handled within the structure. The largest quantity of nutshell and grains was recovered from F15, F114, F149, F152, all located in the southern half of the hall, and this may indicate that food processing or storage was being carried out towards this end of the building.

The large grain assemblages recovered from a number of timber structures, namely Balbridie and Lismore Fields, might demonstrate that large-scale cereal growing, processing and storage was being carried out in the Neolithic period. There was no evidence, from either site, for grain storage pits, and Fairweather \& Ralston (1993) suggest that the grain was being stored in the timber hall, on floors raised above ground level. Whether this storage was long- or short-term cannot be gleaned from the evidence to date. The presence of large-scale grain stores does, however, suggest that cereal cultivation was managed and enclosed, rather than produced through an informal system. Production of large quantities of grain would have required the organisation of cultivation plots and the management of these areas, although as yet there is very little data to indicate the size and arrangement of these plots, and whether they were permanent features. Evidence from a Neolithic farm at the Knap of Howar (Ritchie 1983) indicated that, to the south of the houses, midden material had been spread out to form a layer of uniform thickness over an area stretching $20 \mathrm{~m}$, and Ritchie suggests that this surface had been created specifically for intensive cultivation.

Cereal chaff from Neolithic contexts tends to be extremely scarce and the plant remains at Lockerbie Academy follow this trend, with only two chaff fragments being present. In most cases the chaff material recovered from British Neolithic sites is from hulled cereals, including emmer and possible einkorn (Triticum monococcum). The removal of the hulls can be aided by parching of the grains over the fire. Any charred chaff remains from this process would be less susceptible to fungal attach and degradation, and are more likely to survive in the archaeological record compared to uncharred remains. The general scarcity of this material, from Neolithic contexts, may augment the possibility that de-husking of the grains was carried out by other processes that did not require fire - such as pounding or rubbing - crop-cleaning by-products remaining from such processes are less likely to be preserved in the archaeological record.

The range of wild taxa recovered from British Neolithic sites is more limited than those identified from European sites, and Lockerbie Academy is no different in this case. Only a small quantity of hazelnut shell, waste nutshell fragments, have been recovered from the Neolithic contexts; unlike European sites, no fruit stones/remains of legumes or other wild plants were recovered. This is principally a factor of the processing activities used to prepare these plant types; unless the plant material being used has become charred it is unlikely to be preserved in the archaeological record. Much of the plant material recovered from European sites is recovered from waterlogged deposits, the plant remains being preserved in anaerobic conditions. Such waterlogged deposits are rarely encountered on British Neolithic sites, although on the rare occasion when waterlogged plant assemblages are uncovered it is clear that a range of fruits were collected from the wild during this period, including apples, sloe berries and blackberries (Robinson 2000).

The charcoal assemblage recovered from the structure consisted principally of plate-like oak charcoal fragments. These plate-like fragments probably originated from large oak timbers rather than fragments of roundwood, and given the spread of the oak charcoal, within post-holes which run the length of the structure, the charred timber fragments are most likely structural timbers and suggest that the building was destroyed by fire. Evidence from other Neolithic halls, including Claish, Lismore Fields, Balbridie and Warren Field (Murray \& Murray 2006) also indicate that these structures were destroyed by fire; the hall uncovered at Lockerbie Academy therefore fits into a wellestablished pattern.

Aside from oak charcoal, occasional small fragments of scrubby species, including alder, hazel and willow, were also present in post-holes and pit fills. Hazel is typical of mixed deciduous woodland, probably deriving from the woodland under-storey, while alder and willow would be more typical of wetland or streamside locations. All species would have been collected for use as flooring, bedding, fuel and building materials. Due to the small assemblage recovered from Lockerbie Academy, no meaningful observations can be made about woodland management or fuel use.

\subsubsection{Cultivation of flax}

Recently, there has been an increase in the recovery of linseed (flax) from archaeological deposits, probably as a result of the greater use of soil flotation methods and finer mesh sizes during the processing of bulk soil samples. As a result, flax seeds are now commonly found on medieval and Norse sites, and have been recovered from several later prehistoric sites. The recovery of flax from 
Neolithic deposits is, however, still rare. A few seeds have been found at Windmill Hill, Wiltshire and Balbridie (Fairweather \& Ralston 1993), Lismore Fields (Jones forthcoming), The Stumble, Essex (Greig 1991), and Achnasavil, Kintyre (Carter \& Tipping 1993). The presence of a number of cultivated flax seeds within Neolithic deposits at Lockerbie Academy affirms that flax was indeed being cultivated during this period of prehistory. Compared to other Neolithic sites the quantity of flax seeds recovered at Lockerbie Academy was proportionally much higher relative to the number of cereal grains recovered (Bishop 2007).

There are two possibilities for the recovery of flax seeds from the building: seeds charred during the processing of linseed oil, or a store of flax seeds burnt during the destruction of the building.

Flax processed for linen does not require to be dried, therefore limiting the chance of the flax becoming charred and being preserved in the archaeological record, and the small numbers of flax seeds recovered from prehistoric or later sites are likely to be the result of seeds accidentally burnt during the processing of linseed oil. Linseed oil could have been used for a number of different processes, for instance food preparation/cooking, medicinal uses, for the oiling of wood and/or leather objects, and preserving hemp rope. The crushed seeds left over from production of the linseed oil could also have provided a nutritious animal fodder. While the spread of flax seeds from Lockerbie Academy could also be interpreted as being the remnants of seed processed for oil, it is equally possible that the charred seeds, recovered from the structure, are the remains of a store of flax burnt when the building was destroyed by fire. The bulk of the flax seeds were recovered from the southern end of the building, within postholes associated with the wall of the structure, and may suggest that a store of flax seeds was being kept at this end of the building, burnt seeds finding their way into posthole fills as the remaining unburnt posts rotted.

The cultivation of flax requires good preparation of the land where it is to be grown. Boase (1918) states that 'the land must be deeply worked and firm, with a shallow surface layer to cover the seed after sowing. This is important as the crops grow very rapidly', and intensive weeding is required so that the weeds 'do not spring up and choke it'. Crop rotation is necessary as flax is an exhausting crop, and a gap of seven years between sowing in the same fields is required (Clapham 1986). It is not a restorative crop, as it is pulled rather than cut during harvesting; the seeds are saved for sowing and the straw for fibre, so nothing goes back to the land. The cultivation of flax is, therefore, time-consuming and laborious. With this in mind, it is likely that the growing of flax and production of linseed oil were seen as an important commodity; for instance linseed oil being used particularly for ceremonial activities, or considered to be high status.

\subsection{Discussion of the Neolithic structure}

Despite the degree of plough truncation that has affected the external western wall and much of the northern end of the Lockerbie Academy timber hall, the hall shows a number of similarities with those excavated at Balbridie, Claish and Warren Field. Although it is by no means certain that all of these structures would have served the same function, many of the similarities between them are remarkable; they all have fairly similar dimensions (Balbridie $24 \mathrm{~m} \times 12 \mathrm{~m}$, Claish $24 \mathrm{~m} \times 8.5 \mathrm{~m}$, Warren Field $24 \mathrm{~m} \times 9 \mathrm{~m}$ and Lockerbie Academy up to $27 \mathrm{~m}$ $\times 8 \mathrm{~m}$ ), they all had substantial internal divisions and they all contained fairly large assemblages of material culture. It is also of note that all four timber halls are situated within areas that are particularly fertile and would have been capable of sustaining a comparatively large population density.

\subsubsection{Structure}

From the surviving ground plan, it is hard to ascertain exactly how the building was laid out and constructed. It has been noted by Ian Ralston (pers comm) that there is a lack of post-holes along the axial line. This situation was also apparent at Warren Field, where the axial line was defined by just two massive post-holes, one placed towards either end of the structure. Murray et al (2009) have suggested that the axial posts were positioned first and the rest of the building was laid out in relation to them. Possible axial posts (F134 and F155) were present at Lockerbie Academy, but these were not on the massive scale that they were at Warren Field, suggesting that they played a much less pivotal role in the structure of the building. The plan of the Warren Field hall also suggests that the external walls may have provided a significant element of its structural integrity, whereas the timbers of the internal divisions appear to have been fairly insubstantial in comparison. In contrast, at Lockerbie Academy the layout of the internal divisions suggests that the support for the roof was provided by longitudinal beams positioned on either side of a central aisle, with a much lesser structural role being played by the less substantial external timbers. This appears broadly to parallel the layout at Claish, suggesting structural similarities between these two timber halls. The structural importance of the internal elements at Lockerbie Academy would perhaps explain why they have survived, whereas the less substantial external elements may have been removed by plough truncation.

In the majority of cases, the internal divisions extended towards the axial aisle running through the building approximately at right angles from both the postulated positions of the longitudinal north-south orientated side walls, leaving a $1.6 \mathrm{~m}$ wide aisle running up the centre of the building. This central aisle is largely unencumbered by any 
internal structural features, such as posts underlying an axial ridge beam. Substantial post-holes situated on either side of the aisle would probably have supported the two main roof beams set atop the following features respectively: F145, F17A, F112, F147, F3 (eastern side) and F161A, F144, F149, F2 (western side). Further longitudinal roof purlins would have been positioned at decreasing heights dictated by the pitch of the roof and could also have been supported by the internal divisions as they extended from the central aisle of the structure towards the external longitudinal walls. Such purlins would not necessarily have had to consist of a single length of timber running the full length of the structure, as the gaps between the internal divisions were no greater than $c 4.5 \mathrm{~m}$. Indeed cutting and raising a single longitudinal beam to such a position would have been a major engineering task, as would placing a longitudinal beam along the ridge of the building. Once a selection of shorter beams was set in place, this would have allowed a framework of smaller timber to be lashed together to provide the structural rigidity necessary to support the weight of the roof. Support for an axial ridge beam may have been provided by king-posts that sat on crossbeams bridging the central aisle between the two halves of each internal division.

As mentioned previously, the Lockerbie Academy timber hall had six possible internal divisions (Internal Divisions 1-6 numbered from south to north), dividing it into seven separate compartments (Compartments 1-7 from south to north) or five internal divisions dividing it into six compartments if the separate structures interpretation is adopted. The southernmost compartment was very narrow, with the entranceway into the neighbouring compartment being offset towards the western side of the structure, while the entranceway from the outside appears to have been fairly centrally placed. This narrow first compartment with a screen placed directly in front of the entranceway is broadly paralleled at Balbridie and may have been intended to prevent the wind from blowing straight up the middle of the building.

The following compartment was also fairly narrow, with the combined length of the compartments $\mathrm{A}$ and $\mathrm{B}$ being approximately equal to the length of each of the following individual compartments. This would give a fairly standard gap of $c 4-4.5 \mathrm{~m}$ between the transversal posts supporting the longitudinal purlins in the roof, meaning that the longitudinal purlins would not go unsupported over a greater distance than the aforementioned measurements. The approximately equal size of each compartment might simply relate to the structural integrity of the hall or it could give an indication of social divisions, be they of function, gender, kinship or even age.

Viewed as a separate structure, the smaller northern structure would have been almost trapezoidal in shape, measuring $c 7.5 \mathrm{~m} \times 5.5 \mathrm{~m}$ externally. For a structure of this size, the post-holes appear to have been particularly massive, with the largest (F116) measuring up to $0.9 \mathrm{~m}$ in diameter and the post-hole for the possible centre post (F155) measuring $0.92 \mathrm{~m}$ $\times 0.63 \mathrm{~m}$. Post-holes of this magnitude are on a par with the largest identified for the southern part of the structure and seem out of proportion to the size of the northern structure. It is also unclear why such a massive central post was required, as this would have severely restricted the internal space. It is also perhaps of note that the gap between the southern wall of the northern structure and the northernmost internal division of the main structure was almost identical to the width of the two internal compartments that lay immediately to the south.

While these factors would appear to tip the balance in favour of the single structure interpretation, the misalignment of the internal posts to the north of the F2/F3 transverse combined with lack of features remains problematic. Certainly, it would be difficult to project a meaningful beam-line beyond F2/F3 based on the position of post-holes F132 and F164, but a transversal beam between F117 and F135 would have meant that the beam-lines would not necessarily have had to directly overlie the postholes. However, this explanation fails to explain why the building technique changed from aligned post-pits creating a broad central aisle to a row of misaligned post-holes.

Another question that remains unanswered is why the western side and the north-eastern side should have suffered from such a considerable degree of truncation when compared with the southern and northern ends and the southern part of the eastern side. Pauketat and Alt (2005) have suggested that a team of excavators would have produced postholes of differing depths according to arm length, while Loveday (2008) has suggested that turf rather than wood may have been used where there was no evidence of the side walls. While the ideas put forward by Pauketat and Alt are probably not applicable to Lockerbie Academy, the use of turf is an interesting suggestion, as this material would leave little or no trace in the archaeological record after several decades of ploughing. The use of turf could certainly explain the missing western wall and allow the two parts of the building to be linked up to create a single larger structure. Furthermore, even where it was apparent that wood had been used for the outer walls, there is no reason why it could not have been faced with turf to provide better insulation and additional structural support. However, with no direct evidence the use of turf is largely speculative.

The arguments for the two interpretations can be summarised as follows:

\section{Single structure (illus 4.1)}

- Possible axial posts can be identified at the northern and southern ends of the structure.

- The misalignment of the northern part of the structure can perhaps be explained by plough truncation or the former presence of an archaeo- 
logically undetectable material such as turf that may have extended the line of the outer walls further to the north.

- The post-holes at the northern end of the structure are of similar size to those at the southern end, and appear disproportionately large for them to be forming a smaller separate structure.

- There is no evidence of a post-hole between F2 and F3, which might have indicated the northern axial post of a shorter main hall with a separate structure to the north.

- The misalignment of the posts forming Internal Division 6 can be explained by a possible transversal beam that could have supported the longitudinal beams without them having to sit directly on top of the posts.

- At $c 4.5 \mathrm{~m}$, the gap between Internal Divisions 5 and 6 is broadly the same as it is for the three preceeding compartments.

- Radiocarbon dates suggest that the northern end of the structure is contemporary with the southern end.

Separate structures (illus 4.2)

- The northern part of the structure is misaligned with the southern part. It is also slightly narrower, and the curve of the gable appears to be considerably tighter than that at the southern end.

- Internal Division 6 consists of separate post-holes, whereas those of the other internal divisions consist of construction trenches that are separated by a broad central aisle.

- The post-holes constituting Internal Division 6 are misaligned with the perceived line of the longitudinal beams.

- There is a large gap between Internal Divisions 5 and 6 containing no obvious features.

- The post-hole for the northern axial post of the southern structure may have been removed by plough truncation, or some other system of structural support may have been in place at this end of the structure.

Due to the poor survival of this structure it has not been possible to ascertain which interpretation is most likely to be correct and based on the available evidence the author considers both to be of equal merit.

\subsubsection{Function}

Since the excavation of Balbridie, there has been a significant increase in the number of structures in Scotland that have been classified as 'timber halls'. Much of this increase can be attributed to an Aerial Survey Programme commenced by the Royal Commission for Ancient and Historical Monuments of Scotland (RCAHMS) in 1976 and consequently, a number of sites are known only from cropmarks and remain undated. This has sparked a considerable amount of debate as to whether structures of a superficially similar morphology would have served the same function, or indeed, would even have dated to the same period. In a recent article Kenneth Brophy (2007) has argued for two separate phases of timber hall construction during the Neolithic; an early Neolithic phase consisting of roofed or roofable halls and a Later Neolithic phase consisting of unroofed structures. The radiocarbon dates obtained for the Lockerbie Academy hall place it firmly in the former category and make it broadly contemporary with the previously excavated examples of Balbridie, Warren Field and Claish.

While the similarities between these structures are undeniable, there is considerable debate as to their function. Early interpretations (Kinnes 1985) suggested a largely domestic function reflecting an early farming community that was both permanent and sedentary, and parallels have been drawn with the European longhouses. There can be little doubt that the Lockerbie Academy timber could have functioned as a domestic dwelling. The size of the structure would have easily housed an extended family and the internal divisions may indicate that different activities were carried out in different areas of the building.

Others (Topping 1997; Barclay et al 2002; Cross 2003) have argued for a more multi-faceted role, Brophy (2007) suggesting that they served a purpose that went beyond the purely functional. One suggestion is that they served as buildings for communal gatherings (Cross 2003) and were perhaps used for large-scale feasting. The animal bone, nutshell and pottery identified at Lockerbie Academy certainly indicate that food preparation was undertaken within the structure, but there was no clear evidence that this was carried out on anything more than a domestic scale. It is also perhaps of note that the internal compartments were of approximately the same dimensions, with no apparent effort being made to create a single large open space that would have accommodated a large gathering. This was also the case at Claish, where the closely spaced post-holes do not appear to have been conducive to large volumes of people, but at Balbridie, Ralston has suggested the structure 'had been laid out so as to provide two substantial blocks of space with little in the way of structural encumbrances (Ralston 1982, 242). Furthermore, Ashmore (1996, 32-3) has suggested that if Balbridie had been used for feasting, it could have perhaps accommodated somewhere in the region of 30-50 people. Warren Field also had the kind of substantial blocks of space that would have made it suitable for communal gatherings. This would perhaps indicate that despite the many apparent similarities between the structures, not all Early Neolithic timber halls served the same function.

A more ritual role has been suggested by Topping (1997) and Barclay et al (2002) with the internal divisions representing the control of movement 
within the building. Topping (1997) in particular has speculated that Balbridie was a 'cult house of regional significance'. However, ritualism and symbolism pervade many aspects of everyday life so interpretations of this nature would not necessarily preclude a primarily domestic function.

The excavation of the Lockerbie Academy site has now extended the known distribution of Brophy's (2007) 'roofed' timber halls into south-west Scotland and possible further examples are known from aerial photographs at Noranbank, Angus and at Sprouston, Borders. Recently obtained radiocarbon dates would also indicate that Doon Hill A (East Lothian), previously thought to be Early Historic, is in fact Neolithic (I. Ralston pers comm). Outwith Scotland, rectangular Neolithic buildings have been excavated at White Horse Stone, Kent (Hayden 2007), Llandygai, Bangor (Kenney 2008), and Parc Cybi, Holyhead (J. Kenney pers comm), while in Ireland over 90 rectangular Neolithic structures have been identified (Armit et al 2003). However, the majority of these structures were on a considerably smaller scale than the Scottish examples and are more likely to have served a purely domestic function.

The discovery of a previously unknown example so far removed spatially from the known examples, yet being contemporary in dating terms to the previously excavated examples, suggests that large timber halls may have been more widespread than previously thought. Given that the known examples lie within highly fertile areas, it is reasonable to suppose that further examples have fallen victim to plough truncation and that not all surviving structures will be visible on aerial photographs. However, this should not be taken to imply that they were ever commonplace. There are no known examples to the north of Aberdeen, and aside from a possible example at Kirkconnel (Dumfries \& Galloway), which is actually considered more likely to be Early Historic in date, there are no other examples towards the western side of the country. While it is unclear exactly what kind of function these structures would have served, any kind of building of this magnitude would imply a degree of social control or co-operation that was beyond the ordinary for the period. Their occurrence within highly fertile areas of the country is likely to imply control over large areas of agricultural ground, and whatever their function, be it primarily domestic, communal or ritual, there can be little doubt that these structures were of great significance to the people of the time.

\subsubsection{Destruction}

In common with the other excavated examples at Balbridie, Warren Field and Claish, the Lockerbie Academy timber hall appears to have been burnt down at the end of its lifespan. Large concentrations of oak charcoal were recovered from features F112, F117, F125, F149 and F161, and pottery and lithics from the structure showed evidence of burning. A possible slight reddening of the subsoil is also apparent in some of the site photographs, but this evidence is possibly rather conjectural as the site appears to have been heavily truncated and it seems unlikely that even a very severe fire would have scorched the subsoil to any great depth. The experimental burning of ground-set posts by Murray et al (2009) suggests that the posts were unlikely to be affected below ground level, and therefore the oak charcoal within the post-holes is likely to represent material that was charred above ground level and dropped down into holes as the unburnt remainder of the post rotted away. It is also unlikely that any material such as lithics or pottery that had already found its way into the post-holes prior to the destruction of the structure would have been affected by the fire. This would appear to leave two possibilities; either that the lithics and pottery were already burnt and were deposited in the post-holes prior to destruction, or that they were above ground at the time of the fire and represent a post-destruction deposition within the post-holes. The spread of radiocarbon dates obtained from charred emmer wheat suggests that burnt material was finding its way into the post-holes during the time that the hall was in use and it could be that there was a similar situation regarding the lithics and pottery. Consequently, the best evidence for the burning of the structure is provided by the concentrations of oak charcoal which was found within post-holes running much of the length of the structure. The destruction of Neolithic structures using fire appears to be a recurring theme, suggesting that it was a deliberate act marking the end of the use of that particular structure. 


\section{BRONZE AGE CEMETERY (Area D)}

\subsection{Introduction}

The Bronze Age cemetery (illus 12) was situated at the summit of a low rounded gravel knoll towards the centre of the evaluation area. This would have been a very prominent location and would probably have been inter-visible with the Bronze Age cemetery at Kirkburn, lying slightly to the north. The cemetery consisted of three graves containing cremated remains and two possible inhumation

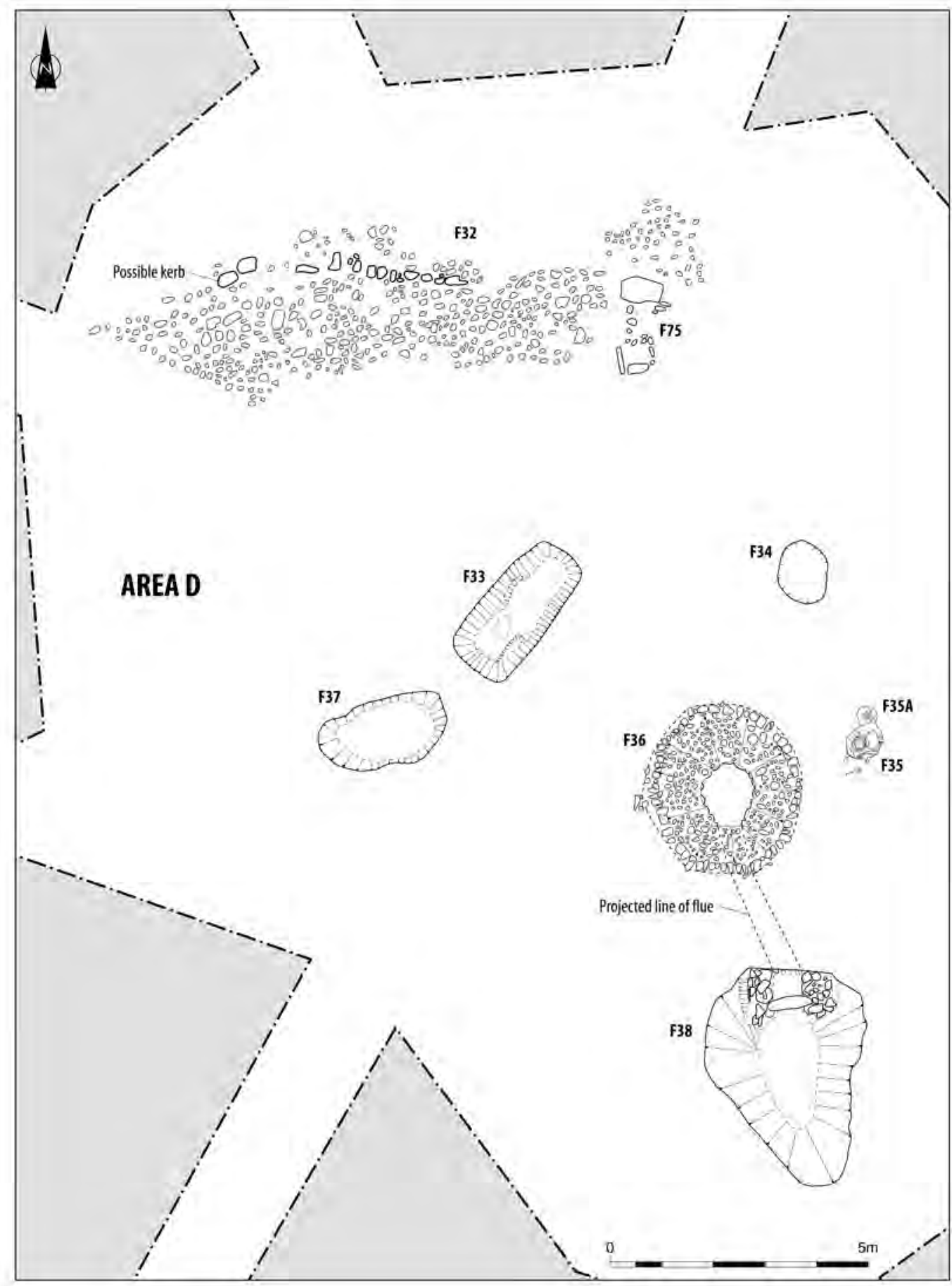

Illus 12 Plan of Area D: funerary features and medieval corn-drying kiln 


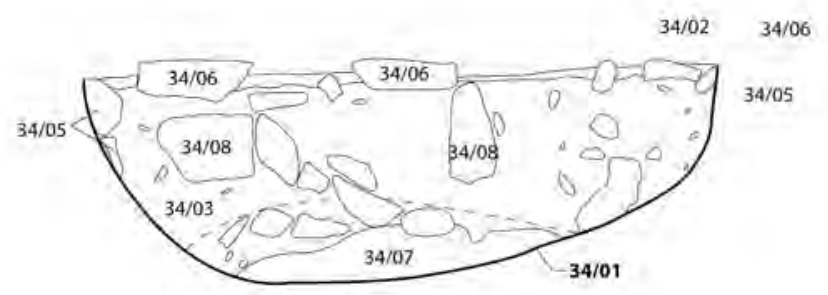

F34, east-facing section

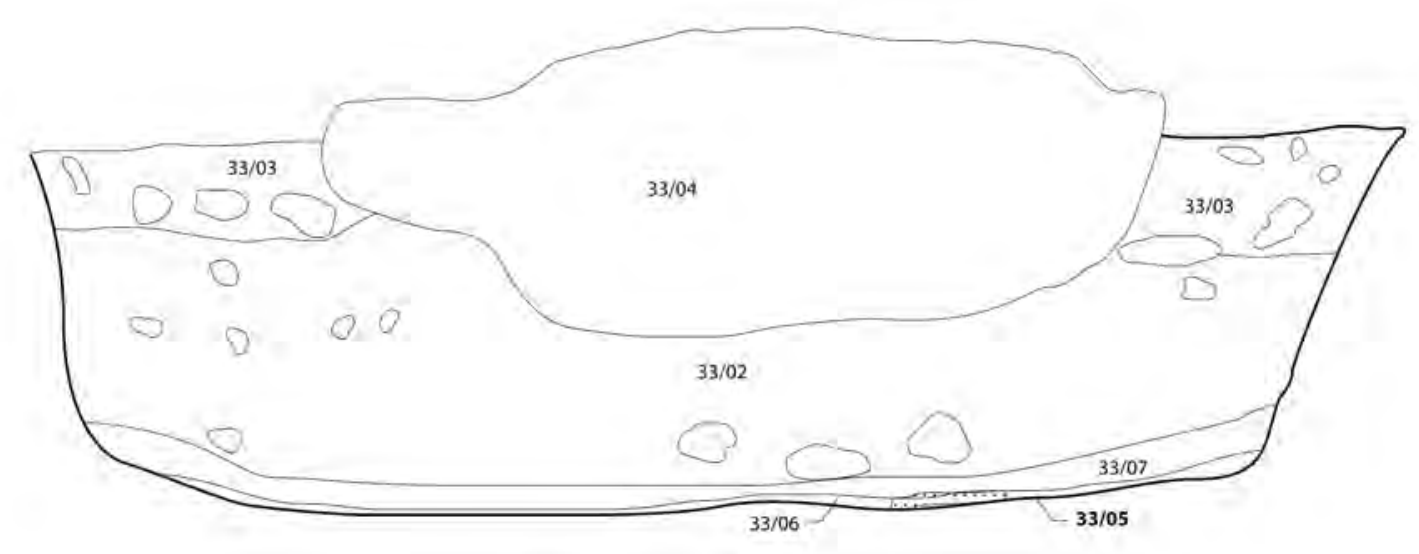

F33, east-facing section

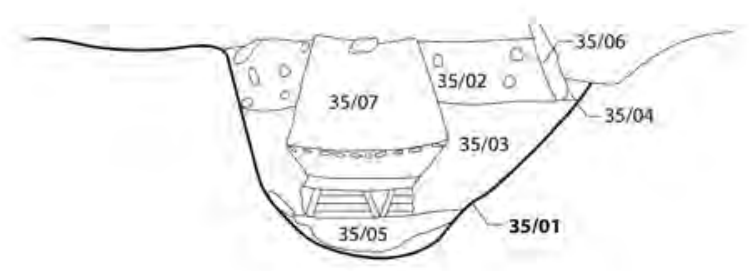

F35, SE-facing section

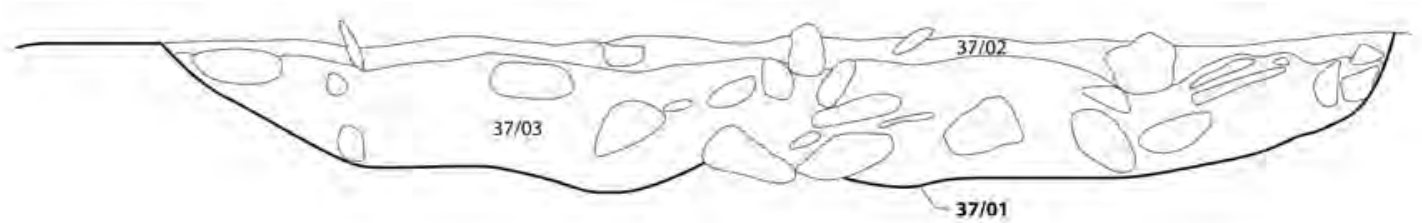

F37, SE-facing section

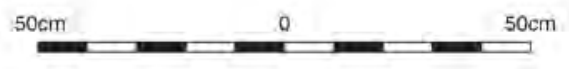

Illus 13 Selected sections of graves 
graves, but more interments may have been present prior to the insertion of a post-medieval corn-drying kiln. The largest of the possible inhumation graves (F33) was located at the very summit of the knoll with a large stone placed over the top (illus 13), and the other graves were placed around it. A bank of stones situated a little to the north of the graves may have been the denuded remains of a ring-cairn, which was possibly robbed out when the corn-drying kiln was constructed.

\subsection{The graves}

\subsubsection{Central grave F33}

A large pit (illus 12) occupied the centre of the top of the knoll. It was sub-rectangular in shape, measuring $2.7 \mathrm{~m}$ north to south by $1.4 \mathrm{~m}$ east to west and $0.7 \mathrm{~m}$ deep. A massive capstone measuring $1.7 \mathrm{~m}$ by $0.8 \mathrm{~m}$ by $0.6 \mathrm{~m}$ thick had been placed on the backfill of the pit. It is estimated that the capstone would have weighed around 6-7 metric tons. The space left between the capstone and the edge of the pit had been back-filled with soil containing a few fragments of cremated bone and small rounded stones. The cremated bone was scattered throughout the fill in very small quantities and might represent the residue from an earlier cremation burial on the site. The capstone sat on top of a $0.25 \mathrm{~m}$ thick layer of sandy clay and beneath this, the primary fill consisted of a thin layer of black/dark brown silty clay. A flat, riveted copper alloy dagger of Butterwick type, buried in its sheath, and a barbed and tanged arrowhead were recovered from the primary fill towards the south-western end of the pit. A radiocarbon date of 2140-1910 cal BC at $2 \sigma$ (see section 4.3) was obtained from the organic remains of the dagger sheath. This date lies within the general date range of $c 2200 \mathrm{BC}$ to $1950 \mathrm{BC}$ for flat riveted daggers of this type. No human remains were identified in the acidic soil, but a layer of darker material (33/05) towards the southern end of the pit may have been a 'body shadow'.

\subsubsection{Cremation burial F34}

Pit F34 (illus 12) was sub-rectangular on plan, measuring $1.18 \mathrm{~m}$ north to south by $0.9 \mathrm{~m}$ east to west by $0.47 \mathrm{~m}$ deep. A deposit of cremated bone had been placed at the base of the pit. The cremated bone suggested the presence of at least two individuals; an adult male and a juvenile (Anderson below). This deposit was almost entirely charcoal-free, suggesting that it had been picked out from the pyre debris prior to being placed in the pit. An antler pin and seven burnt flints including a plano-convex knife, were recovered from the cremation deposit (McLaren below; Warren below). A layer of large, rounded stones had then been placed over the cremation and a stone wristguard had been placed on top of the stones. The pit was backfilled using redeposited natural subsoil and rounded stones. The top of the backfilled pit was then covered with sub-angular stones, and a layer of dark-brown sandy silt had built up on top of them. A radiocarbon date of $2130-1920$ cal BC $(2 \sigma)$ was obtained from the cremated bone.

\subsubsection{Cremation burial F35A}

Pit F35A was incomplete, having been cut into by a later cremation burial (F35). The surviving remains of the pit measured $0.35 \mathrm{~m}$ north to south by $0.4 \mathrm{~m}$ east to west by $0.45 \mathrm{~m}$ deep. Cremated remains were identified on the base of the pit, but these had been disturbed at the southern end by the excavation of the later pit. The small quantity of bone was identified as adult (Anderson below). Overlying the cremated remains there was a lens of darker organic soil, but there were no artefacts present and no visible charcoal. The pit had been backfilled with redeposited subsoil and stone and a larger stone had been placed in the pit and covered over with a further deposit of subsoil. Some larger rounded stones placed within the upper layer of redeposited subsoil may have been to mark the position of the grave. Radiocarbon dating of the cremated bone indicates that this burial dated to $2030-1880 \mathrm{cal} \mathrm{BC}$ $(2 \sigma)$, making it broadly contemporary with the cremated remains from F34.

\subsubsection{Cremation burial with Collared Urn F35}

Pit F35 (illus 12) was ovoid in shape, measuring $1.05 \mathrm{~m}$ in length by $0.65 \mathrm{~m}$ in width and had cut through the southern edge of cremation pit F35A. This pit contained an inverted Collared Urn (illus 13), which was sitting on top of a slab of red sandstone measuring $c 0.35 \mathrm{~m}$ across by $0.07 \mathrm{~m}$ thick. The pit had been lined with edge-set slabs, possibly after the pot had been set in place. The gap between the stones and the edge of the pit had been filled with reddish-brown silty sand, which contained fragments of cremated bone, which may have been redeposited from pit F35A. An irregular flake of chert was also recovered from this deposit. The urn still survived to a maximum height of $0.42 \mathrm{~m}$, although the base of the vessel was largely missing, probably having been damaged by ploughing. Some fragments of the base were recovered from inside the vessel, indicating that it had been complete at the time of burial. The urn contained the cremated bone of a mature adult male, and a possible hammerstone. Radiocarbon dating of the cremated bone from the urn produced a date of $1910-1690$ cal вс $(2 \sigma)$, suggesting a slightly later date than those obtained for the other burials.

\subsubsection{Grave F37}

Grave F37 (illus 12) was sub-oval in shape, measuring $2.5 \mathrm{~m}$ by $1.3 \mathrm{~m}$ and $0.3 \mathrm{~m}$ deep. The 
Table 4 Radiocarbon dates from the Bronze Age cemetery

\begin{tabular}{lllllrr}
\hline SUERC Lab No. & Context & Type & Species & Date BP & Calibrated 1 $\boldsymbol{\sigma}$ BC & Calibrated 2 $\boldsymbol{\sigma}$ BC \\
\hline 19244 & F34/07 & Cremated bone & Human & $3635 \pm 25$ & $2030-1955$ & $2130-1920$ \\
19245 & F35/09 & Cremated bone & Human & $3490 \pm 35$ & $1880-1760$ & $1910-1690$ \\
19246 & F35A/03 & Cremated bone & Human & $3590 \pm 30$ & $2010-1890$ & $2030-1880$ \\
19817 & F33/05 & Animal hide & Indeterminate & $3645 \pm 35$ & $2120-1950$ & $2140-1910$ \\
\hline
\end{tabular}

primary fill of the pit was $c 0.25 \mathrm{~m}$ deep and consisted of many large to medium rounded stones sitting within a matrix of orange/grey-brown sandy silt. The upper fill of the pit was $c 0.05 \mathrm{~m}$ deep and consisted of grey-brown silty sand containing a large quantity of sub-rounded small/medium-sized stones. There was no evidence of human remains or grave goods and the interpretation of this feature as an inhumation burial is based entirely on the morphology of the feature and its position within a known cemetery.

\subsubsection{Possible ring cairn F32 and cist F75}

Immediately to the north of the Bronze Age cemetery, a stone bank (F32) measuring $12 \mathrm{~m}$ long by $3 \mathrm{~m}$ wide was identified (illus 12). The bank had a slight curve to it, which followed the curve of the summit of the knoll. This curve might indicate that it was the remains of a ring-cairn, which would originally have enclosed the cemetery. Along the northern edge of the stone bank, a possible kerb was identified, defining what has been interpreted as the outer face of the ring cairn.

At the eastern end of the stone bank, a possible cist (F75) was identified. This was defined by three end-set stone slabs and measured $0.5 \mathrm{~m} \times 0.5 \mathrm{~m}$. It sat within a shallow cut with a depth of $c 0.1 \mathrm{~m}$. A large flat stone located $c 0.5 \mathrm{~m}$ to the north may have been a capstone and measured $0.8 \mathrm{~m} \times 0.5 \mathrm{~m}$. There was no evidence of a burial and the interpretation of this feature as a burial cist is based entirely on its morphology.

\subsection{Radiocarbon dates}

Four samples were submitted for dating. Three dates came from cremated human bone and one date came from the dagger's sheath of animal hide recovered from the central grave. The date (2140-1910 cal BC $(2 \sigma))$ obtained from the central burial is broadly in keeping with the dates from F34 and F35A (Table 4), which were both obtained from cremated bone. A chi-squared test of the radiocarbon dates suggests that burials F33, F34 and F35A were broadly contemporary, but that F35 may have been inserted some 50-300 years later.

\subsection{Collared urn, by Melanie Johnson}

\subsubsection{Introduction}

A Collared Urn containing the cremated remains of a mature adult male was found within stonelined pit F35. The urn was exposed by excavating a box-section around the pit; the pit fill was then removed and sampled. The urn was bandaged and consolidated as appropriate, in order to lift it in one piece. Conservation and excavation of the urn were carried out by Will Murray of the Scottish Conservation Studio; its contents were removed in $3 \mathrm{~cm}$ spits. A detailed conservation report has been deposited with the site archive.

The vessel was inverted and was found sitting on a flat slab of red sandstone measuring $c 0.35 \mathrm{~m}$ across by $0.07 \mathrm{~m}$ thick, and had been propped up on one side with two small thin stones placed under the rim, perhaps functioning as chocking stones to level up the vessel. The base of the vessel was missing, with just a few fragments found inside it, presumably caused by ploughing knocking off its uppermost part. The cremated bone was found towards the rim of the vessel, with the rest of the pot's contents comprising soil and stones; this suggests that when the vessel was deposited it contained only the cremated bone, which did not fill the pot. When the vessel was inverted to go into the pit, the bone settled towards the rim of the pot leaving a void in the rest of the vessel; this void probably filled with soil following the damage to the base. Some large stones were found in the upper fills of the urn, which had probably fallen in, and some body sherds had also been pushed down into the fill. One of these stones was a possible hammerstone (Jackson below), and it is unclear whether this was deliberately deposited or not. Radiocarbon dating of the cremated bone from the urn produced a date of 1910-1690 cal BC $(2 \sigma)$.

\subsubsection{Description}

The vessel is tripartite in form, tall and narrow, with a base diameter of approximately $110 \mathrm{~mm}$ and a rim diameter of $320 \mathrm{~mm}$ (illus 14). The rim is flattopped, almost upright, and, along with the collar, slightly thicker than the walls of the pot. The collar is straight, turning at approximately $90^{\circ}$ in to the 

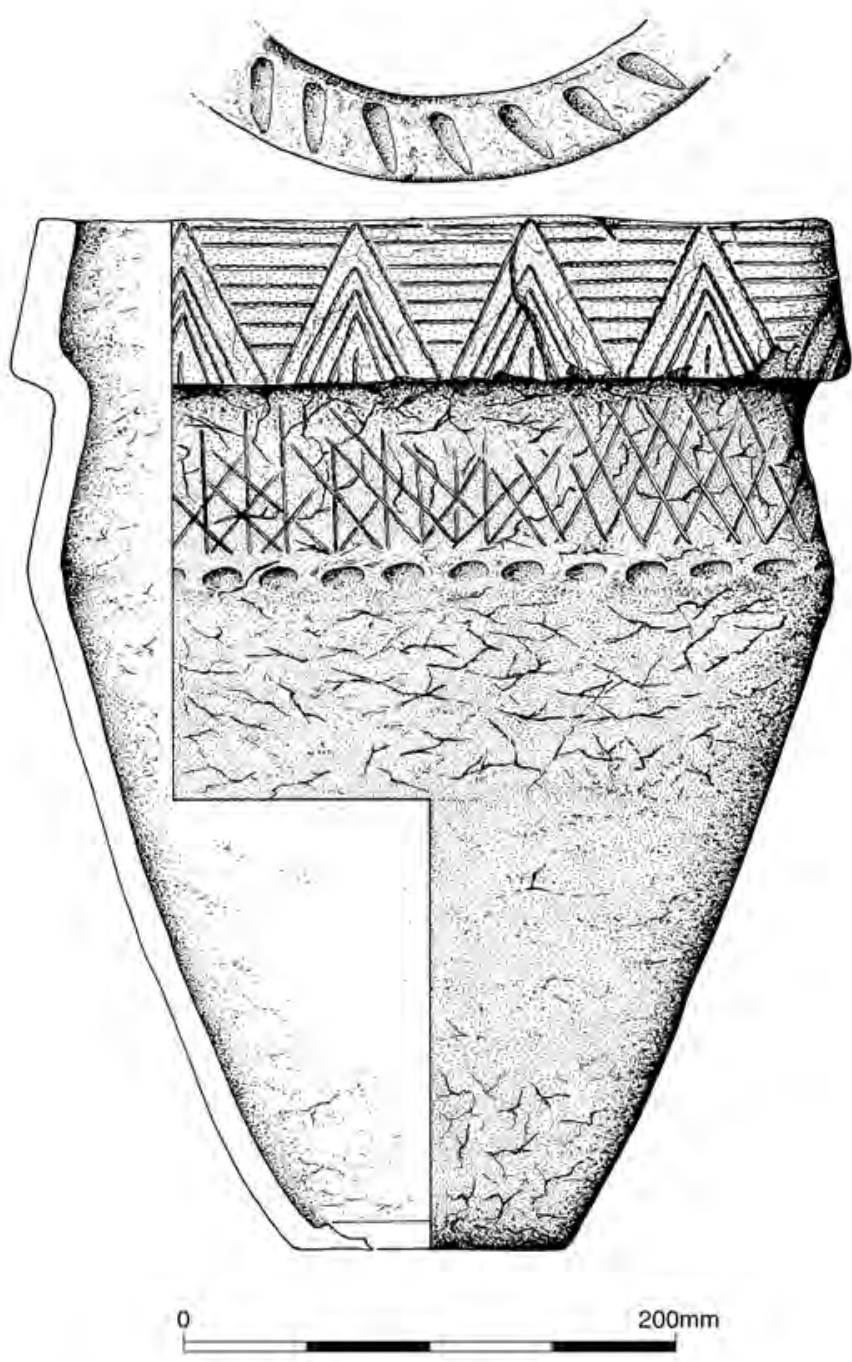

Illus 14 Area D collared urn (F35)

neck, which is also straight. The neck and collar are both $c 70 \mathrm{~mm}$ long. The body tapers down below the shoulder to a flat base. The vessel stands $420 \mathrm{~mm}$ high and has walls of average thickness $10-15 \mathrm{~mm}$. It is complete except for the base, of which only a small part survives; the rest is likely to have been lost through plough action. Overall it is in good condition. However, part of the collar and rim has been pushed in from the outside, so the rim circumference is uneven and is now oval in shape. This probably occurred after the pot had been placed on the slab and could have been caused by a stone falling into the pit during backfilling or being pushed against the vessel as the pit's fill settled; there is also damage to the vessel's surface at this point on the exterior, with surface loss and extensive cracking.

The fabric is well-fired and hard, with a hackly fracture, medium coarse, and both surfaces have been smoothed. In colour it has an orange/orangebrown exterior shading to a dark-grey interior in places. Fine cracking is evident on the exterior, with protruding inclusions. Inclusions comprise $3-5 \%$ content of small grit and stones, the latter up to $10 \mathrm{~mm}$ in size. Laminar fracture is evident at coil joins. Some sooting is evident on the interior.

The vessel is decorated with impressed twisted cord on the collar and neck, with narrow horizontal oval impressions running along the shoulder. The twisted cord impressions across the neck form a lattice motif around the whole pot, but half of the pot has additional vertical lines running through the lattice and unevenly dividing it. On the collar there are triangles of twisted cord, with the spaces between filled by horizontal lines. The rim top is decorated with a series of small oval impressions.

\subsubsection{Discussion, with Alison Sheridan}

Thanks to the results of the National Museums Scotland Dating Cremated Bones Project (Sheridan 2003) and the comprehensive dating of an Early Bronze Age cemetery at Skilmafilly, Aberdeenshire (Johnson \& Cameron forthcoming), it is now clear that the currency of Collared Urn use in Scotland falls mostly within the date bracket 1900-1600 BC (Sheridan 2007c, 165) - a range within which the Lockerbie urn date of 1910-1690 cal BC (SUERC19245) fits well. A similar currency has been found for Irish Collared Urns (Brindley 2007), and although far fewer reliable radiocarbon dates exist for their English counterparts, it seems that Longworth's (1984) argument for their initial emergence in England, then their spread northwards and westwards, holds true (Sheridan 2007c, 165); Needham has argued that they were probably first used around 2100/2000 BC (Needham 1996). Their adoption forms part of a wider change in funerary traditions, from around the 21st century $\mathrm{BC}$, in which cremation became increasingly popular as the method of dealing with the body.

Collared Urns are well represented in southern Scotland and northern England, with a nearby example known from the Early Bronze Age cemetery at Kirkburn, Lockerbie (Cormack 1963, Pit 35). In a similar fashion to the present example, the Kirkburn Collared Urn had been inverted onto three flattish stones within a pit, with flat stones placed within the pit around the urn. The urn was decorated with incised herringbone/chevrons across the collar and neck.

\subsection{Chipped stone, by Graeme Warren}

Nine artefacts were recovered from Area D, all in association with cremated bone or other burial deposits of Bronze Age date, including one (F35) associated with a Collared Urn. Seven burnt flints including a plano-convex knife were found in the cremation deposit F34/07; one flint barbed and tanged arrowhead from the 'body shadow' F33/05 associated with a copper alloy dagger, and an irregular flake of blue-grey southern uplands chert was recovered 


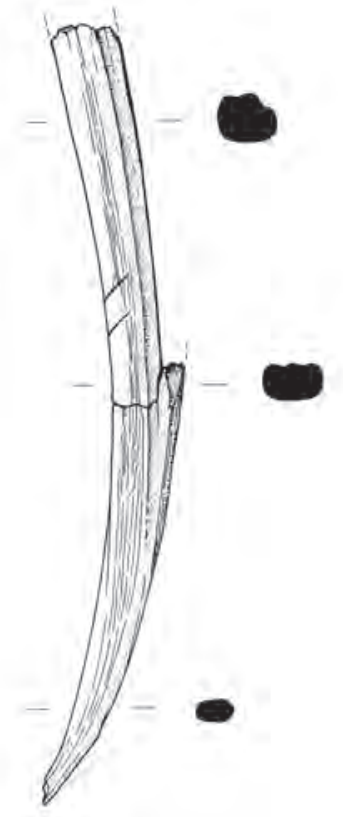

Bone pin

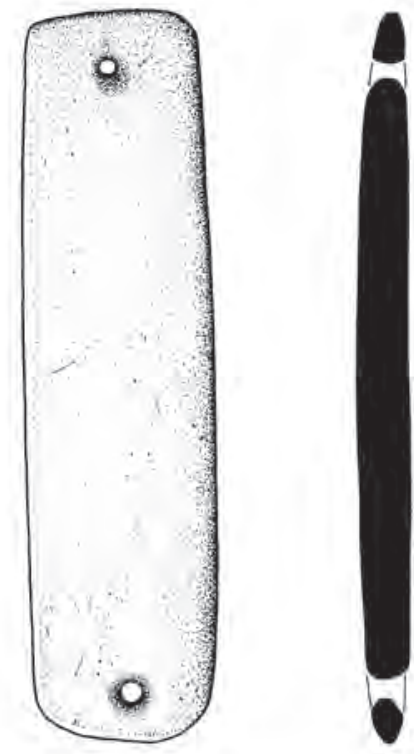

Stone wristguard
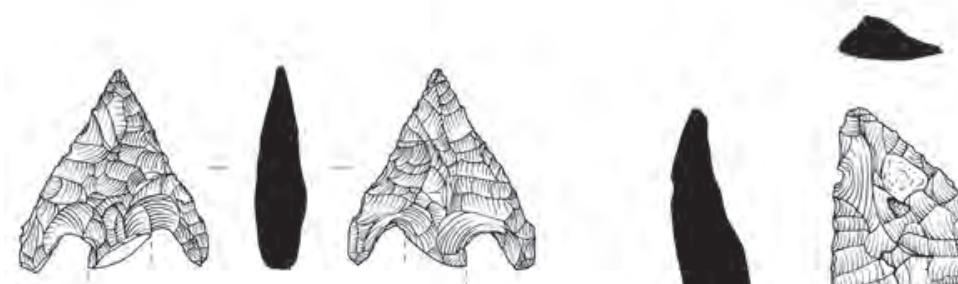

No. 10
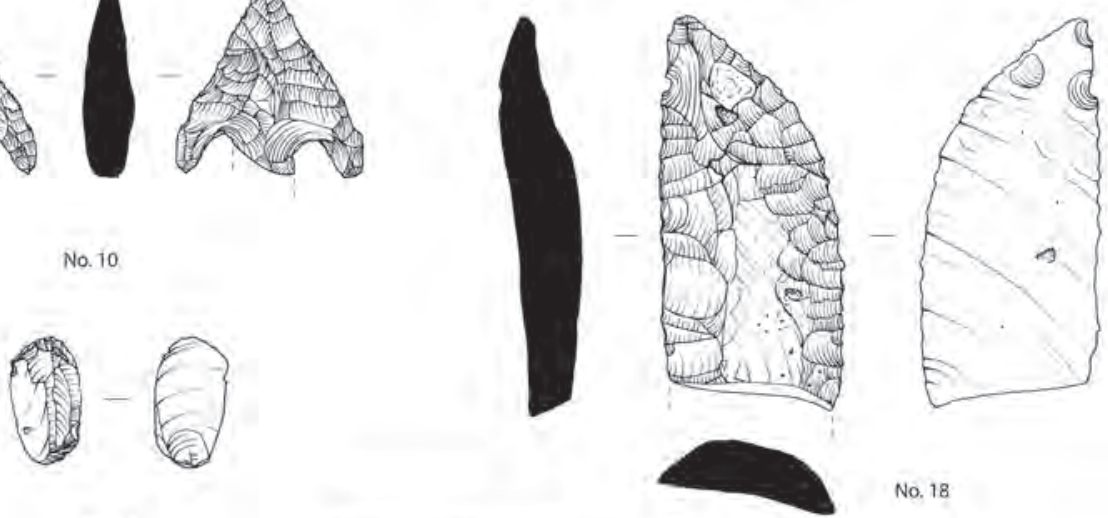

No. 18

No. 17

Flint artefacts

0

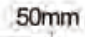

Illus 15 Area D finds from F34 and arrowhead No. 10 from F33

from a fill of F35. This piece came from the backfill of the pit and may simply be residual.

The arrowhead (10) (illus 15) from the body shadow is a small $(20 \times 19 \times 2 \mathrm{~mm})$ but fine example of a 'Sutton' barbed and tanged arrowhead with straight laterals (Green 1980). The barbs are rounded/ pointed but minor damage to the tang means that this is unclassifiable in length/morphology; the overall form is therefore unclear. The artefact is generally in very fine condition, and the tip is very fresh. The artefact was found in association with a copper alloy dagger of Butterwick type. As reviewed by Sheridan \& Cowie (2003, table 4), lithic artefacts associated with Butterwick type daggers in Scotland are rare, limited to a small number of burnt chips from Cleigh, Argyll \& Bute. More broadly, the same review notes that dagger graves sometimes include barbed and tanged arrowheads (in flint or quartz), whereas graves with bronze knife-daggers appear to be more likely to include plano-convex stone knives. The current Lockerbie find is in keeping with this pattern and the association is an important addition to the corpus.

The small assemblage from F34/07 seems to include artefacts that have passed through the cremation process, including one elaborate knife. The seven artefacts from the cremation deposit include five small burnt pieces, one a blade burnt 
after manufacture, the rest thermal spalls. A tiny $(12 \times 7 \times 2 \mathrm{~mm})$ convex end scraper is manufactured on a small flint flake (17) (illus 15) and heavily burnt post flaking. A broken plano-convex knife (18) (illus 15) (surviving fragment $40 \times 19 \times 6 \mathrm{~mm}$ ), with a slight curve to the right at distal lateral was identified. The overall morphology is obscured by the break, but there are suggestions of crescentic shape. The artefact is heavily burnt, again post flaking. Plano-convex knives are well known from Bronze Age burial contexts, often in association with Food Vessels, but also a variety of Urns (Clark 1932). For example, at Kirkburn, a comparable example ( $c 50 \mathrm{~mm}$ in maximum length) had been deposited unburnt in a Collared Urn along with cremated remains (Cormack 1963, 128). This example reminds us that very similar artefacts may have entered a cremation deposit through different routes. Finlayson (in Mercer \& Midgeley 1997) discusses use-wear analysis of a small sample of unburnt plano-convex knives, and argues that the more elaborate examples were not manufactured for practical use.

\subsection{Stone objects}

\subsubsection{Hammerstone from F35, by Adam Jackson}

A hammerstone recovered from within cremation urn F35 is of typical expedient form and was quite possibly used once and discarded. Such finds are commonplace on Scottish sites of prehistoric and later date. It is impossible to determine whether the stone was deliberately placed in the cremation urn, or accidentally deposited during the infilling of the pit.

\subsubsection{The stone wristguard from F34, by Alison Sheridan and Adam Jackson}

The wristguard (illus 15 ) is $73 \mathrm{~mm}$ long, $18 \mathrm{~mm}$ wide and $6 \mathrm{~mm}$ in maximum thickness. Its two perforations, drilled from both sides, measure $1.5 \mathrm{~mm}$ at their narrowest and are positioned at either end; one is midway across the width, the other slightly offcentre. Rectangular in shape, its corners are gently squared off at one end and rounded at the other. Its sides are basically straight - one side tapers minimally towards the ends - and it is flat on both its upper and lower surfaces. According to the latest typological scheme for wristguards (Fokkens et al 2008, fig. 1), the Lockerbie Academy example falls within the '2Spp' type (ie two perforations; straight sides; flat (plano) on top and underside; this equates to Smith's '2SF' type (Smith 2006) and Atkinson's 'B1' type (as cited in Clarke 1970). Within the size range recorded for British wristguards by Ann Woodward and colleagues, the Lockerbie Academy specimen falls towards the smaller end (Woodward et al 2006, 534). The narrowness of the perforations suggests that the wristguard may well have been riveted to a strap made of animal hide, rather than being fixed to the wrist using a thong.

There are no obvious signs of wear, but a shallow spall is missing from one end on the underside, having become detached in antiquity from beside one of the perforations. The spall scar is darker than the rest of the wristguard, and it may be that both the spalling and this discoloration were caused by heat damage if the object, like the other artefacts in the grave, had been with the corpse on the pyre. The degree of burning is not as severe as that seen on the flint artefacts from the grave, however.

The stone from which the wristguard has been made is a fine-grained rock, of pale bluish/ greenish-grey colour, with small, dark red-brown mineral inclusions. The object's outer surfaces have been stained orange from contact with the local, sandstone-derived sediment, but the original colour is visible down the holes, especially on the top side. Analysis and petrological evaluation of the stone were undertaken as part of a current project encompassing British wristguards, Ritual in Early Bronze Age Grave Goods, directed by Ann Woodward and John Hunter of the University of Birmingham (Woodward et al forthcoming). There was particular interest in this specimen as Woodward et al had discovered that other speckled wristguards, of similar-looking blue/green-grey stone, had been made from tuff from a specific area in Great Langdale, Cumbria (Roe \& Woodward 2007; Woodward et al 2006, 538. Great Langdale tuff had previously been used to make Group VI stone axeheads). Electron microprobe analysis and the production of highmagnification backscatter images was undertaken by Lore Troalen, of National Museums Scotland, using the NMS' scanning electron microscope, and the results were evaluated by project petrologist Dr Rob Ixer, who reports: 'The very fine-grained nature of the bracer makes a lithological identification very difficult. The evidence from the SEM photographs suggests that this non-clastic, uniform rock, despite its poor planar fabric, is an altered ?basic lava rather than a volcaniclastic. It lacks most of the defining characteristics of the Group VI bracers. Petrological thin-sectioning would be necessary to obtain further information' (R Ixer pers comm).

The Lockerbie Academy wristguard is the twentythird such object to have been found in Scotland (this total excludes two items that had previously been listed as wristguards by Harbison in his 1976 survey, but rejected by Woodward et al). The others mostly cluster in Aberdeenshire and around the Moray Firth, but there is a scatter in the Hebrides and in southern Scotland. Across the North Channel, there is a remarkable concentration in County Antrim (ibid, Fig. 2) - no doubt partly due to intensive antiquarian activity in this part of Ireland during the 19th century (Woodman et al 2006). Most Irish wristguards are of two-holed type, with straight or tapering sides, whereas in Scotland, from the twenty examples whose shape is known, 
only eleven - just over $50 \%$, in other words - are twoholed. The Lockerbie Academy example is similar in shape and colour to one from Mid Torrs, Glenluce (NMS X.AT 1; Harbison 1976, 29). Colour seems to have been a significant factor in the choice of stone for making wristguards (Woodward et al 2006, 534-5). Most of the Irish examples are of reddish stone, while in Britain there was a preference for grey, including blue-grey and green-grey variants (as seen in the Group VI and Lockerbie Academy examples), and also mid to dark green. One group, mostly from southern England, had been made from a distincitve whitish-blue nephrite, almost certainly imported.

Stone wristguards have been found in both Chalcolithic and Early Bronze Age contexts in Britain and on the Continent and seem to be a Beaker period innovation, being part of a set of prestige items buried with, and signalling, high-status 'hunter/warrior' males. The adult's remains in the Lockerbie Academy grave are those of a male (Anderson above). Wristguards are one element in the archery equipment that often features in these funerary assemblages. They were introduced to Britain, as part of a set of Continental novelties, by Beaker users. The earliest dated wristguards in Britain - from the 'Amesbury Archer' in Wiltshire and from Dornoch Nursery Cist in Highland - date to $3890 \pm 32$ BP (P-13852, 2471-2243 cal BC at $2 \sigma)$ and

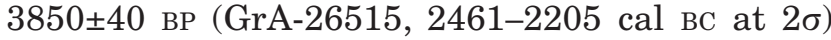
respectively, and are two-holed, with straight sides (Fitzpatrick 2002; Ashmore 1989; Sheridan 2007d, 109). Ann Woodward et al, in their review of British wristguards, have argued that the more elaborate wristguard types, including the waisted, four-holed examples (eg Ardiffery, Cruden, Aberdeenshire: Kenworthy 1976, 81), developed after the two-holed examples had been in use for some time, emerging around the time of Needham's Beaker 'fission horizon' (Needham 2005), when Beaker use and diversity increased. This is borne out by (inter alia) the date of $3732 \pm 27$ вр (KIA-25326, 2204-2035 cal $\mathrm{BC}$ at $2 \sigma$ ) for one such example, of Great Langdale tuff, found at Ferry Fryston, West Yorkshire (Brown et al 2007, 30). That two-holed wristguards continued in use after these more elaborate versions had emerged is shown by a fragmentary example from Old Rayne, Aberdeenshire (old at its time of deposition and dated to $3690 \pm 45 \mathrm{BP}$, GrA23982, 2201-1951 cal BC at 2б: Sheridan 2007d, 114) and by the Lockerbie Academy example, itself dated to $3635 \pm 25$ вP (SUERC-19244, 2126-1922 cal $\mathrm{BC}$ at $2 \sigma$ ). The latest British wristguards, found in a Collared Urn in Lancashire and a Cordoned Urn in Ferniegair, South Lanarkshire, date to within the first half of the second millennium and may have been heirlooms.

There has been much recent discussion about the function and use of wristguards, with Fokkens et al pointing out $(2008,112-6)$ that, among 30 examples from across Europe where the position of the wristguard with regard to the corpse's arm could be determined confidently, in 17 cases it lay on the outside of the wrist. In these cases, at least, the wristguard would not have functioned to protect the wrist but would have been a prestigious ornament, analogous to the native American silver ketoh that were worn in the same way (ibid). Whether or not the Lockerbie Academy example had protected its owner's wrist, it would undoubtedly have been a status symbol; the special regard in which the Lockerbie Academy wristguard was held is shown in its position in the grave, placed carefully on top of stones covering the deposit of cremated bones and other artefacts.

\subsection{The antler pin, by Dawn McLaren}

Two conjoining fragments of an incomplete, curved and calcined pin (illus 15) were recovered from amongst an unurned cremation deposit at the base of pit F34 (illus 13) along with seven burnt flints including a plano-convex knife (Warren above). The fragments are from the shaft and point only and their overall length is $79 \mathrm{~mm}$, and weight $3.5 \mathrm{~g}$. Thin cracks are present along the length of the pin, probably due to heat damage, which has resulted in the loss of the head and a long splinter from one edge. The remaining shaft is oval-sectioned $(7 \times 5 \mathrm{~mm})$, tapering to a fine narrow point $1.5 \mathrm{~mm}$ in diameter. The pin's original length is unknown.

The pin has been manufactured from the tip of a small roe deer antler tine, its shape following the natural curvature of the tine (A Kitchener pers comm). Although artificial flattening of one face and abrasion around the point has been undertaken, modification of the raw material is limited, with areas of the natural ribbed compact outer tissue remaining. Faint traces of polish are visible on the shaft and point, but this is likely to be from the natural activity of the deer rather than deliberate modification. The white, calcined, brittle appearance of the pin suggests that it passed through the pyre, being worn by the deceased. The transverse crescentric cracks along its length are almost certainly the result of heat distortion.

Eight Bronze Age bone/antler pin types have been classified by Longworth $(1984,63-4)$ which include imperforate, perforated and decorated examples. Due to the loss of the head of the Lockerbie Academy pin, it has not been possible to identify the type. Bone/antler pins are common finds from Bronze Age deposits of cremated remains with five examples known from Dumfries \& Galloway (Bishop 1919; Cormack 1963; Cowie et al 1981), all of which are manufactured from bone. This is the only antler example known to the writer in this locality, although other Scottish examples come from elsewhere such as Cairnpapple Hill, West Lothian (Piggott 1948, $110,123)$ and Seafield West, Inverness, Highland (Cressey \& Sheridan 2003, 66, fig. 14). The fact that these artefacts are consistently found in a calcined state argues for their use as a fastener for a funerary 
garment, rather than as a pin to secure a bag containing the cremated human remains.

\subsection{The bronze dagger from the central grave (F33), by Alison Sheridan and Peter Northover}

\subsubsection{Description}

The dagger (illus 16-17) consists of a flat copper alloy blade; three plug rivets that had been used to fix the hilt to the blade (of which one is still in situ); fragments of a ribbed copper alloy hiltband (a decorative binding around the pommel); and traces of its horn hilt and animal hide sheath (all suggesting that the dagger was probably buried complete with the hilt). A small piece of wood found in the vicinity of the dagger could conceivably have come from its hilt, while other detached organic fragments, consisting of a thin layer of blackish, mineralised fibrous material attaching to numerous small lumps of sediment found close to the dagger blade, may well have belonged to the sheath. Unfortunately, as the dagger was not lifted in a block and excavated under laboratory conditions, details regarding the relative positions of this fibrous material, the wood fragment and the blade have been lost.

The blade is almost triangular, with a damaged, arched heel which had originally housed the three plug rivets. The blade's edges were originally straight before curving in to a rather blunt point; while the more intact of the two edges is slightly bevelled as a result of sharpening, the edges were not deliberately bevelled. Much of one edge, approximately $10 \mathrm{~mm}$ of the point and a section of the other edge near the tip are missing, as is about one quarter of the heel, including the area where two of the rivet holes once were. The notch-like shape of the central rivet hole (to house the largest rivet) is misleading: comparison with all similar daggers makes it clear that it was indeed originally a hole. The largest of the three rivets would have occupied this central hole. There is a well-defined omega-shaped hilt mark at the top end of the blade, just below where the rivets had been (illus 17.1).

The blade's surface displays a brownish-red earthy encrustation over a dry, smooth, slightly glossy, pale green patina, beneath which are exposed areas of darker, blue-green corrosion products forming a surface to thick green corrosion products, most probably the hydroxychlorides atacamite and paratacamite. Where the patina is damaged, secondary corrosion products have erupted, and in fractures at the edge the purplish colour of cuprite is visible.

The dagger as it survives measures $141 \mathrm{~mm}$ in length and $54 \mathrm{~mm}$ at its maximum width; the original length would have been between $150 \mathrm{~mm}$ and $155 \mathrm{~mm}$ and the maximum width at the heel would have been approximately $63 \mathrm{~mm}$, assuming the blade was fully symmetrical. Its maximum thickness (excluding areas of thick corrosion products) is $3.4 \mathrm{~mm}$.

That the dagger's hilt was made (at least partly)
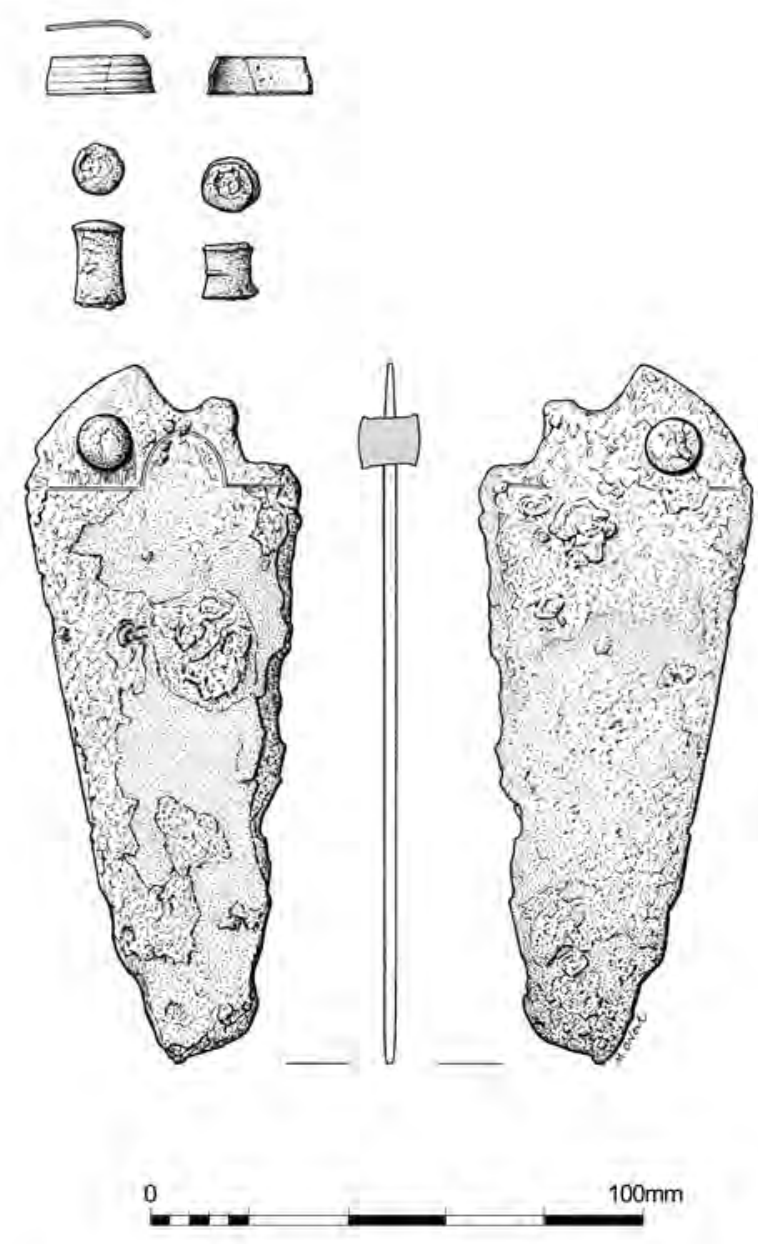

Illus 16 Dagger from F33

of horn - most probably bovine horn (Jacqui Watson pers comm) - is demonstrated by traces that remain in the vicinity of the in situ rivet on either side of the blade (illus 17.2) and on each of the detached rivets. The cellular structure of the interior of the horn is aligned along the dagger's long axis, indicating the use of one or two horn plates, cut vertically along the horn, to construct the hilt. The thickness of the largest rivet indicates that the hilt was originally $c 11 \mathrm{~mm}$ thick at its centre.

The hiltband consists of two conjoining thin yellowish-green copper alloy fragments forming a piece around $23 \mathrm{~mm}$ long, $7.7 \mathrm{~mm}$ wide and $1.25 \mathrm{~mm}$ thick which curves gently at one end (illus 17.3) but is otherwise straight. This indicates that the pommel's long sides had originally been flat (or at least flattish), and its ends gently rounded. The exterior had been decorated with four low horizontal ribs in false relief, giving it a corrugated appearance; these are most clearly visible on the curving section, and appear to be worn nearly smooth on the flat area. Tiny patches of black organic material on the inner suface (illus 17.4) could conceivably be wood, suggesting that the dagger's pommel (of which the hiltband is an ornamental binding) was wooden. It is unclear whether the detached piece of 


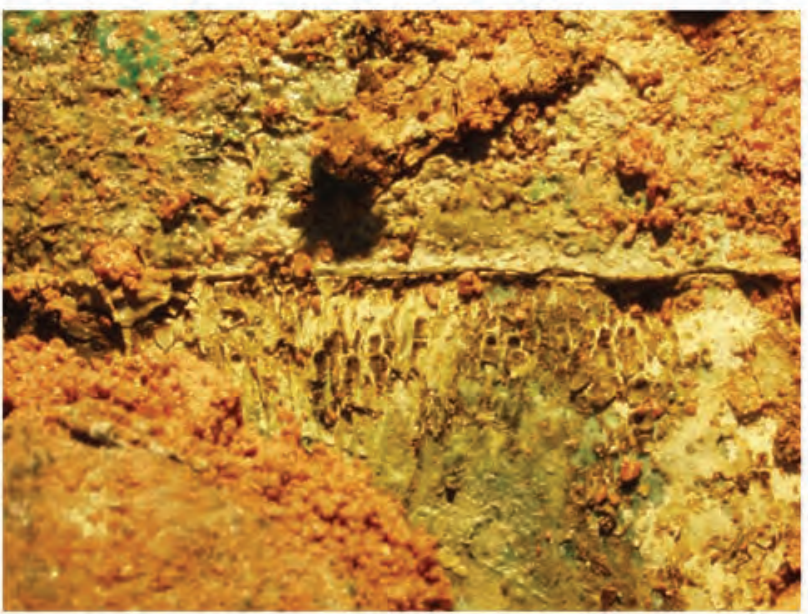

Illus. 17.1 - Edge of omega hilt

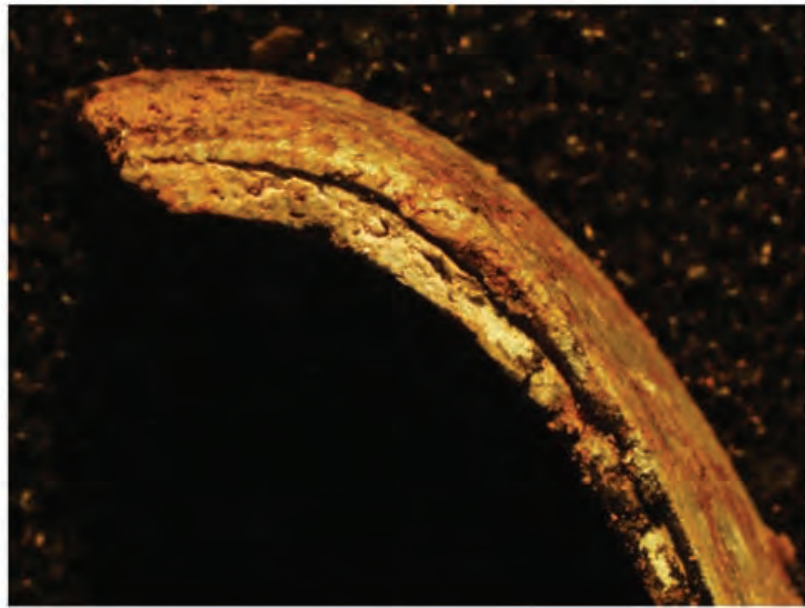

Illus. 17.3 - Edge of hilt band

Illus 17 Dagger: microscope photographs

wood $(20.3 \times 9.9 \times 8.9 \mathrm{~mm}$, illus 17.4$)$ comes from the pommel; it is too thick to have been part of a composite, rigid scabbard. Semi-quantitative compositional analysis of the surface of the hiltband by Lore Troalen (National Museums Scotland), using $\mathrm{X}$-ray fluorescence spectrometry (XRF), revealed a very high tin content, $86-87 \%$. While there may have been some post-depositional surface enrichment as tin migrated to the surface during degradation - the surfaces of the two detached rivets also had elevated tin contents, of $42 \%$ and $27 \%$ respectively (cf the analytical results for the blade, below) - it seems at least a possibility that the hiltband was deliberately tin-enriched, possibly by tinning. This would give it a silvery appearance, contrasting with the golden colour of the blade.

Traces of degraded organic material on the surface of the blade are likely to be the remains of an animal hide sheath; one fragment of this material was used for radiocarbon dating. (The term 'sheath'

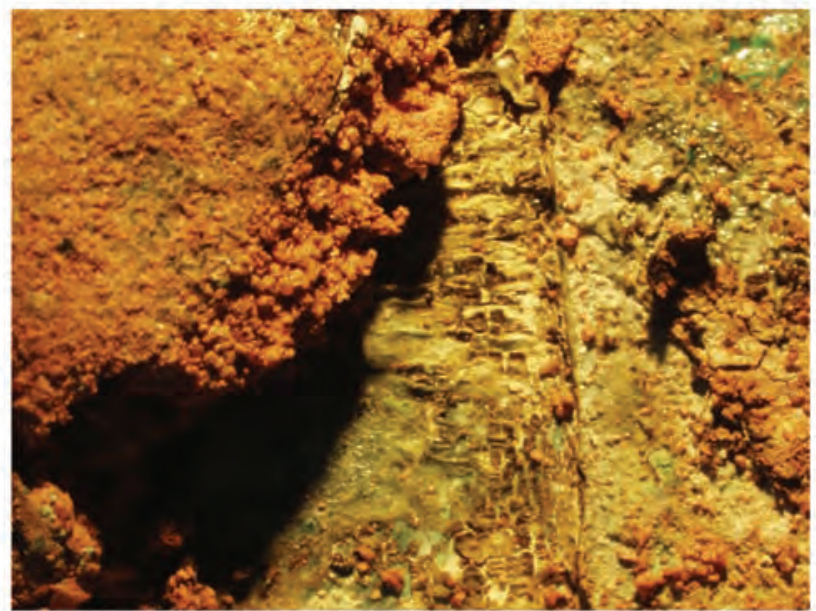

Illus. 17.2 - Hilt horn and rivet

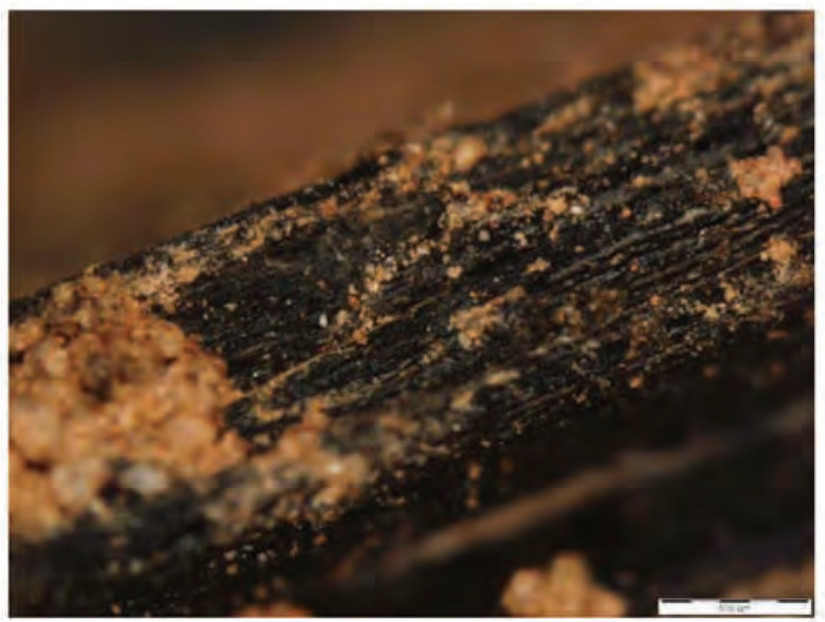

Illus. 17.4 - Wood hilt detail

is used to denote a single-material and possibly slightly flexible cover, in contrast to a composite (wood and hide), rigid scabbard. There was no clear evidence for the former presence of any wooden plate.) Some of these patches had what appeared to be fine hairs, suggesting that the outside of the sheath had been the natural hairy exterior of the hide. Additional evidence to support this comes from the dark fibrous material attached to lumps of sediment, for which the following identification has been provided by Penelope Walton Rogers (the Anglo-Saxon Laboratory), on the basis of optical microscopy, using incident light at magnification up to $\times 160$ and transmitted light up to $\times 640$ : 'Most of the black sample showed the attenuated mesh of collagen. This apparently fibrous material is in fact from the skin layer of the hide. The paler fibres had the appearance of animal coat fibres, although no cuticular scale pattern was preserved on the sample examined. They were 15-42 microns 
diameter and cross-sections were oval. It is impossible to identify species from this limited amount of data. However, the fibres seem fine for ox (even allowing for some shrinkage during mineralisation). Other species, such as sheep, would provide a better match for the range of diameters and crosssectional shape.' Given that ox-hide, rather than sheepskin, has been noted for other Early Bronze Age dagger sheaths and scabbards (Ryder 1964), an interpretation of the evidence as ox-hide in this case seems more likely. DNA analysis should help to provide a definitive identification.

Flat daggers are the earliest type of dagger to appear in bronze in Britain and, in fact, only one copper example is known, from Rudston in East Yorkshire (Gerloff 1975, no. 38); other copper associated with flat daggers occurs only as rivets. Flat daggers were fully catalogued by Gerloff (ibid) who divided them into a number of types, groups and variants (although some of these groups are uncomfortably heterogeneous in both the size and shape of the blades). Several flat daggers have been found since that publication, for example the blade of her Type Butterwick from Gravelly Guy, Stanton Harcourt, Oxfordshire, which combines a bronze blade, copper rivets and a type of bone pommel normally associated with tanged copper daggers (Northover 2005). Recent Scottish finds have been another example of Type Butterwick from Seafield West, Highland (Northover 2003a), and one of Type Milston, Variant East Kennet from Rameldry Farm, Fife (Northover 2003b).

For daggers like the Lockerbie Academy example, with a triangular or sub-triangular blade, Gerloff proposed two major types: Butterwick, with a rather broad, rounded tip to the blade and an omega-shaped hilt mark, and Masterton, where the sides are straight and the blade tapers to a sharply angled point, and with a V- or omega-shaped hilt mark. There is also a strong north-south divide in their distribution, with Type Butterwick daggers being found mainly in the south of England, Wales and the Peak District, and Type Masterton mainly in the north of England and Scotland, with some overlap in the Peak District and one example in south-east England. Another difference between the two types may be seen in their proportions. Where maximum width is plotted against length, for a given length Type Butterwick tends to be the broader of the two.

The Lockerbie dagger itself has the outline of a Type Butterwick blade, with a more rounded point and an omega-shaped hilt mark. Plotting the proportions of the Lockerbie Academy dagger against those of both Types Butterwick and Masterton, the blade tends towards the more slender Masterton proportions, although having the Butterwick outline. It must be remembered, though, that the dimensions of a number of the blades will have been affected by re-sharpening and by corrosion, especially where the corpse has been buried unburnt, a grave environment can be very inimical to bronze.
It should be noted, however, that the best parallels for the ribbed hiltband are those associated with the Masterton-type daggers from Skateraw, East Lothian (Gerloff 1975, plate 8, no. 83) and Collessie, Fife (ibid, no. 84), both of gold. A third gold-ribbed hiltband was found associated with a ribbed flat dagger, of a more 'developed' form according to Gerloff's typology, from Blackwaterfoot on the Isle of Bute (Henshall 1968, Fig. 42.5). It may be that the dagger blade started its life in southern Britain - as explained below, its composition suggests that it might possibly have been made in Wales - and that its hiltband was added later, in Scotland (although this cannot be demonstrated compositionally, due to the advanced mineralisation of the hiltband).

The Lockerbie Academy dagger adds to the growing number of Early Bronze Age 'dagger graves' in Scotland (see Sheridan \& Cowie 2003 for a recent review of the dagger graves containing flat riveted daggers). The available dating evidence for flat riveted daggers of Types Butterwick and Masterton indicates a currency within the date range 2200 $1950 \mathrm{BC}$, and possibly a narrower date range than that; the date of $2140-1910 \mathrm{cal} \mathrm{BC}$ at $2 \sigma(3645 \pm 35 \mathrm{BP}$, SUERC-19817) obtained for the Lockerbie Academy dagger sheath falls within this range. The evidence from associated, reliably-sexed skeletons indicates that 'dagger graves' are those of high-status males (usually those of relatively advanced age), so this strongly suggests that the individual buried at Lockerbie Academy was an adult man.

\subsubsection{Analysis of the dagger blade, by Peter Northover}

Sampling and analysis

The corroded state of the rivets, and the fact that both they and the hiltband were too completely mineralised, precluded their sampling for analysis (but see above regarding the semi-quantitative compositional analysis of their surface using XRF); also, the edges of the blade were too deeply corroded to allow the cutting of a metallographic sample. Therefore, a single sample was drilled from the blade only, using a hand-held modelmaker's electric drill with a $0.7 \mathrm{~mm}$ diameter bit. The sample was hotmounted in a carbon-filled thermosetting resin, and then ground and polished to a $1 \mu \mathrm{m}$ diamond finish. Analysis was by electron probe microanalysis using wavelength dispersive spectrometry. Operating conditions were an accelerating voltage of $20 \mathrm{kV}$, a beam current of 30nA, and an X-ray take-off angle of $40^{\circ}$. Counting times were $10 \mathrm{~s}$ or 20 s per element, and pure element and mineral standards were used. Seventeen elements were analysed as listed in Table 5; detection limits were 100-200ppm.

Five areas, each 30 by $50 \mu \mathrm{m}$, were analysed on the sample. Individual analyses and their means, normalised to $100 \%$, are given in the table; all concentrations are in weight $\%$. 
Table 5 Element analysis of samples from the dagger blade

\begin{tabular}{lccccccccccccccccc}
\hline Sample & Fe & $\mathbf{C o}$ & $\mathbf{N i}$ & $\mathbf{C u}$ & $\mathbf{Z n}$ & $\mathbf{A s}$ & $\mathbf{S b}$ & $\mathbf{S n}$ & $\mathbf{A g}$ & $\mathbf{B i}$ & $\mathbf{P b}$ & $\mathbf{A u}$ & $\mathbf{C d}$ & $\mathbf{S}$ & $\mathbf{A l}$ & $\mathbf{S i}$ & $\mathbf{M n}$ \\
\hline $\mathrm{R} 3149 / 1$ & 0.03 & 0.02 & 0.07 & 89.83 & 0.00 & 0.00 & 0.00 & 10.01 & 0.00 & 0.00 & 0.01 & 0.02 & 0.00 & 0.01 & 0.00 & 0.01 & 0.00 \\
$\mathrm{R} 3149 / 2$ & 0.10 & 0.00 & 0.03 & 88.44 & 0.00 & 0.00 & 0.00 & 11.42 & 0.00 & 0.00 & 0.00 & 0.00 & 0.00 & 0.00 & 0.00 & 0.01 & 0.00 \\
$\mathrm{R} 3149 / 3$ & 0.02 & 0.01 & 0.06 & 85.09 & 0.02 & 0.00 & 0.00 & 14.44 & 0.00 & 0.00 & 0.07 & 0.00 & 0.00 & 0.28 & 0.00 & 0.01 & 0.01 \\
$\mathrm{R} 3149 / 4$ & 0.00 & 0.01 & 0.07 & 86.89 & 0.00 & 0.03 & 0.00 & 12.97 & 0.00 & 0.00 & 0.01 & 0.00 & 0.00 & 0.00 & 0.02 & 0.01 & 0.00 \\
R3149/5 & 0.00 & 0.01 & 0.07 & 89.21 & 0.00 & 0.02 & 0.00 & 10.56 & 0.08 & 0.00 & 0.00 & 0.00 & 0.00 & 0.04 & 0.00 & 0.00 & 0.00 \\
R3149/Mean & 0.03 & 0.01 & 0.06 & 87.89 & 0.00 & 0.01 & 0.00 & 11.88 & 0.02 & 0.00 & 0.02 & 0.00 & 0.00 & 0.07 & 0.00 & 0.01 & 0.00 \\
\hline
\end{tabular}

Table 6 Percentages of identified fragments out of total identified to area of skeleton (*expected proportions from McKinley 1994, 6)

\begin{tabular}{lcccccc}
\hline Burial & Total wt/g & \% Identified & \% Skull & \% Axial & \% U limb & \% L limb \\
\hline Expected $^{*}$ & & & 18.2 & 20.6 & 23.1 & 38.1 \\
F34/07 & 2183.1 & 48.7 & 38.4 & 13.9 & 15.8 & 31.9 \\
F35/09 & 1598.5 & 48.2 & 24.9 & 9.7 & 12.6 & 52.8 \\
F35A & 18.4 & 62.0 & 44.7 & - & - & 55.3 \\
\hline
\end{tabular}

The alloy

The dagger blade was formed from an unleaded medium tin bronze containing $11.9 \%$ tin. The only significant impurities were $0.06 \%$ nickel and $0.07 \%$ sulphur; all other impurities sought were at, or close to, their limits of detection.

At the outset the variable state of corrosion of Early Bronze Age dagger blades makes assessment of the data difficult, especially in terms of the tin contents. Corrosion-free areas were selected for analysis by electron microprobe, as the metal was well-wrought and annealed (and so homogeneous), and therefore representative. As tin contents are frequently enhanced by corrosion some of the higher tin contents found elsewhere may be suspect. That said, tin contents are generally in the range $8-12 \%$. This dagger is at the higher end of that range and typical enough of the earliest bronze metalwork in most areas of Britain.

At the time bronze was first used in Britain, in the 21st century BC, the majority of copper was supplied from Ireland, characterised by an $\mathrm{As} / \mathrm{Sb} /$ Ag impurity pattern ('A' metal, Northover 1980), with some local production beginning in Wales and England with copper with either very low levels of impurities ('C' metal) or As/Ni impurities ('B' metal). In Scotland local production, for example of Migdale axes, is dominated by a metal similar to the Irish 'A' metal but with different proportions of arsenic and antimony. Also in Scotland there is some 'B' and ' $\mathrm{C}$ ' metal but this is very much associated with decorated flat axes probably representing direct imports from Ireland.

Plotting antimony against arsenic as the two most diagnostic impurities produces interesting results. The impurity patterns divide into three groups, those with arsenic and antimony, those with no antimony and a very small cluster with very low impurities.
The first group is influenced by Irish and Scottish sources, and the second two by non-Scottish sources. There is one Scottish dagger, that from Masterton, Fife, which has the same levels of arsenic and antimony as the Lockerbie dagger. However, it is very different in having significant silver and lead impurities, and therefore has no connection with the Lockerbie Academy dagger.

\subsubsection{Discussion}

The form of the Lockerbie Academy dagger is that of Gerloff's Type Butterwick, the earliest form of flat bronze dagger in southern England. As so few (three) Type Butterwick daggers are known from Scotland one might reasonably conclude that the Lockerbie Academy dagger was not made in Scotland. This is supported by the impurity pattern: it is low in almost all impurities except for small traces of nickel and sulphur. There is, of course, the possibility that it was made in Scotland of Irish metal, but this particular impurity pattern does not feature in Ireland. Thus the origin is most probably in England or Wales, although there are no exact parallels. The closest lie in metal group 'B4' which may have a Welsh origin (Northover 1980).

\subsection{Cremated bone, by Sue Anderson}

\subsubsection{Description}

This report examines the cremated bone from three Bronze Age burials, one urned and two unurned, as well as the burnt or cremated bone from other contexts.

Collection methods varied depending on the size 


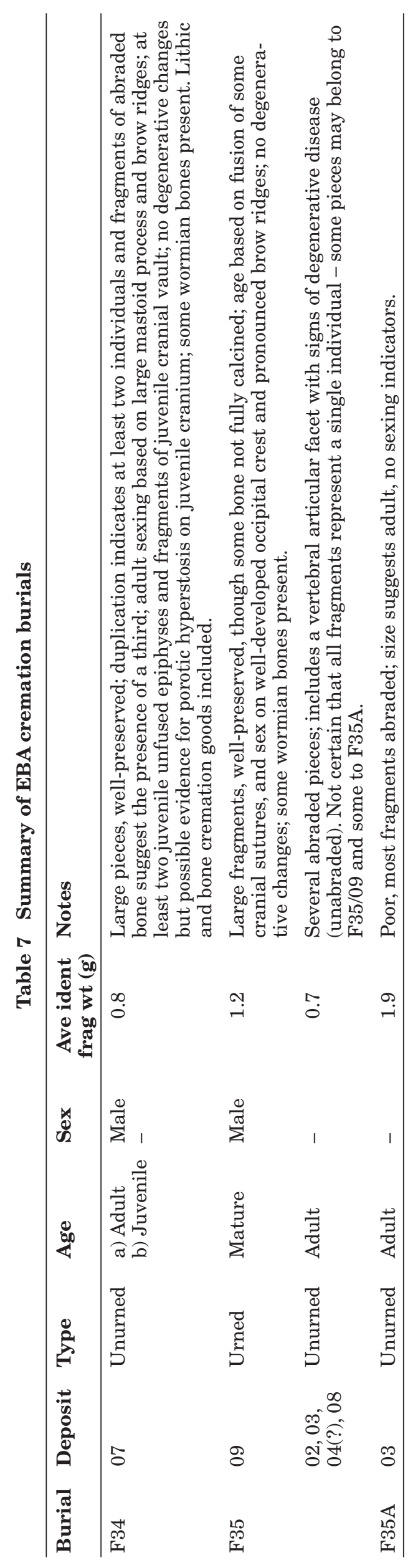


and type of deposit. The burnt bone from the urned burial (F35) was collected in spits of up to $3 \mathrm{~cm}$ in depth. The remainder were collected as single groups of bone. Apart from fragments which were handcollected on site, large groups of bone (including separate spits) were wet-sieved and sorted into fractions $<5 \mathrm{~mm},>5 \mathrm{~mm}$ and $>10 \mathrm{~mm}$ prior to analysis. The smaller fractions were mixed with pea-grit and were separated by hand during analysis so that the bone could be weighed. The fractions were sorted into five categories: skull, axial, upper limb, lower limb and unidentified. All fragments in the first four categories were counted and weighed to the nearest tenth of a gram, those in the fifth were weighed only. This allowed an average fragment weight to be calculated for the identified material. Measurements of maximum skull and long bone fragment sizes were also recorded for the $>10 \mathrm{~mm}$ fragments. These data are listed in the archive.

Observations were made, where possible, concerning bone colour, age, sex, dental remains and pathology. Identifiable fragments were noted. Age of juveniles was estimated from tooth eruption and/ or epiphyseal fusion where possible, age of adults from degenerative changes. Sexing of adults was based on size and robusticity. Methods used follow the Workshop of European Anthropologists (WEA 1980) and McKinley (1994 and 2004). A catalogue of burials is included in the archive.

Table 6 shows the bone weights, percentages of identified bone from each burial, and the proportions of bone identified from the four areas of the skeleton (skull, axial, upper limb, lower limb). Expected proportions are provided in the first row.

This shows that skull fragments are always overrepresented amongst the identifiable material, and that occasionally other areas of the skeleton may be. For example, the proportion of lower limb remains is significantly higher than expected in F35/09, the urned burial. It has been suggested that 'it should be possible to recognise any bias in the collection of certain areas of the body after cremation' (McKinley 1994, 6). However, there is also some bias inherent in the identification of elements. McKinley notes the ease with which even tiny fragments of skull can be recognised, and conversely the difficulty of identifying long bone fragments. These figures can therefore provide only a rough guide to what was originally collected.

Mays (1998, table 11.2) notes that the combusted weight of an adult skeleton has a mean of around $1500 \mathrm{~g}$ for females and $2300 \mathrm{~g}$ for males. Two of the burials in this group, F34/07 and F35/09, are within this range, although F34/07 represents more than one individual (see Table 7 and paras below). F35A was represented by very little bone, probably due to being cut by F35. Bone from the fill of the latter may belong to the former, but this only supplies an additional $22.5 \mathrm{~g}$.

In addition to the three burials, deposits of cremated human bone were found in grave F33 $(0.6 \mathrm{~g})$, and the fills of the corn-drier and its flue
$(3.7 \mathrm{~g})$. This material is assumed to be redeposited, although the inclusion of cremated material in inhumation burials has been noted elsewhere (for example at nearby Kirkburn; Cormack 1963) and may sometimes have been deliberate. The small quantity found in F33 is more suggestive of accidental incorporation.

A summary of observations made for the three main burials is presented in Table 7. Two of the burials appear to have contained a single individual, although one of these (F35) may have included some redeposited material from another. F34, however, contained at least two and possibly three individuals. The possible remains of the third individual were recognised from the presence of abraded fragments. These are too few to indicate a separate individual and they may well have been collected and included in error if the pyre site had been used previously. The presence of a child in an adult cremation burial is not unusual, and such inclusion would explain the relatively large quantity of bone in this burial. The minimum number of individuals (MNI) for this group is four. Two adults were probably male, but the others were not sexable. A few redeposited fragments from grave F33 and corn-drier F36/F38 might represent a fifth and sixth individual.

One individual, amongst the ?redeposited remains around the urn in F35, showed signs of degeneration of the spine. The juvenile in F34/07 may have suffered from porotic hyperostosis, which causes pitting on the surface of the skull and is related to iron-deficiency anaemia. A fragment of adult mandible from F34/07 showed signs of periodontal disease in the form of pitting and new bone growth to the rear of the socket for the third molar root. Wormian bones, extra-sutural bones of the skull which may have a genetic component in their presence or which can be related to stress during development, were present in two burials, F34/07 and F35/09. No other evidence for pathological changes or congenital anomalies was observed.

One of these burials was excavated in spits and this allows for the relative proportions of the four main skeletal areas to be compared. The urn was inverted and was excavated from the base, with spits 1-7 (ie the bottom $21 \mathrm{~cm}$ ) being empty. Apart from tiny fragments from spits 4 and 7 , all material was recovered from spits 8-9, with spit 9 representing the top (rim) of the vessel. There is a degree of patterning in the distribution. Upper limb bone is particularly well-represented towards the top (9), decreasing lower down the vessel (8), whilst skull fragments show a slight increase towards the lower layer at the expense of lower-limb bones. Axial fragments are better represented in the top than lower down in the vessel.

Whilst this may suggest a degree of sorting during collection, the fact that elements from all parts of the body are represented throughout the vessel suggests that this is more likely to be due to convenience than any ritual patterning. F35 was very thoroughly collected, several small bones of the feet 
being present, for example. The evidence from this urn seems to show that the collector was methodical, starting at the feet and working up the pyre. A degree of mixing is to be expected due to the subsequent inversion of the vessel.

The degree of fragmentation, based on average fragment weight, can also be compared between the spits in this vessel. The largest fragments from all skeletal areas apart from the axial region were found in spit 8 . This may partially be a result of inverting the vessel for burial, as smaller fragments might be expected to work their way down through air gaps following deposition. The difference in size of skull fragments between the two spits is quite marked and does tend to suggest that the larger fragments were collected first, which is slightly at odds with the suggestion of meticulous collection from the feet upwards, as suggested by the patterning of body parts.

The majority of bone in this group was fully oxidised and cream to white in colour, although a few fragments from the two more complete burials were grey or brown, indicating incomplete oxidation. This was particularly true of F35, in which at least one of the femora appeared relatively unburnt, suggesting that some bones or fragments may have fallen through the pyre before they were fully calcined. The presence of a high proportion of white bone indicates firing temperatures in excess of $c 600^{\circ} \mathrm{C}$ (McKinley 2004, 11). It has been suggested (Mays 1999, 159) that uniformity of colour in surviving bone may be due to poor survival of less well cremated bone. Whilst this appears not to be the case for the urned cremation (despite its relatively low weight of bone for an adult male), differential preservation may have affected the other two burials, both of which contained much higher proportions of white bone.

\subsubsection{Summary and discussion}

Three cremation burials contained the remains of at least four individuals. The burials contained two adult males, an unsexed adult and a child of indeterminate age. As is generally the case in cremated assemblages, there is little information on the daily stresses and strains of life which leave their mark on the skeleton, but one individual had evidence for changes of the spine which are associated with increasing age, one had a minor infection of the mandibular bone and one may have suffered from anaemia.

Some insight into the cremation ritual can be gained based on the evidence of the vessel which was excavated in spits, the colour of the bone and the degree of fragmentation. The distribution and size of material deposited in the urn may indicate thoroughness and attention to detail of the individual(s) who collected it. The degree of fragmentation suggests that material was carefully collected from the pyre and not subjected to any further intentional breakage before it entered the burial pit or urn. However, the incorporation of abraded material in one of the burials could indicate the reuse of an earlier pyre site from which the bone had not been collected with such care. Most of the bone from the site indicates that firing reached the high temperatures normally associated with cremation, but the urn burial may not have achieved this fully.

\subsection{Discussion of the Bronze Age funerary features, with Alison Sheridan}

The cemetery appears to be fairly typical of those dating to the Early Bronze Age in terms of its location, on the summit of a small natural knoll, in its spatial organisation, featuring a primary grave (F33), surrounded by secondary graves, and in the variety of funerary practices represented. It consisted of two possible inhumation graves, three cremation burials and the remains of a stone cist set within an area of stones that has tentatively been interpreted as a possible ring cairn. Radiocarbon results suggest its use over several generations between $2140-1910 \mathrm{cal}$ $\mathrm{BC}(2 \sigma)$ and $1910-1690 \mathrm{cal} \mathrm{BC}(2 \sigma)$, a date range that is supported by the typology of the artefacts recovered, which include a bronze dagger and a Collared Urn. Of the four dated graves (F33, F34, F35 and F35A), the radiocarbon dates suggest that F33, F34 and F35A may have been contemporary, whereas grave F35 may have been inserted between 50 and 300 years later. Where the sex of the deceased could be determined (either directly from the bones, or indirectly from grave goods), it consistently seems to be male.

One of the most striking features of this cemetery is the variety of burial rites, even among the graves that are thought to be contemporary. Cremation burial F35A had simply been placed in a shallow pit with no grave goods and covered over with two layers of redeposited natural subsoil, which were divided by a large stone. Although a few stones had been placed within the upper fill, this feature was practically invisible prior to excavation. Therefore, it is considered likely that the presence of this cremation burial was not known when the pit for the later urned burial (F35) was cut into it. In contrast, cremation deposit F34, which contained an antler pin and a small assemblage of lithics, had a small cairn-like pile of stones built up over it and a stone wristguard had been placed on top of the pile of stones prior to the back-filling of the pit. The position of this grave pit had been marked by a layer of flat stones placed over the upper fill. Although broadly contemporary with F34 and F35A, central burial F33 was an inhumation burial containing a copper alloy dagger and a barbed and tanged flint arrowhead. Inhumation F37 appeared to be of a similar nature to F33, but this burial did not contain any grave goods and it had not been covered by the type of massive boulder that marked the position of F33. Due to the lack of dating evidence, it is unclear if it was contemporary with F33. The reason for the 
variety of rites remains unclear, although the shift from inhumation to cremation - reflected in the fact that the primary grave featured the former, and most of the secondary graves the latter - reflects a broader chronological trend. An element of status differentiation seems clear, with the rich grave goods and massive covering stone of F33 suggesting the presence of a high-status man in this 'foundation' grave. The wristguard from F34 would also have been a status indicator.

The closest comparison to the Lockerbie Academy site, both in terms of content and proximity, is the burial site at Kirkburn (Cormack 1963), less than half a kilometre to the north. Like the Lockerbie Academy site, Kirkburn was also situated on a small knoll or hillock, lying between the Kirk Burn and the River Dryfe in close proximity to one of the major north/south routes in Scotland. The site itself was on a rather larger scale than the cemetery at the Lockerbie Academy site, consisting of 14 probable burials representing 16 persons. Three burials of four individuals were in cinerary urns, one burial of two persons was contained within a small cist and the remainder were contained in small pits.

What is considered to be the central burial (F33) at Lockerbie Academy is closely paralleled by a large pit (Kirkburn feature 24) at the centre of the burial site at Kirkburn (although no grave goods were found in the latter). At $9 \mathrm{ft}(2.7 \mathrm{~m}) \times 4 \mathrm{ft} 6 \mathrm{in}$ $(1.4 \mathrm{~m})$, this pit was the same size as that excavated at Lockerbie Academy and had the same NE by SW orientation. It was also very similar in terms of the fill in that it consisted of tightly compacted stone containing a few cremated bone splinters. Cormack considered that the stones from throughout the pit were too tightly packed to represent collapse on the decay of a coffin or small mortuary building, and the same conclusion can be drawn for the Lockerbie Academy example. Given the location of these large pits at the very highest point on their respective knolls, it is likely that they represent the inhumation of a particularly significant member of a family or community, with other members being placed in satellite burials around this main burial. The presence of a small quantity of cremated bone from around the edges of the upper fill of the central burial might indicate that there had been an earlier cremation burial on the site that was destroyed when the central burial was inserted.

Where the central burial at Lockerbie Academy differs from that at Kirkburn is through the presence of the massive boulder sitting within the fill of the feature. Based on a weight of 2.3-2.75 metric tons per cubic metre, it is estimated that the boulder may have weighed as much as 6-7 metric tons. Assuming that this boulder would have had to have been brought in from elsewhere, its transportation and manoeuvring into position would have involved a significant imput of labour. During the course of the excavation there was some speculation that it may have been a fallen standing stone, although no evidence of a socket was identified. The author was unable to find any direct comparisons for a stone of this size sitting within the fill of a grave, but a massive boulder of a similar size covered a cist burial in the Early Bronze Age cemetery at Holly Road, Leven, Fife (Lewis \& Terry 2004).

The high status of the individual buried in F33 is underlined by the presence of a dagger and barbed and tanged arrowhead; by the huge covering boulder; and by its central position in the cemetery. The Lockerbie Academy 'dagger grave' brings the total of such graves in Scotland to 31 (see Sheridan $\&$ Cowie 2003, table 4 for details of the others and cf Henshall 1968). The next nearest example, roughly contemporary with this one, is from Carlochan Cairn, Dumfries \& Galloway (Sheridan \& Cowie 2003). Although initially introduced as part of the Beaker 'package' of novelties, the practice of burying an important male with a dagger became particularly popular as soon as bronze began to be used, during the 22nd century BC (Henshall 1968; Sheridan \& Cowie 2003).

The other artefact indicative of high status is the wristguard, found in F34. As explained in Sheridan and Jackson's report (above), this object might never have protected a wrist, but it would have been a prestigious ornament and status symbol, and it might have been worn on the pyre. The plano-convex flint knife found in F34 is paralleled at Kirkburn, but the Kirkburn example had not been subject to the cremation process and was recovered from inside an urn (Kirkburn Urn 3, Pit 35).

Other Bronze Age funerary finds within the Lockerbie area include a Cordoned Urn from Shuttlefield, in which a knife-dagger blade was found (Rae 1880; NMRS N0. NY18SW 20), an urn from Broomhill (Anon 1871; NY08SE 26) and five Collared Urns from Millhouse Bridge (Morrison 1968 and Longworth 1984; NY18NW 5). Little is known about the Broomhill urn other than that it contained fragments of bone and several teeth and that it was found in a cist in about 1865 . 


\section{EARLY HISTORIC TIMBER HALLS (Area C)}

\subsection{Introduction}

The Anglian hall (illus 18-22) was situated on lowlying ground immediately to the north-west of the small knoll with the Bronze Age cemetery at the summit. This area of the field would not have been a particularly prominent one as it was overlooked not only by the knoll, but also by the flat plateau to the north, where the Neolithic structure was situated, and by rising ground to the south and west. The hall was orientated approximately NNE to SSW and was defined by massive post-holes and construction trenches. Two parallel lines of post-holes were also identified, one cutting across the interior of the

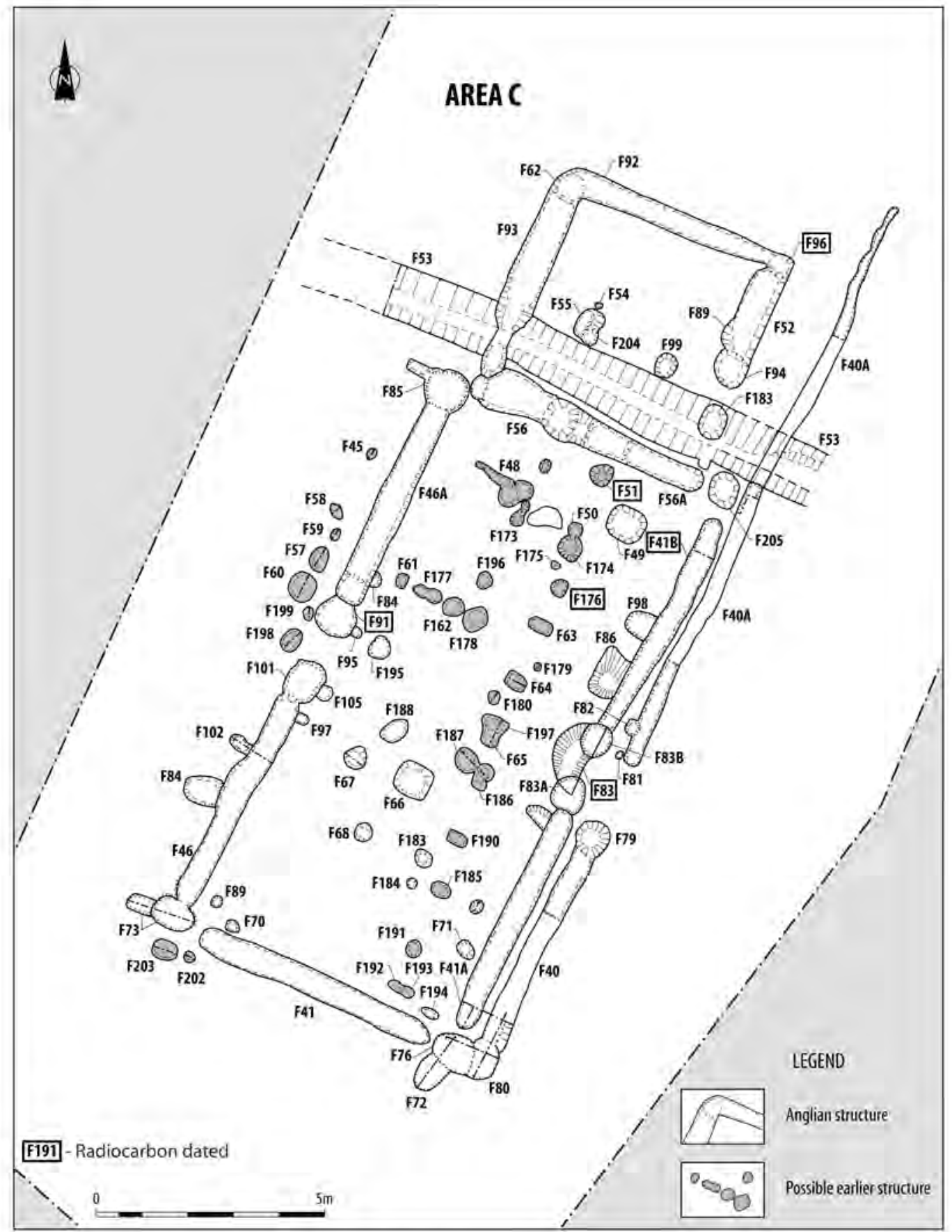

Illus 18 Plan of Area C: Anglian hall and earlier structure 


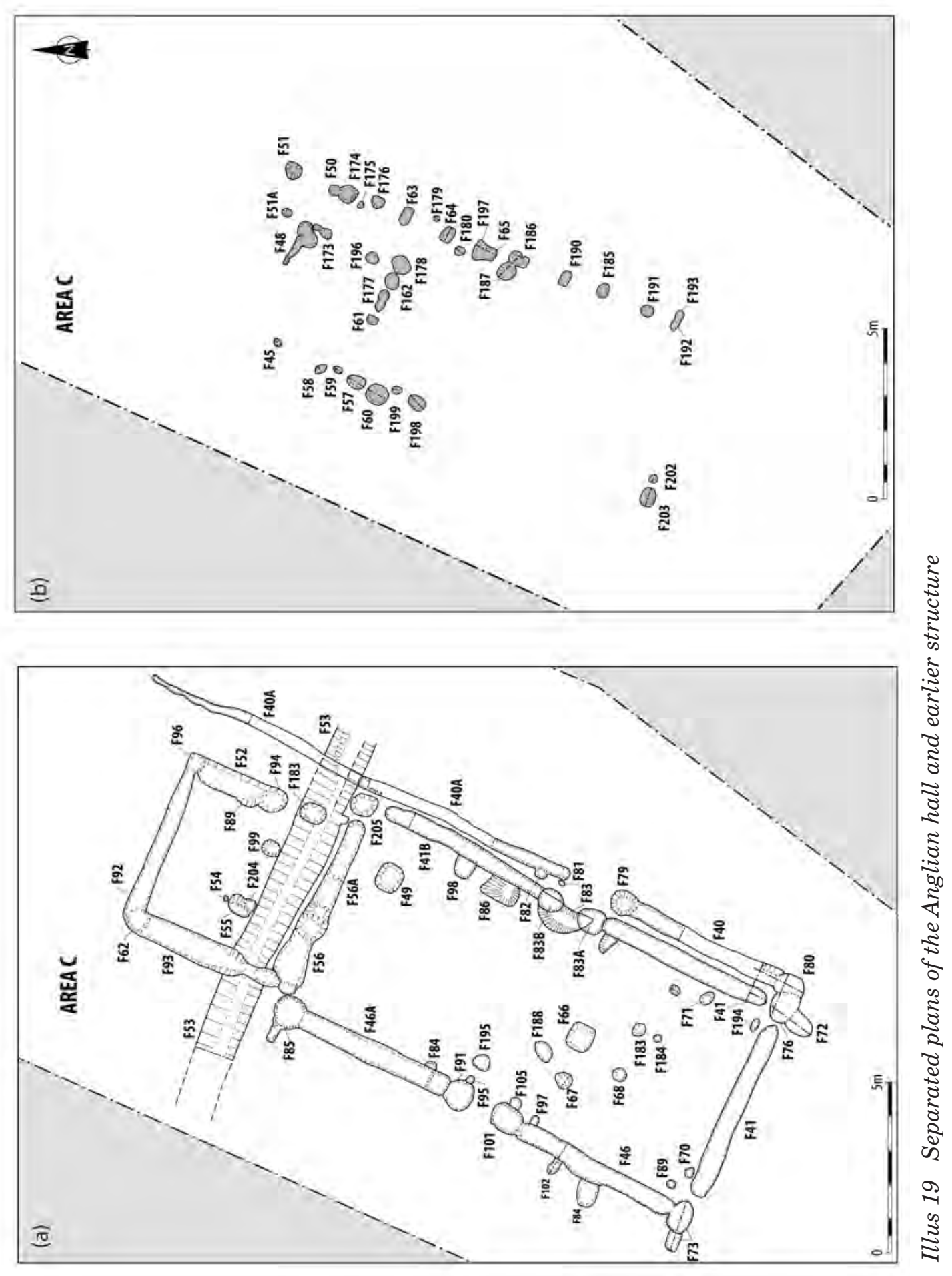




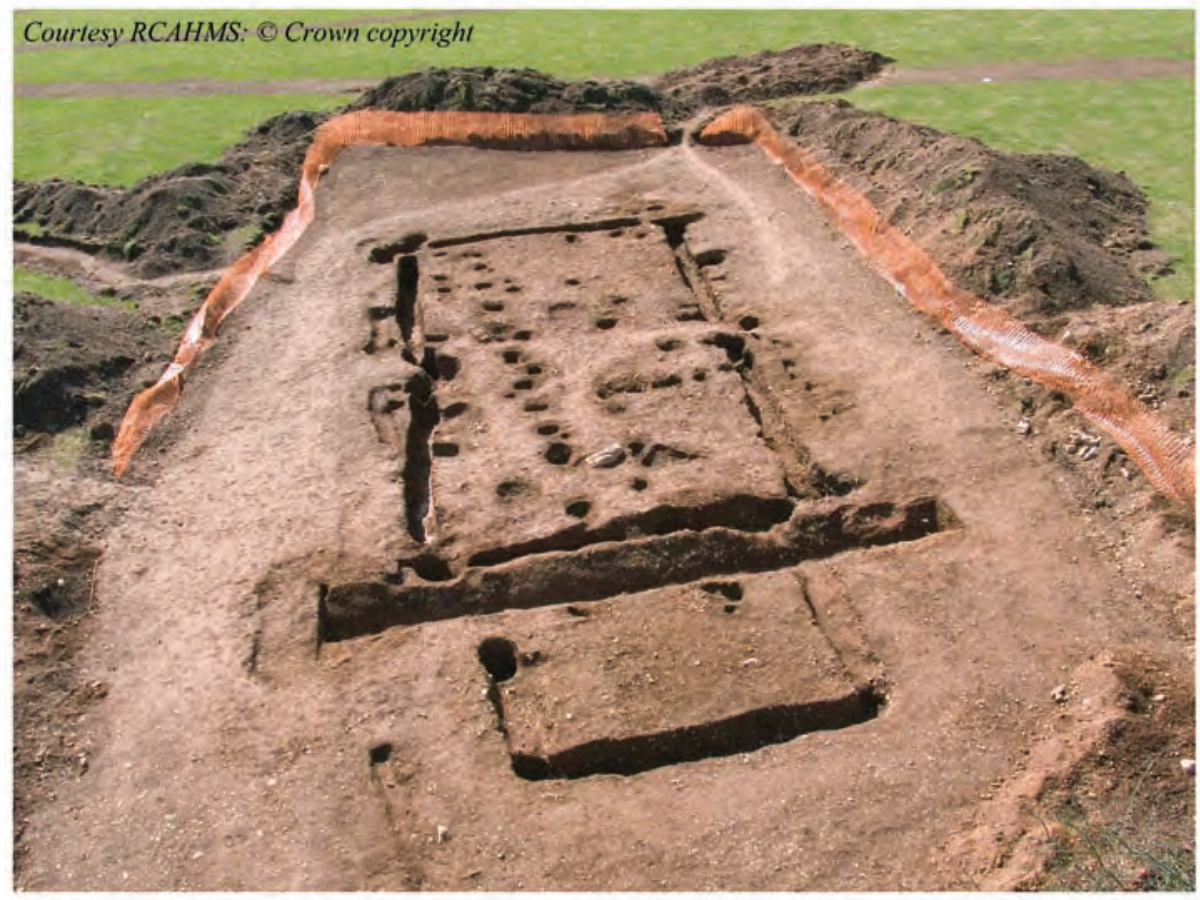

Illus 20 Anglian hall and earlier structure from north

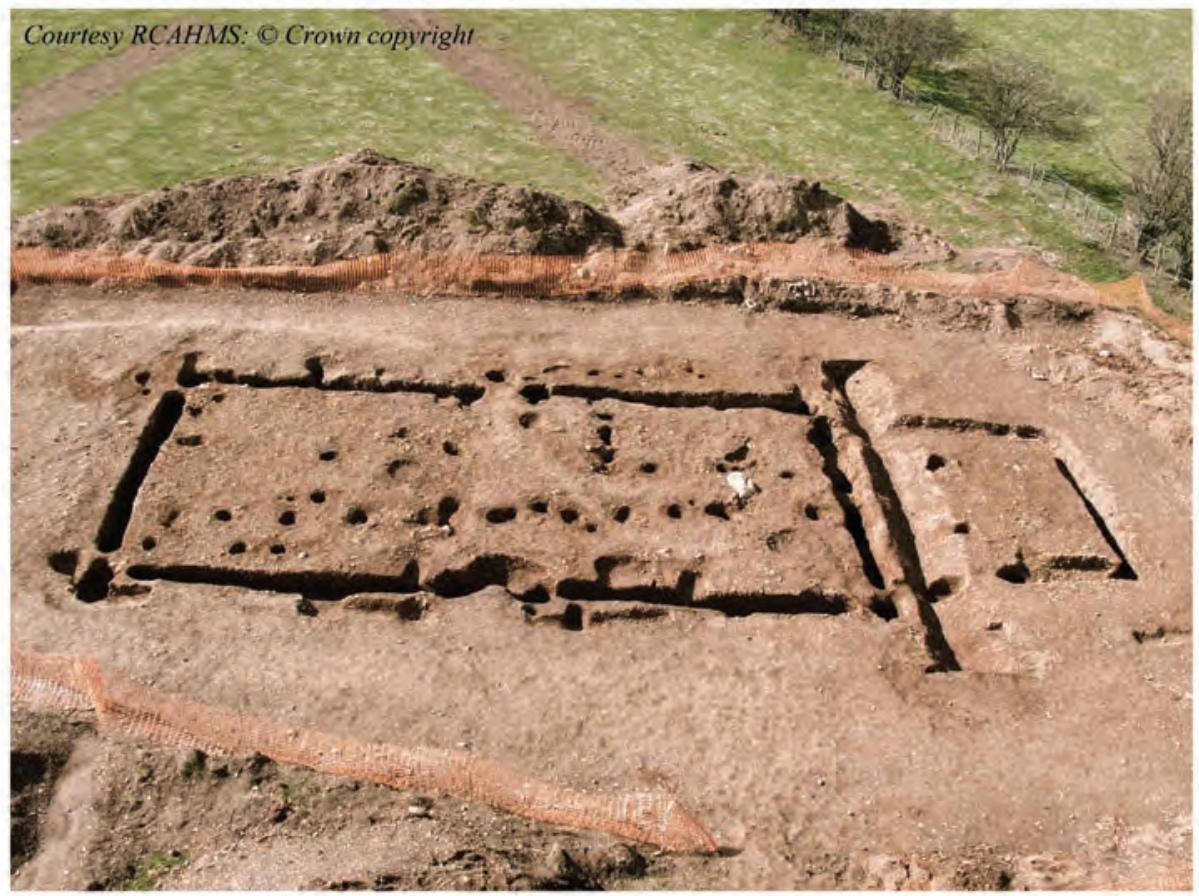

Illus 21 Anglian hall and earlier structure from east

Anglian hall and the other just outwith the line of its western wall. Although broadly on the same alignment, the lines of post-holes ran at a slight angle to the Anglian hall, suggesting that they may have been a separate and unrelated structure of a similar scale. All the features associated with these timber halls were $100 \%$ excavated and 130 samples, giving a good spatial spread across the structures, were taken for the retrieval of archaeobotanical evidence. Although a single sherd of Roman pottery was recovered from the Anglian hall, the weight of evidence provided by the radiocarbon dates and the typology of the principal structure are sufficient to dismiss the possibility that this was a Roman building and the sherd is likely to have been residual. Torwood Roman Camp (NY18SW 11.00) is 

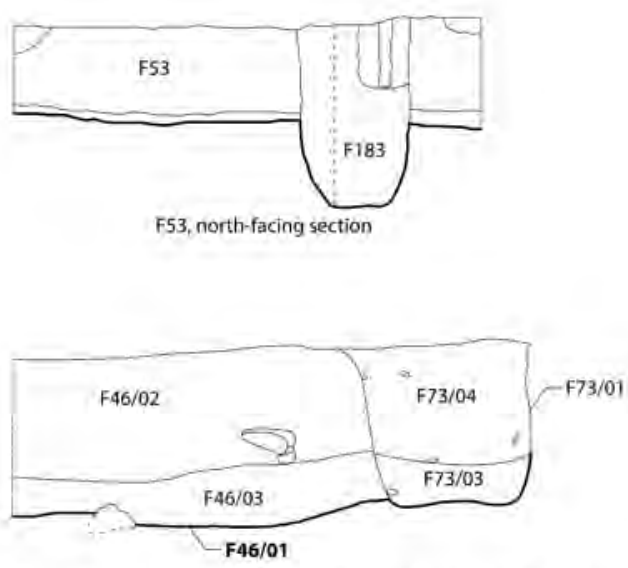

F46 \& F73, west-facing section of SW terminal end (post-hole)
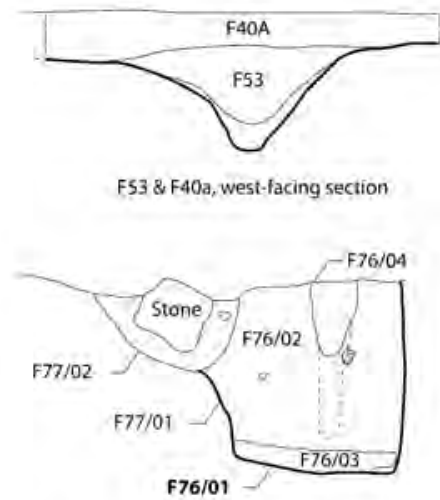

F76, east-facing section (large post-hole)

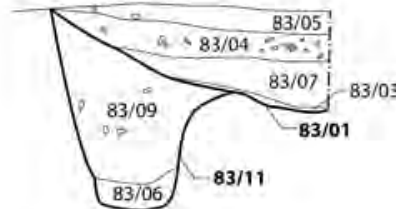

F83, west-facing section

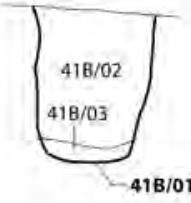

F41B, NNE-facing section

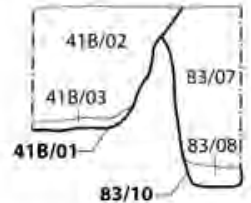

F41B \& F83, WNW-facing section

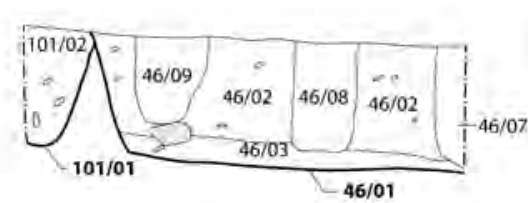

F46 \& F101, WNW-facing section

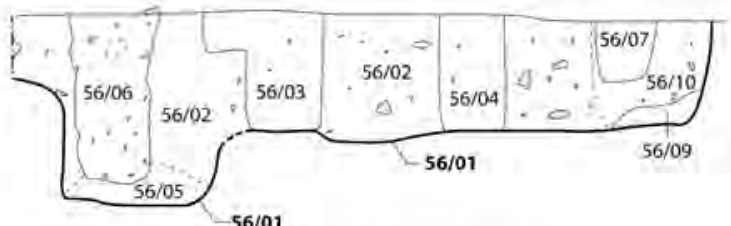

F56, NNE-facing section

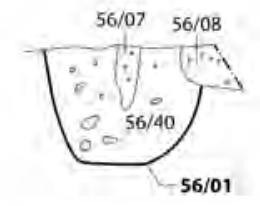

F56, ESE-facing section

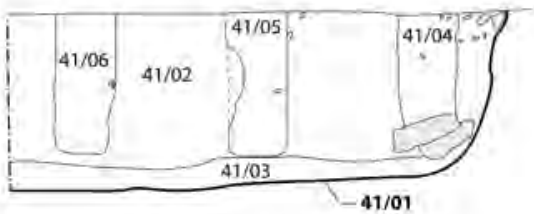

F41, NNE-facing section

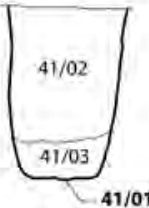

F41, WNW-facing section

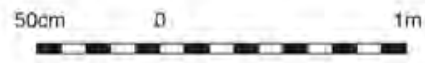

Illus 22 Anglian hall, selected sections of post-holes and construction trenches

situated $c 1 \mathrm{~km}$ to the west of Lockerbie Academy, indicating Roman influence within the area.

\subsection{Anglian hall}

The Anglian hall (illus 19.1) measured 19m NNE to SSW by $7 \mathrm{~m}$ overall and comprised a main structure with a single small annex to the north. The main structure was rectangular in plan, measuring $14 \mathrm{~m}$ NNE to SSW by $7 \mathrm{~m}$ and the annex, which was almost square, measured $5 \mathrm{~m}$ NNE to SSW by $5.5 \mathrm{~m}$. Apart from a single sherd of possible Roman pottery identified within construction trench F40, no artefacts were recovered from this structure and its interpretation as a hall of Anglian type is 
based on a combination of its radiocarbon dates and known comparable examples from elsewhere in the country.

The walls of the main hall were defined by four large corner post-holes (F73, F76, F85 and F205), linked by construction trenches (F41, F41A, F41B, F46, F46A, F56 and F56A). The corner post-holes were all $c 0.8 \mathrm{~m}$ in diameter and survived to a depth of $c 0.65 \mathrm{~m}$. One possible post-pipe measuring $0.2 \mathrm{~m}$ in diameter was identified in post-hole F76. Additional slots projecting outwards from post-holes F73, F76 and F85 could represent the foundations of close-set buttresses (illus 22).

The construction trenches defining the walls of the structure typically measured $c 0.5 \mathrm{~m}$ wide by $0.75 \mathrm{~m}$ deep and had sides that were vertical. The southern wall and the northern wall were defined by single construction trenches running between the corner posts, but the construction trenches defining the longer western and eastern walls were in two sections, divided by centrally located entranceways. Several post-pipes were identified within the construction trenches, indicating that they had once held timber uprights. The vertical nature of the sides of the construction trenches suggests that they were backfilled as soon as the uprights had been inserted. Typically, the post-pipes measured $c$ $0.25-0.3 \mathrm{~m}$ in diameter by $0.5 \mathrm{~m}$ in depth and were located $0.45 \mathrm{~m}$ apart. However, others appeared more sub-rectangular in shape, measuring $c 0.2 \mathrm{~m}$ by $0.3 \mathrm{~m}$. Overall, the number of post-pipes identified was low, possibly suggesting that they had been pulled out after the abandonment of the structure and either used elsewhere or burnt as firewood.

The two entranceways were centrally located along either side of the main axis of the building and were positioned directly opposite each other. The western entrance was defined by post-holes F91 and F101 (illus 22), which were $c 0.9 \mathrm{~m}$ in diameter by $0.5 \mathrm{~m}$ deep and were situated $c 0.7 \mathrm{~m}$ apart. Four small post-holes (F84, F95, F97 and F105), two on either side of the doorway along the inner face of the wall, suggest that there may have been some kind of inner framework embellishing the doorway.

The eastern entranceway was defined by postholes F83A and F83B, which measured $0.7 \mathrm{~m}$ in diameter by $0.75 \mathrm{~m}$ deep and were situated $0.5 \mathrm{~m}$ apart (illus 22). Both post-holes had been cut by pit F83, which appears to have been inserted at a later date, possibly after the entranceway had gone out of use. Pit F83 measured $c 2 \mathrm{~m}$ north to south by $0.8 \mathrm{~m}$ east to west and had a depth of $0.4 \mathrm{~m}$. The lower fill of the pit contained a large quantity of burnt daub with wattle impressions.

A shallow linear feature (F40, F40A) measuring c $0.6 \mathrm{~m}$ wide by $0.25 \mathrm{~m}$ deep was identified running parallel with the eastern edge of the building. This feature was divided into two sections, with a gap of $c 1.3 \mathrm{~m}$ directly opposite the entranceway in the eastern wall. This may have been a drainage gully, designed to channel away water from the roof of the structure.
The remains of the annex abutted the northern end of the main structure and were defined by three conjoined construction trenches (F52, F92 and F93). The construction trench that defined the northern wall of the annex (F92) measured $0.55 \mathrm{~m}$ in depth by $0.5 \mathrm{~m}$ in width and those defining the eastern (F52) and western (F93) walls were wider and shallower, with a depth of $0.3 \mathrm{~m}$ and a width of $0.7 \mathrm{~m}$. Post-holes (F62 and F96) with a diameter of $c 0.5 \mathrm{~m}$ and a depth of $0.55 \mathrm{~m}$ were located at the north-west and northeast corners and a further two post-holes (F94 and F183) defined a possible entranceway set within the eastern wall. These post-holes measured $0.6 \mathrm{~m}$ in diameter by $c 0.7 \mathrm{~m}$ deep and were situated $0.4 \mathrm{~m}$ apart. A possible internal division on an east to west axis is represented by post-holes F55/F204 and F99. A flint chip was recovered from post-hole F55 (G Warren in archive).

\subsubsection{Phasing of the hall, annex and V-shaped ditch}

A large ditch (F53; illus 22) identified running parallel with the northern wall of the main hall at a distance of $c 0.2 \mathrm{~m}$ might indicate that the main hall was constructed first and that the annex was added at a later date. This ditch had a V-shaped profile with a width of $c 1.3 \mathrm{~m}$ and a depth of $c 0.55 \mathrm{~m}$. The fact that the ditch appeared to respect the northern wall of the main structure suggests that the main hall and ditch may have been contemporary. However two of the features (F93 and F183) associated with the annex were cut into the ditch fill, indicating that the annex post-dated the deliberate back filling of the ditch. The case for the main hall pre-dating the annex appears to be supported by construction trench F93 cutting construction trench F56, but the degree of overlap between these two features was too small for the relationship to be determined with any great degree of certainty. Possible drip gully F40A also cut the fill of the ditch (illus 22) suggesting that it may have been a later addition. The scope of the mitigation measures did not allow the full extent of the ditch to be determined, but it is possible that it may have been an enclosure such as that identified at Doon Hill. Radiocarbon dates obtained for both parts of the structure were inconclusive in relation to determining the phasing as they indicated them to be broadly contemporary.

\section{$5.3 \quad$ Post-built structure}

The ground plan of the possible post-built structure (illus 19.2) was very hard to decipher from the surviving remains, but a straight line from NNE to SSW could be drawn between post-holes F51, F50, F174, F175, F176, F63, F179, F64, F180, F197, F65, F186/F187, F190, F185, F191 and F192/ F193, possibly representing a $12 \mathrm{~m}$ length of the alignment of the eastern wall. This post alignment 
was set at a slight angle to that of the Anglian hall and consequently it was considered unlikely to represent an associated internal feature. A further line of post-holes (F45, F58, F59, F57, F60, F199, F198 and F203) running parallel with the first at a distance of $c 5 \mathrm{~m}$ is likely to represent the alignment of the western wall. Post-holes F84 and F102 might also have been part of this wall, although they were slightly out of alignment with the others. There was no clear evidence of the southern and northern walls, although these might be represented by post-holes F202 (south) and F51A (north). Attached to the western wall was a possible internal division represented by post-holes F61, F177, F162, F178, F196, F173 and F48. The possible internal division was almost square in plan, measuring $c 3.5 \mathrm{~m}$ by $c 3 \mathrm{~m}$. The largest of the post-holes forming the post-built structure measured up to $0.8 \mathrm{~m}$ in diameter, but the majority survived to a depth of less than $0.2 \mathrm{~m}$ indicating that they had been heavily truncated.

\subsection{Internal features}

A number of apparently random features (F49, F66, F67, F68, F70, F71, F89, F161, F162, F175, F177, F178, F179, F180, F183, F184, F187, F188, F193, F194 and F195) were identified within the footprint of the Anglian hall. These all consisted of small pits or post-holes. Pits F49 and F66 were very similar in size and shape, being sub-square with a measurement of $c 0.7 \mathrm{~m}$ across, and both had a charcoal-rich fill containing burnt bone. Given the position of pit F66 along the north-south central axis of the Anglian hall, it is probable that it was a hearth and pit F49 may have served the same function. It is unclear whether the remaining features were associated with the Anglian hall or the post-built structure. Features F86, F98 (eastern side), F97 and F84 (western side) cut the main construction trenches and might represent internal buttressing that was inserted at a later date.

\subsection{Radiocarbon dates}

Three paired samples and four single samples were submitted for dating (Table 8). The three paired samples were charred barley and the single samples were birch charcoal (2), hazel charcoal (1) and willow charcoal (1). Three samples came from post-holes thought to be associated with the earlier post-defined structure and seven samples came from the Anglian hall. An earliest date of 430-620 cal AD $(2 \sigma)$ was obtained from F96, which was associated with the Anglian hall annex. This early date for the annex is at odds with the phasing of the site, which suggests that the annex is the latest feature, and can be explained by problems relating to the accuracy of radiocarbon dates from this period. The dates for the post-defined structure and the Anglian hall are broadly contemporary, suggesting the destruction of the former immediately prior to the construction of the latter.

\subsection{Roman pottery, by $R M M c B r i d e$}

F40/02 produced a single curved, flange fragment from a bowl, probably a mortarium. The sherd is made in a gritty orange fabric, with common quartz and occasional rounded sandstone inclusions and is likely to have been of local or regional manufacture. Acidic conditions in the soil have detrimentally affected the surface of the sherd. The profile is too small to form any firm conclusions, but the fabric is consistent with mortaria from the north-west of England, dating from the late first century, when local production replaced the dwindling imports from Verulamium and France, into the 2nd century.

\subsection{Fired clay, by Sue Anderson}

A very large quantity of fired clay, 1631 pieces weighing $19,621 \mathrm{~g}$, was recovered. The majority of this (1375 fragments, 17,400g) came from pit

Table 8 Radiocarbon dates for the post-built and Anglian structures

\begin{tabular}{llllccc}
\hline Lab No. & Context & Type & Species & Date BP & $\begin{array}{c}\text { Calibrated } \\
\mathbf{1} \boldsymbol{\sigma} \text { AD }\end{array}$ & $\begin{array}{c}\text { Calibrated } \\
\mathbf{2} \boldsymbol{\sigma} \text { AD }\end{array}$ \\
\hline 19265 & F51/02 & Charred grain & Barley & $1410 \pm 30$ & $610-655$ & $590-670$ \\
19266 & F51/02 & Charred grain & Barley & $1390 \pm 30$ & $620-665$ & $600-675$ \\
19267 & F91/04 & Charred grain & Barley & $1400 \pm 30$ & $620-660$ & $595-670$ \\
19268 & F91/04 & Charred grain & Barley & $1425 \pm 30$ & $605-650$ & $575-660$ \\
19269 & F41B/04 & Charred grain & Barley & $1490 \pm 30$ & $545-605$ & $460-650$ \\
19270 & F41B/04 & Charred grain & Barley & $1430 \pm 30$ & $605-650$ & $570-660$ \\
19810 & F176/02 & Charcoal & Salix sp. & $1455 \pm 35$ & $580-645$ & $550-660$ \\
19811 & F96/02 & Charcoal & Corylus sp. & $1520 \pm 35$ & $440-600$ & $430-620$ \\
19812 & F91/05 & Charcoal & Betula sp. & $1495 \pm 35$ & $540-610$ & $430-650$ \\
19813 & F83/02 & Charcoal & Betula $\mathrm{sp}$. & $1450 \pm 35$ & $580-645$ & $550-660$ \\
\hline
\end{tabular}




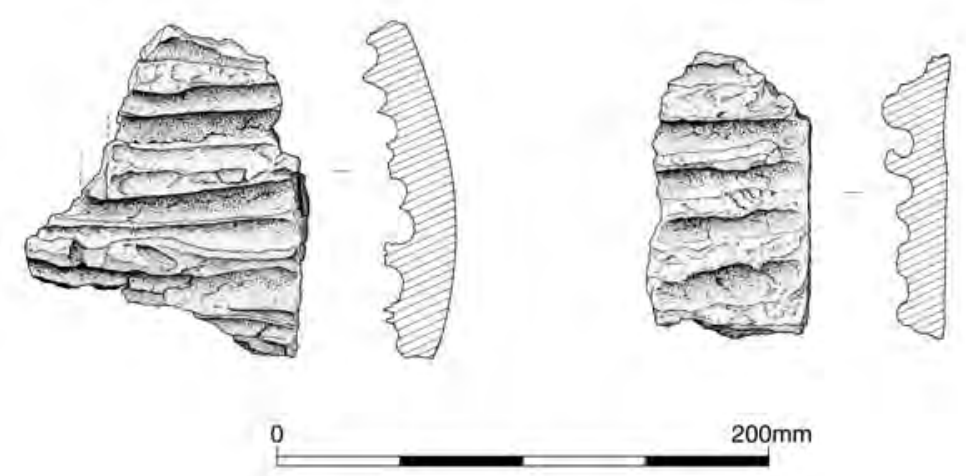

Illus 23 Fired clay

F83, which cut the post-holes forming the eastern entrance of the Anglian structure.

All fragments were in a uniform fabric comprising a fine, soft matrix with small voids, which probably represent a filler such as grass. Most fragments were buff to orange in colour, but fragments which had been exposed to greater heat were dense and reduced to a dark grey. Fragments like these were occasionally vitrified or warped.

Although many pieces were small and abraded, several more complete fragments were present, allowing the character of the material to be reconstructed. The majority of fragments had one smoothed surface, generally flat, and an underside with impressions of woven withies and staves. The withies were made of roundwood stems, most likely hazel (although a fragment recovered from F83 for radiocarbon dating was identified as birch (Table 6)), and varied in diameter between $10 \mathrm{~mm}$ and $16 \mathrm{~mm}$. Occasional impressions of cleft, squared laths were also found interspersed with the withies. Upright staves generally appeared to be roundwood of slightly greater diameter (18-20mm being most common). No pieces were large enough to include the impressions of two staves, so the distance between these is unknown, but one fragment with a single upright was $118 \mathrm{~mm}$ long from the edge of the stave, suggesting a gap of at least this size. One fragment had a stave running parallel at $75 \mathrm{~mm}$ from the panel edge. Potentially the remains of burnt oak (Hastie below) recovered along with the daub could represent the remains of the staves.

Several panel edge fragments were recovered, all of which had withy impressions running at rightangles to the edge (illus 23), suggesting that they were pressed against vertical timbers. In general the daub had been applied to the wattle framework up to a thickness of $c 10 \mathrm{~mm}$, although one fragment was $25 \mathrm{~mm}$ thick. Edge fragments were sometimes thicker where they had been pressed against the timber, presumably to ensure a tight fit here, since the clay might be expected to shrink slightly as it dried. There is a possibility that some timbers may have been slightly chamfered.

The smoothed surfaces of the daub had been finished off with a thin layer of finer clay, usually around $1-1.5 \mathrm{~mm}$ thick. In many cases this layer was grey, suggesting that it had been fired in a reducing atmosphere and was therefore probably internal. Some fragments showed evidence of thicker layers of clay externally, possibly representing repairs to eroded surfaces. Some of these showed signs of cracking and shrinkage due to burning.

Whilst most surfaces were approximately flat, suggesting that they came from a square-framed structure, there were a few examples with slight concavities, and one example in particular was noticeably convex (illus 23). It is possible that this shape was a result of warping due to firing as the piece was relatively highly fired. Whilst convex pieces could have been used in the formation of an oven dome or similar structure, this fragment was an edge piece and is therefore more likely to have formed part of a square panel than a rounded structure.

Whilst there is no definite evidence for the use of wattle and daub infill in the main construction of high-status timber buildings during the Anglian period, daub has been recovered from contemporary sites. At the large rural Middle Saxon settlement at Brandon, Suffolk (Anderson forthcoming), large quantities of daub were thought to be related to later (post 10th-century) structures on the site, but fragments were occasionally recovered from features which suggested the material was more likely to have been used in internal partitions. Certainly there is more evidence for wattle and daub construction in urban centres such as Anglian York (Lane 2005) and Middle Saxon London (Cowie \& Whytehead 1989), where lower status and industrial buildings were less likely to be built entirely of timber and there were readily available sources of clay.

Charcoal recovered from amongst the daub suggests that the material belongs to the Anglian period. Distribution on the site is largely confined to features close to pit F83, from which the majority of the material was recovered. Features which formed part of the structure of the Anglian building produced small quantities, particularly the two postholes either side of F83, and the slot trenches and associated features to the south (F41A, F40, F90). Another large pit, F86, to the north of F83 contained 
Table 9 Anglian hall: summary of carbonised cereal remains by feature type

\begin{tabular}{|c|c|c|c|c|c|c|c|c|c|c|c|c|c|}
\hline & & \multirow{2}{*}{$\begin{array}{l}\text { Structure } \\
\text { Feature type }\end{array}$} & \multirow{2}{*}{$\begin{array}{l}\text { Early } \\
\text { structure } \\
\qquad \text { PH }\end{array}$} & \multirow{2}{*}{$\begin{array}{l}\text { Annex } \\
\text { WP }\end{array}$} & \multicolumn{3}{|c|}{ Main building } & \multirow[b]{2}{*}{ EE } & \multirow[b]{2}{*}{ PIT } & \multirow[b]{2}{*}{ PH } & \multirow[b]{2}{*}{ UPF } & \multirow[b]{2}{*}{ HP } & \multirow[b]{2}{*}{ WE } \\
\hline & & & & & CT & $\mathbf{C P}$ & DG & & & & & & \\
\hline Wild taxa & Plant part & $\begin{array}{l}\text { Common } \\
\text { name }\end{array}$ & & & & & & & & & & & \\
\hline Corylus avellana & nutshell & hazel & & & & + & + & & & & & & \\
\hline Polygonum sp. & nutlet & persicaria & & & & & & & & 1 & & 3 & \\
\hline Potentilla sp. & seed & cinquefoil & & & 1 & & & & & & & & \\
\hline Calluna vulgaris & florets / buds & heather/ling & & & ++ & ++ & & & ++ & & & & \\
\hline Bromus / Lolium & caryopsis & $\begin{array}{l}\text { brome/rye- } \\
\text { grass }\end{array}$ & & & & & & & & & & 1 & \\
\hline Carex sp. & achene & sedge & & & & & & 2 & & & & & \\
\hline cf. Carex sp. & & sedge & & & 1 & & & & & & & & \\
\hline \multirow[t]{2}{*}{ Indeterminate } & seed & indeterminate & 1 & & 1 & & & & & & & & \\
\hline & & Rhizomes & + & & + & & & & & & & & \\
\hline \multicolumn{14}{|l|}{ Cereal grain } \\
\hline cf. Triticum sp. & caryopsis & wheat & 1 & & & & & & & & & & \\
\hline Hordeum sp. & caryopsis & barley & 14 & & 2 & & & 6 & 18 & 7 & & 4 & 7 \\
\hline cf. Hordeum sp. & caryopsis & barley & & & 2 & & & 1 & 1 & 1 & & & \\
\hline Hordeum hulled & caryopsis & hulled barley & 3 & & & & & & 14 & 7 & & 11 & \\
\hline $\begin{array}{l}\text { Hordeum naked } \\
\text { (TW) }\end{array}$ & caryopsis & naked barley & & & & & & 1 & & & & & \\
\hline Avena sp. & caryopsis & oat & & & 1 & 1 & & & 7 & 1 & 1 & & \\
\hline Cereal indet & caryopsis & indeterminate & & 1 & 5 & 1 & & & 1 & 3 & & 3 & \\
\hline
\end{tabular}

Key: $\mathrm{PH}=$ post-hole, $\mathrm{WP}=$ wall posts, $\mathrm{CT}=$ construction trenches, $\mathrm{CP}=$ corner posts, $\mathrm{DG}=$ drainage gullies, $\mathrm{EE}=$ eastern entrance, $\mathrm{PIT}$ $=$ pits, $\mathrm{UPF}=$ unphased features, $\mathrm{HP}=$ hearth pit, $\mathrm{WE}=$ western entrance; $+=$ rare,$++=$ occasional

125 fragments; this feature cut slot trench F41B. Small fragments were also collected from F39, F49, F55 and F87. This may indicate that the material was deposited during the demolition of the Phase 2 structure. However, its origin remains a mystery as there is no evidence that the structure burnt down.

\subsection{Slag, by Dawn McLaren}

Two fragments of non-magnetic vitrified material were recovered: one a small nodule of fuel ash slag from a post-hole (F197, 0.5g), the other a heavily vitrified amalgam of earth, sand, gravel and distorted clay fragments $(\mathrm{F} 87,834 \mathrm{~g})$. This came from the fill of a possible pit cutting the Anglian structure and may be related to the fired clay also recovered from this feature.

\subsection{Bone, by Sue Anderson}

Fragments of heavily calcined bone, with a total weight of $7.9 \mathrm{~g}$, were recovered from three features (F48, F49 and F83), two in association with burnt daub which may represent material which was accidentally burnt at the same time. Fragments were too small to identify to species, although one piece was probably bird and there were pieces of a large mammal.

\subsection{Charred plant remains, by Mhairi Hastie}

\subsubsection{Composition of plant remains}

One hundred and thirty samples were retained from deposits associated with an Anglian timber hall and a possible earlier structure. Of these, 110 samples were processed for the retrieval of palaeobotanical remains and artefacts. No floor surfaces survived, and all the plant remains recovered were from negative features, primarily post-holes and construction trenches.

Thirty-four samples contained very small quantities of carbonised cereal remains (summary, Table 9). Samples generally contained no more than five grains per sample, the majority of which were much abraded, indicating that the material is likely to be intrusive and does not relate to the original function of the feature from which they were recovered. Increased numbers of cereal grains were recovered from the fill of a pit (F86) and a hearth (F66). Barley was the most common cereal grain recovered from the cereal assemblages, a few grains of which were identified as the hulled variety. One grain of naked 
barley was recovered from the fill of a pit (F83) located at the east entrance to the hall. One possible grain of wheat was present in the fill of a post-hole (F180) associated with a structure that is believed to pre-date the Anglian hall. Preservation of the wheat grain was poor and it could not be identified to species level.

The wild taxa recovered from this area were very sparse. Poorly preserved remains of knotgrass (Polygonum sp.), cinquefoil (Potentilla sp.), brome/ rye-grass (Bromus/Lolium sp.) heather florest/ buds (Calluna/Ling sp.) and sedge (Carex sp.) were recovered along with the cereal grain.

Charcoal was recovered from the majority of samples. Thirty-four samples contained sufficiently large fragments of charcoal for species identification (4mm or greater). The wood assemblage consisted of a mixture of species including oak (Quercus sp.), alder (Alnus sp.), birch (Betula sp.) and heather (Calluna sp.). A high concentration of well preserved burnt oak timber was recovered along with fragments of wattle from the fill of a pit (F83) situated at the eastern entrance.

\subsubsection{Cereal processing}

Very little pertinent evidence is known for the Early Historic period in north Britain. This is to a large degree a reflection of the small number of settlements attributable to this span that have been excavated over the years. Smith (1991) does, however, argue that the lack of archaeobotanical remains from such sites may be the result of general house-keeping, with domestic refuse swept from buildings on a regular basis and carted away either to be spread on fields or deposited in rubbish pits and middens.

Where botanical remains have been identified - for instance Easter Kinnear (Driscoll 1997), Whithorn (Hill 1996), Hoddom (Holden 2006), Buiston (Holden \& Boardman 2000), Edinburgh Castle (Boardman 1997), and Ballingarry Down, Liher and Lisleagh (Monk 1990) - they indicate that barley was the main cultivated crop along with smaller amounts of oats, bread/club wheat and rye. The cereal assemblage recovered from Lockerbie, comprising hulled barley with occasional grains of oat and wheat, therefore fits within an established pattern.

Given the low frequency of plant material recovered from the structures, any context-related variations are difficult to interpret, although slightly more cereal remains were recovered from a firepit (F66) located towards the centre of the southern end of the hall. The presence of grain within the firepit may suggest that corn processing was being carried out near to the fire. Grain accidentally burnt during such drying activities would have found its way into many different features through sweeping and trampling of hearth ash throughout the building. Similar spreads of material have been identified from settlement sites from the Bronze Age to the medieval period, and are probably a result of continual drying and processing of corn on a dayto-day basis.

\subsubsection{Exploitation of local woodland}

Small roundwood and amorphous fragments of alder, birch and heather were present throughout pits, post-holes and beam-slots of both the Anglian hall and possible earlier structure. The charcoal assemblage is very similar in composition to other sites of this period, including Easter Kinnear (Driscoll 1997) and Whithorn (Hill 1996). All species present would have been locally available. Alder and willow could have been collected from wet areas close to the Dryfe Water and River Annan while the other species probably derived from local deciduous woodland.

Large quantities of oak charcoal were recovered from five deposits, F78, F83, F87, F100, F180, the highest concentration of oak being present in the fill of pit F83, located next to the eastern entrance of the hall. In this case, fragments of oak timbers and wattle were recovered together. Large quantities of burnt silicate were also present suggesting that the material in the pit had been subjected to high temperatures and burnt in situ. This pit is believed to post-date the eastern entrance and it has been suggested above that the feature was a demolition pit used to dispose of waste material from a phase of replacement of this entrance. Certainly this explanation would correspond with the large quantities of oak timber and wattle recovered from this feature, and the high concentration of silicate suggests that the timber and wattle were dumped into the pit and then deliberately set alight. However, the presence of large quantities of daub, already fragmented (and therefore 'fired') when it went into the pit, would appear to refute this evidence (S Anderson pers comm).

\subsection{Discussion of the Anglian hall and earlier structure}

Features that are thought to be typical of Anglian or Anglo-Saxon buildings include doors in the middle of the long sides, weak corners, annexes and internal partitions (Marshall \& Marshall 1991). Other features often encountered include post or plankin-trench construction and buttressed corners. The example excavated at Lockerbie Academy appears to have been fairly typical. It had opposing entranceways positioned in the long sides of the main structure and a small annex abutting the northern end. There was no evidence of weak corners (corners that cut across diagonally rather than the walls meeting each other at right angles, often defined by two diagonally positioned post-holes), with the corners being defined by four large post-holes with evidence of buttressing placed close in against them. The church excavated at Brandon, Suffolk (Carr et 
al 1988) had single post-holes containing abutting planks that had been placed at right angles to one another, but these post-holes were elongated and cut diagonally across the corners, whereas those at Lockerbie were much more circular and appeared to create a right-angled corner.

The lack of surviving timbers or stains at Lockerbie makes it hard to determine the construction method used, but the size and shape of the post-holes would suggest that the corners were defined by substantial posts rather than abutting planks. The posts were linked by continuous bedding trenches, which had timber uprights set into them. Impressions left by the timber uprights generally appeared to be circular in shape, with a diameter of $c 0.3 \mathrm{~m}$, suggesting post-in-trench rather than plank-in-trench construction. However, some of the post-pipes identified in F41A measured $c 0.3 \mathrm{~m}$ long by $0.2 \mathrm{~m}$ wide, possibly suggesting that a degree of squaring of the timbers had been undertaken. The type of corner identified at Lockerbie Academy is broadly paralleled at Castle Park, Dunbar (Phase 8, Building 3; Perry 2000), which also appeared to have had the same post-in-trench construction method. However, the Dunbar example had been damaged by later phases of construction, making overall comparisons between the two structures difficult. The size of the timber uprights at Lockerbie Academy suggests that they would have made a significant contribution to the structural integrity of the building.

Analysis of data relating to the size of excavated Anglo-Saxon buildings (Marshall \& Marshall 1991) suggests that the Lockerbie Academy Anglian hall at $14 \mathrm{~m} \times 7 \mathrm{~m}$ (excluding annex) was at the very top end of the normal building size range. Larger buildings have been identified at Sprouston (up to $28 \mathrm{~m} \times 9 \mathrm{~m}$; Smith 1991, although Sprouston is known from cropmarks only and has never been excavated) and Yeavering (up to $25.3 \mathrm{~m} \times 14.7 \mathrm{~m}$; Hope-Taylor 1977), but otherwise, the majority of these structures are not more than the $14 \mathrm{~m}$ length of the Lockerbie example. The $7 \mathrm{~m}$ width of the Lockerbie example is also at the top end of the normal range. Sizes seem to have been determined by the availability of timber suitable for use as a single beam that would have had the structural integrity to span the building. When the data relating to the size of AngloSaxon buildings was analysed in 1991 (Marshall \& Marshall 1991) only five excavated Anglo-Saxon sites had buildings with widths over $7 \mathrm{~m}$. These were Yeavering (nine structures), Cowdery's Down (five), Doon Hill (one), Thirlings (two) and Cheddar (one). Marshall \& Marshall (1991) have observed that the lengths and widths of the majority of Anglo-Saxon structures are multipliers of $3.5 \mathrm{~m}$, while Huggins (1991) has argued the case for them having been laid out using $4.65 \mathrm{~m}$ rods, giving the Lockerbie example a length of 3 rods and a width of 1.5 rods.

The palaeobotanical evidence from the Lockerbie Academy Anglian hall, combined with the presence of two possible hearths, suggests a possible domestic function, although this should in no way be taken to imply that it was anything along the lines of a large, permanently occupied farmhouse. Alcock (2003) has suggested that Doon Hill A may have been a lesser royal centre, which was visited periodically by the royal court, with the majority of the court perhaps being housed in temporary accommodation. Recently obtained radiocarbon dates now suggest that Doon Hill A is actually Neolithic in date, but Alcock's suggestion might be equally applicable to the later Anglian Doon Hill B. With the Lockerbie Academy Anglian Hall being of similar size to that excavated at Doon Hill, this hypothesis might be equally applicable, with the use of the aforementioned temporary accommodation explaining the lack of any other structures of Anglian date within the vicinity. The lack of any material culture is perhaps also in keeping with periodic occupation, with all possessions possibly being removed when it was not occupied. A rarity of occupation material from the larger halls was also noted by Hope-Taylor (1977) at Yeavering, who suggests that this was as a result of careful sweeping, presumably of wooden floors. Great or royal halls are portrayed in Beowulf as places for banqueting and wine-drinking (Alcock 2003), but other probable uses were for holding council and as lordly or kingly residences. Hope-Taylor (1977) has suggested that the annexes such as that identified at Lockerbie may have been sleeping chambers.

Many of the characteristics of the Lockerbie Anglian hall broadly parallel those of Hope-Taylor's 'Yeavering Style IIIA' timber halls (Hope-Taylor 1977). These generally had a 2:1 ratio, were defined by deep construction trenches with evidence of sophisticated up and down wall construction and had entranceways centrally placed on the long sides only. The later Style IIIB halls were broadly the same, but with the addition of doors in the end walls, and the earlier Style II halls had simple palisade-type walls set within a shallow foundation trench. HopeTaylor has attributed the Type II-IIIAB halls to the reign of Aethelfrith of the Bernician dynasty ( $\mathrm{AD}$ 593-616), probably to the period AD 605-16. Aethelfrith was the ruler singled out by the venerable Bede for his great successes over the British. It may have been Aethelfrith who destroyed a British army near Catterick $c$ AD 600 in a battle described in the early poem Gododdin, and his defeat of Aedan MacGabhran of the Dalriada Scots at the Battle of Degsastan (possibly Liddesdale) in AD 603 indicates a northward expansion into what is now south-west Scotland.

The halls with annexes at Yeavering belong to Hope-Taylor's Style IV, which had less substantial walls than the Style IIIAB type. The lighter construction of the walls was compensated for by the placement of large ridge-posts, which meant that the doors in the end walls had to be placed asymmetrically. Hope-Taylor has attributed this style to the reign of Oswald (AD 634-641) and has cited possible Dalriadic/Irish influences resulting from the time 
that Oswald spent in exile in Dalriada during the reign of Edwin (AD 616-33).

Hope-Taylor's attempts to relate the chronology of Yeavering to known historical kings have now been called into question. No radiocarbon dates were obtained for the site and the only two datable items recovered were an iron buckle-loop dated to between $c$ AD 570-80 and $c$ AD 630-40, and a goldwashed copper-alloy copy of a Merovingian coin of the mid-late 7th century (Alcock 2003). The historical evidence relating to Yeavering is also rather patchy, coming from small snippets of information provided by Bede. Based on Hope-Taylor's tenuous chronology for Yeavering, the apparent phasing at Lockerbie Academy does fit in nicely with the postulation that the main hall was constructed in the reign of Aethelfrith during an initial Northumbrian advance into the British-held territories of what is now south-west Scotland, with the annex being a later addition, possibly during the reign of Oswald. However, in reality there is insufficient evidence to be able to tie it down to individual rulers.

The presence of post-built structures on the same site is paralleled at Yeavering (Hope-Taylor 1977), Sprouston (Smith 1991) and Doon Hill (Hope-Taylor 1980). Hope-Taylor (1977) has attributed the postbuilt Style IA and shallow foundation trench built Style IB to a period predating Anglian influence. However, these were small squat buildings of wattle and daub construction and appear to bear little resemblance to the large post-built structure at Lockerbie Academy. Large post-built structures comparable in size to the major halls of Yeavering Style IIIC were identified at Sprouston, but here the phasing suggests a mid seventh century date (Smith 1991). Smith has suggested that they might represent the visible expression of what is essentially a British vernacular tradition that was more longlasting at Sprouston than it had been at Yeavering. However, the idea that all Anglian structures were post- or plank-in-trench-built and that all post-built structures belong to a native British tradition is a gross oversimplification of the evidence. Anglian post-built structures are known from Brandon, Suffolk (Carr et al 1988) and from Catholme, Staffordshire (Losco-Bradley \& Kinsley 2002), raising the possibility that the post-built structure might simply have been an earlier Anglian hall that was replaced due to decay.

Alcock (2003) has given some credence to the idea of the Angles taking over existing British settlements through the suggestion that the important Anglian settlements of Yeavering and Milfield have British-derived names. There has also been some speculation that the great enclosures identified at sites such as Sprouston, Yeavering and Doon Hill may have been derived from palisades erected by the Britons during the Roman and early post-Roman period (Alcock 2003), giving a degree of credibility to the suggestion that the origins of these sites predated the Anglian period. The dates obtained for the Lockerbie Anglian hall would suggest that this structure relates to a period of very early Northumbrian influence in south-west Scotland, possibly suggesting that the earlier post-built structure related to an earlier British tradition, but a very shortlived post-built Anglian Hall is not beyond the bounds of possibility.

Although there is a significant amount of documentary evidence concerning the Northumbrian occupation of south-west Scotland, the archaeological evidence is comparatively sparse, making the discovery of the Lockerbie Academy hall particularly significant. Previous archaeological finds from this period have tended to take the form of items such as sculptures and carved crosses, the best known example being the Ruthwell Cross, which has been dated to the late 7th/early 8th century AD. However, placename evidence suggesting Anglian influence has been documented extending well into Galloway and Carrick (Brooke 1991), and Northumbrian ecclesiastical sites have been excavated at Hoddom (Lowe 2006) and Whithorn (Hill 1996).

Hoddom has long been renowned as a place that has produced a large quantity of Anglo-Saxon sculpture, and work carried out in advance of an area of quarrying led to the discovery and excavation of an ecclesiastical site. Laing (1969) has stated that there were pagan Angles in the Hoddom area about $\mathrm{AD} 600$ and the earliest phase of the Hoddom ecclesiastical site excavated by Lowe was radiocarbon-dated to $c \mathrm{AD} 650$, placing it only slightly later than the Lockerbie Academy hall. The structures dating to this earliest phase consisted of two large timber buildings (S6.1 and S10) measuring $16.2 \mathrm{~m}$ long by $4.6-6.75 \mathrm{~m}$ wide and $14 \mathrm{~m}$ long by $6-6.6 \mathrm{~m}$ wide respectively. Although of similar size to the Lockerbie hall, these structures were both post-built, with post-in-trench construction being notable by its absence (Lowe 2006). There also appears to have been an absence of opposed doorways in the long sides and of the types of annexes identified at Yeavering. Bruce Walker (Lowe 2006, 184) has suggested that the Hoddom structures employed the use of curved principal rafters (ie cruck blades) to form a series of 'Highland' or 'Celtic couples'. Analogies with later Hebridean blackhouses possibly suggest that the Hoddom structures might contain aspects of British architecture, and there was certainly no evidence of the overtly Anglian architecture of the Lockerbie Academy hall. This might be taken to imply that the incoming Northumbrians were adopting aspects of vernacular architecture. A possible post-built Early Historic timber hall measuring $c 17 \mathrm{~m}$ by $c$ $5.5 \mathrm{~m}$ was also identified at Kirkconnel (Reynolds 1980), but it is unclear if it was a British or Northumbrian structure. Direct comparisons between the excavated structures at Hoddom and the post-built structure at Lockerbie Academy were not possible, due to the poor survival of the latter.

The implication of the possible retention of aspects of the vernacular architecture is perhaps that although the south-west of Scotland was under Northumbrian political control, the number 
of incomers was comparatively small and many vernacular traditions survived even within areas of significant Northumbrian influence. Harding (2004) has suggested that the appearance of Anglian crosses and sculptures and the establishment of monastic settlements represent changes brought about by intermarriage and the conversion of ruling elites, and this argument certainly seems to be supported by the apparent retention of aspects of the vernacular architecture. One possible explanation for the overtly Anglian architecture of Lockerbie on a site that possibly contained a native British hall might be that it was constructed during a time of conflict, when a clearly visible display of Northumbrian dominance was deemed necessary. 


\section{POST-MEDIEVAL CORN-DRYING KILN (AREA D)}

\subsection{Description}

The corn-drying kiln was situated on the southern side of the cemetery in Area D (illus 12). It consisted of a circular stone-lined bowl (F36) (illus 12 and 24) and a teardrop-shaped fire-pit (F38), which were conjoined by a stone-lined flue. The stone-lined bowl was conical in shape and had been cut into the side of the knoll to a depth of $2.14 \mathrm{~m}$. It had an internal diameter of $2.7 \mathrm{~m}$ at the surface, narrowing down to $c 1 \mathrm{~m}$ at the base. A thin layer of charcoal and grey carbonised material was identified at the base of the bowl and the natural subsoil beneath it had been baked hard by the intensity of heat from the flue. During the excavation, the backfill of the kiln was emptied, but the stone structure was left in situ.

The firepit (F38) for the kiln had been cut into the side of the knoll $c 2 \mathrm{~m}$ to the south of the bowl. It measured $4.5 \mathrm{~m}$ north-south by $3 \mathrm{~m}$ east-west and had been excavated to a maximum depth of $2 \mathrm{~m}$. At the northern end of the pit, the stones forming the entrance to the flue were uncovered. The entrance to the flue measured $0.8 \mathrm{~m}$ in height by $0.5 \mathrm{~m}$ in width. Just inside the flue, the natural subsoil had been baked solid where the fire had been lit and there was a considerable build-up of black, yellow, orange and white ash. Further accumulations of ash were present at the southern end of the firepit and probably constitute material that had been shovelled out of the flue entrance. The build-up of layers suggests that there had been numerous phases of emptying, and indicates that it was in use over a long period of time. Charred oats from the uppermost phase of emptying produced radiocar-

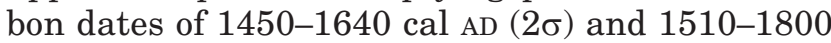
cal $\mathrm{AD}(2 \sigma)$, indicating a date between the mid 15 th and late 18th centuries for the use of this structure (Table 10).

The flue had been constructed within a $1.5 \mathrm{~m}$ wide by $2 \mathrm{~m}$ deep cut, which ran a distance of $3.5 \mathrm{~m}$ from the base of the fire-pit to the base of the bowl. On completion of the stonework, the cut had been back-filled using redeposited natural. Internally, the flue measured $0.48 \mathrm{~m}$ in height by $0.45 \mathrm{~m}$ in width and had a nicely constructed lintel at either end.

\subsection{Slag, by Dawn McLaren}

A total of $766.6 \mathrm{~g}$ was recovered from Area D and consists of low-density, non-magnetic vitrified amalgams of earth, sand, gravel and ash, and nodules of burnt clay. This vitrified material is created when materials such as earth, clay, stones or ceramics are subjected to high temperatures, for example in a hearth. These range in colour from light grey to dark brown and are often glassy in patches. All of this material was associated with the corn-drying kiln, and represents debris from its use. Only one fragment, recovered from the main fill of the kiln, was magnetic. This may be a fragment of ironworking waste, but its size makes it impossible to confirm the process that produced it, and there is no evidence of in-situ ironworking.

Recovery of slag, burnt organic material and clinker from the interior of medieval corn-drying kilns is known from Dairy Park, Dunrobin, Sutherland (Close-Brooks 1980, 336, 338, 340), Don Street, Aberdeen (Cameron et al 1996, 919) and Castle Street, Inverness (Wordsworth 1982, 351-2). Little of this material has been subject to detailed analysis, and their significance in this context remains unclear.

\subsection{Other finds, by Sue Anderson}

Four sherds of pottery included slipped redware and refined whitewares with transfer-printed decoration, all probably 19th-century in date. Two sherds of green bottle glass, one small fragment of clay pipe stem and two pieces of coal were all likely to belong to the same period of site use as the pottery. These were recovered from amongst the stones of the possible ring cairn (32/01), and from the upper fill of the corn-drying kiln (36/02).

\subsection{Animal bone, by Jennifer Thoms}

Eighty-one fragments were present of which only seven were identifiable to element. Of these seven fragments, five were identifiable to species and these were all horse. Another, a fragment of

Table 10 Radiocarbon dates from corn-drying kiln

\begin{tabular}{llllccc}
\hline SUERC Lab No. & Context & Type & Species & Date BP & Calibrated 1 $\boldsymbol{\sigma}$ AD & Calibrated 2 $\boldsymbol{\sigma}$ AD \\
\hline 19260 & F38/02 & Charred grain & Oat & $270 \pm 30$ & $1520-1670$ & $1510-1800$ \\
19264 & F38/02 & Charred grain & Oat & $355 \pm 30$ & $1470-1630$ & $1450-1640$ \\
\hline
\end{tabular}




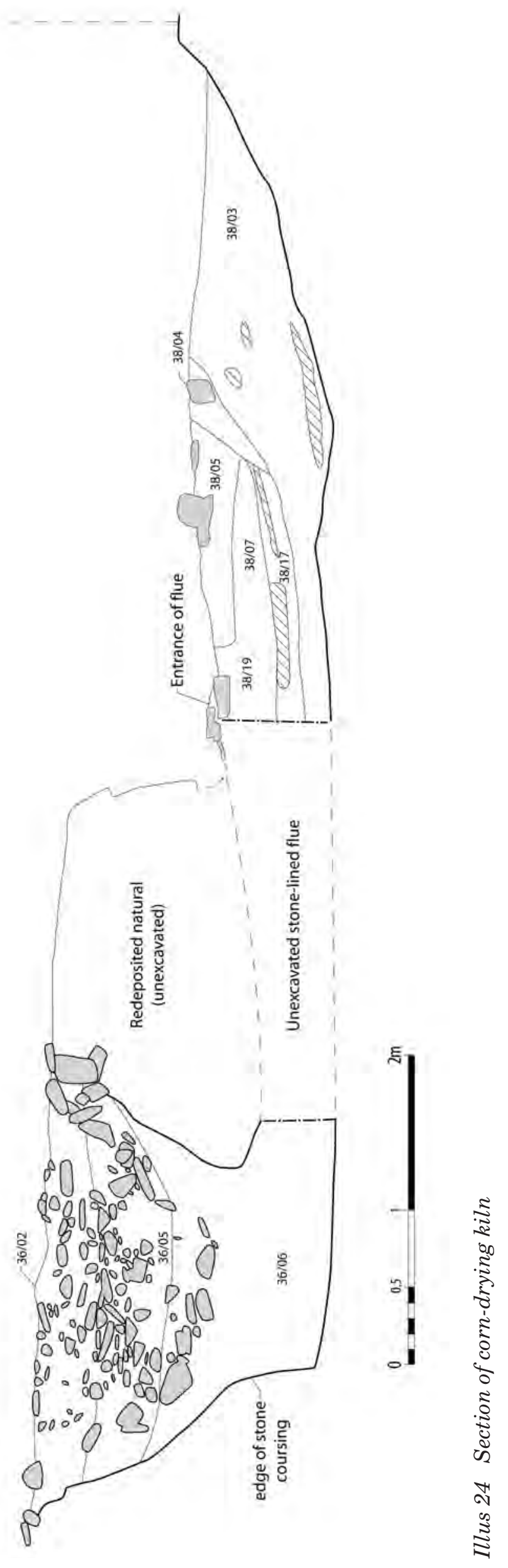


Table 11 Summary of plant remains recovered from the corn-drying kiln

\begin{tabular}{|c|c|c|c|c|c|c|c|c|c|c|c|c|c|c|}
\hline \multirow[b]{2}{*}{ Context } & \multicolumn{5}{|c|}{ Kiln bowl } & \multicolumn{3}{|c|}{ Kiln flue } & \multicolumn{6}{|c|}{ Fire pit } \\
\hline & $36 / 02$ & $36 / 03$ & $36 / 06$ & $36 / 07$ & $36 / 08$ & $38 / 13$ & $38 / 16$ & $38 / 17$ & $38 / 02$ & $38 / 03$ & $38 / 04$ & $38 / 06$ & $\begin{array}{c}38 / 07 \\
\& \\
38 / 15\end{array}$ & $38 / 15$ \\
\hline Cereals & + & + & + & & + & ++ & ++ & & +++ & +++ & ++ & + & + & + \\
\hline Heather & & & & & ++ & & ++++ & +++ & & & + & & & \\
\hline Wild taxa & + & & & & + & & + & + & + & & + & & & \\
\hline
\end{tabular}

Key: $+=$ rare, $++=$ occasional, $+++=$ common and $++++=$ abundant

vertebra, derived from a large mammal which may have been a horse. There were no indications of the age at death of the animal, no teeth retained their occlusal (biting) surface, and there were no proximal epiphyses present on the one identifiable long bone fragment retrieved.

The unidentifiable fragments were all small $(<30 \mathrm{~mm}$ maximum dimension) and were generally in very poor condition. Four of them were burnt and calcified, giving them a white appearance. Such calcification indicates the bones were burnt at a high temperature. No signs of gnawing by carnivores was noted, though such evidence may have been obscured by the poor surface condition of the bones. Only one possible butchery mark was noted: one of the horse molars was cut through diagonally. It is probable that this was done during the excavation process, particularly since butchery of teeth is a pointless exercise, so this one mark should not be interpreted as evidence of butchery. No other taphonomic indicators were noted.

All the bone fragments were retrieved from context F36/02, the upper fill of the corn-drying kiln. The bowl of the conical pit had been lined with stones, and this may have provided the protection necessary for the survival of these few bone fragments in an area where bone would normally decay completely. The lack of the more common domesticates, such as sheep, cattle and pig, among the identifiable bone, indicates this is not a routine dump of domestic or butchery waste. The evidence suggests that the assemblage may represent the remains of a horse burial. The general poor state of the bone indicates acidic soil conditions and suggests that most of the burial has disappeared. The four small $(<20 \mathrm{~mm})$ fragments of burnt bone may be intrusive, probably representing 'background' fragments of ashy bone deposits present in many agricultural soils. Alternatively, they may have derived from the nearby firepit for the corn-drying kiln. Other fragments recovered from lower down in the fill were identified as human and were probably redeposited from the surrounding cremation burials (Anderson above).

\subsection{Charred plant remains, by Mhairi Hastie}

Fourteen samples, of the thirty-two processed from Area D, contained carbonised plant remains, all of which are associated with the corn-drying kiln.

Preservation of the plant remains within the kiln deposits was extremely good, with delicate buds and florets of heather surviving. The majority of plant remains were from the kiln flue and firepit, although occasional cereal grains and other wild taxa were also present in the fills of the kiln bowl (summarised in Table 11).

The cereal assemblage was dominated by oat grains, a small quantity of which still had their palea and lemma bases attached, and were identified as black oat (Avena strigosa). Occasional grains of barley were also present and one grain of bread/club wheat (Triticum aestivo-compactum) was recovered from the back fill of the firepit (F38).

Buds and floret fragments of heather were present in large quantities, particularly within ash deposits at the base of the flue. Small quantities of other wild taxa were also encountered, including hemp-nettle (Galeopsis sp.), corn spurrey, corn marigold (Chrysanthemum segetum) and grass (Gramineae indet.)

Only small quantities of charcoal were recovered from the fill of the kiln, including occasional small fragments of birch, heather and willow.

\subsection{Discussion of the corn-drying kiln, by Mhairi Hastie}

A corn-drying kiln, similar in diameter to other medieval/post-medieval kilns, was uncovered in Area D. It was stone-built and had a bowl with a maximum diameter of $2.7 \mathrm{~m}$. Such kilns were a common feature in Scotland particularly during the medieval and post-medieval periods, and some were still in use until the 20th century especially in Orkney (Fenton 1999). Traditionally these round kilns were regarded as 16th- and 17th-century (postmedieval) in date, yet excavations at Abercairny and Capo (Gibson 1989), and Chapleton (Pollock 1985) indicate that they were in use from at least the 13 th century.

In the Highlands of Scotland kilns were built onto the ends of the farm barn, however, in Lowland areas the kiln was either a free-standing structure built half into a slope or formed part of a small kiln barn built separately from other structures. Each kiln, used to parch the grain prior to threshing, grinding 
and/or malting, would have served a single family or family group. These kilns were used in mainland Scotland until the 18th century, when agricultural improvements brought the development of commercial meal-mills with adjoining large drying kilns (Gibson 1989).

The majority of grains recovered from the kiln were black oat; this species formed the main crop cultivated during the medieval and later periods in Scotland. Fenton (1999) notes that a kiln of similar dimensions to that uncovered at Lockerbie would have held about four sacks of oats, spread to a depth of 3 inches $(8 \mathrm{~cm})$, during each drying session. Occasional grains of barley were also recovered from the kiln. These may have been grown along with the oat either as a deliberately mixed or 'maslin' crop or as a weed of the oat crop, alternatively the grain may have been burnt during a previous drying session.

Of some note is the presence of a grain of bread wheat within the firepit of the kiln. High rainfall, characteristic of the west coast of Scotland, can result in premature germination of wheat (Britnell 2004), and it would have been difficult to cultivate in the west of Scotland due to cold temperatures and a short growing season. The statistical accounts (Statistical Accounts of Scotland 1791-99) indicate that even in the 18th century only oat and barley were being cultivated in this area of Dumfriesshire. Large quantities of bread wheat were recovered from excavations at the monastic settlements of Hoddom (Holden 2006) and Whithorn (Hastie 2003), suggesting that bread wheat was being imported into the region.

Traditionally, dried peat was used to heat the drying kiln (Fenton 1999) as it was less likely to spark than wood and hence limit the chance of the kiln catching fire. This would have produced corn that had a tang of peat-smoke in the taste. The practice of using turf as the main fuel was eventually replaced with the use of chaff, removed from the cereal grains during threshing, as this removed the peaty tang. A high concentration of heather florets and buds, along with damp/acid-loving species such as sedge, and rhizome fragments (underground stems) was recovered from the bowl and flue of the kiln, suggesting that in this case turfs were being used to stock the kiln.

The largest quantity of weed seeds recovered from the whole of the excavated area was recovered from the fill of the kiln. The seeds comprised smallgrained species such as corn spurrey, corn marigold and hemp-nettle, which were all common elements of arable fields prior to the introduction of herbicides. Indeed, corn marigold was such a prevalent weed of medieval crops that laws were passed in the 13th century stating that if a farmer allowed so much as a single plant to produce seed in amongst his crop then he would be fined a sheep (Dalrymple 1776). 


\section{SEGMENTED DITCHED ENCLOSURE (Area B)}

The segmented ditched enclosure (illus 25) was situated on sloping ground just below the lip of the plateau where the Neolithic structure was identified. It had a diameter of $c 25 \mathrm{~m}$ and consisted of four separate segments.

The enclosure ditch consisted of four segments
(F166, F167, F168/F170 and F169) of lengths varying between $c 11 \mathrm{~m}$ and $13 \mathrm{~m}$ and surviving widths of between $0.8 \mathrm{~m}$ and $1.4 \mathrm{~m}$ (segment F168 ran parallel with F170 and is probably a re-cut of this feature). Sections excavated at the ditch terminals and across the centre of the ditches showed that they were very

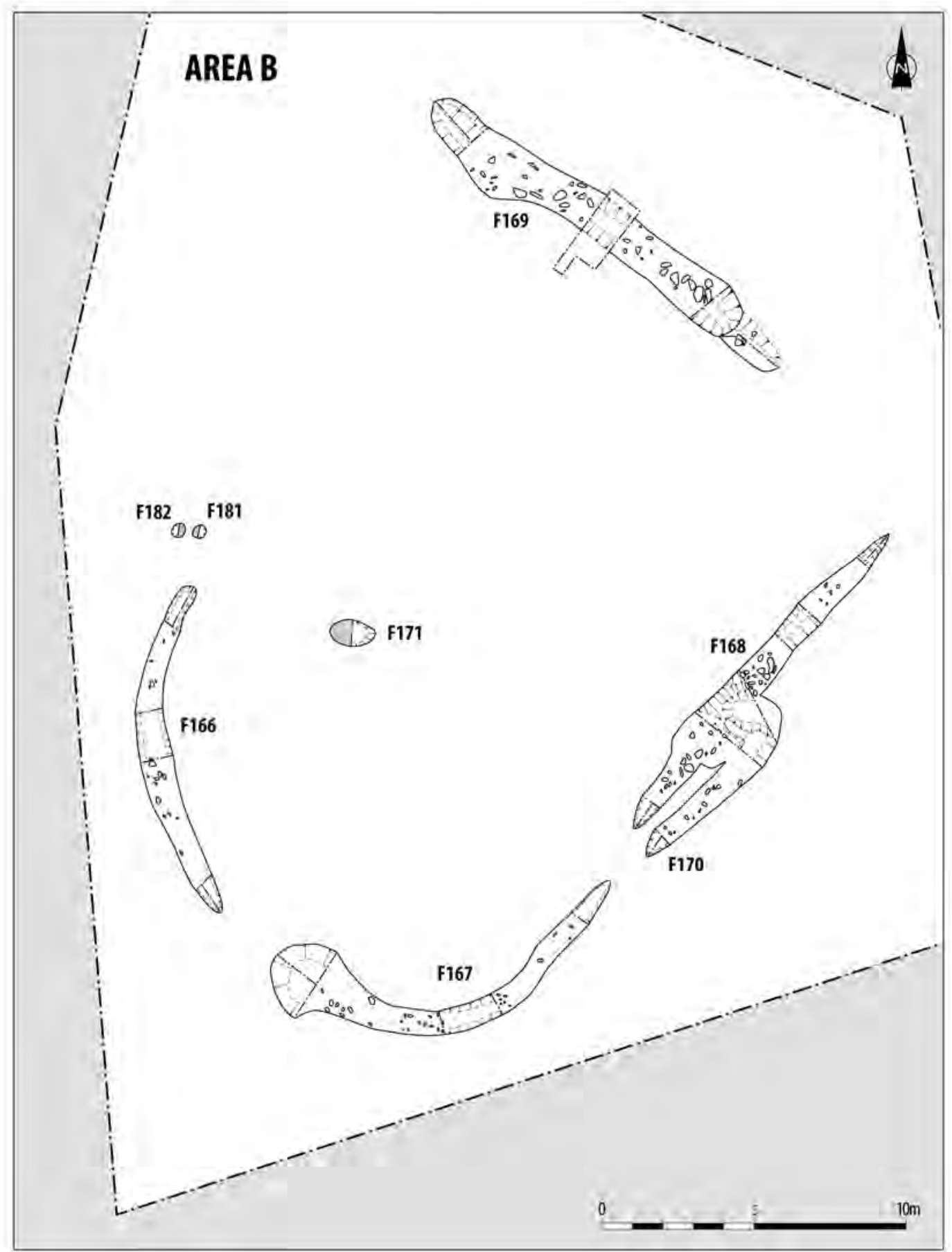

Illus 25 Area B: segmented ditched enclosure 
vestigial, typically only surviving to a depth of $0.1 \mathrm{~m}$. A large gap in the enclosure to the north-west within an area of very shallow topsoil suggests that there may have been a fifth segment that has now been completely ploughed out.

The pit (F171) within the interior of the enclosure was oval in shape, measuring $1.4 \mathrm{~m}$ NW-SE by $0.7 \mathrm{~m}$ SW-NE by $0.24 \mathrm{~m}$ deep. The fill of the pit consisted of mid-brown silt containing lumps of organic material.

Due to the degree of survival, analogies with other sites are problematic. Two recently discovered ringditches from the Colne Valley, West London (Barclay et al 2009) enclosed pits containing cremation burials dating to the latter part of the fourth millennium BC. However, at Lockerbie the absence of both artefacts and material suitable for radiocarbon-dating mean that it is impossible to tell if this enclosure was of a similar date or shared a similar function. The degree of plough truncation suggests that this area has been heavily exploited for agricultural purposes in recent years. 


\section{CONCLUSION}

The excavations carried out at Lockerbie Academy have made a significant contribution to the archaeology of the Neolithic, Bronze Age and Anglian periods in Scotland.

The Early Neolithic timber hall is only the fourth example to be excavated in Scotland (the fifth, if Doon Hill A is indeed Neolithic) and its position within the south-west of the country demonstrates that a building type once thought to be confined to the north-eastern Lowlands may have been considerably more widespread. Radiocarbon dates obtained for these structures suggest that they were broadly contemporary, indicating that they were a relatively short-lived phenomenon dating to the earliest part of the Neolithic. Similarities between the four excavated structures indicate that they may all have served a similar function. Whether they can be interpreted as 'normal' farmhouses is open to debate, but they were all situated within highly fertile plains and potentially represent the control of large tracts of arable land.

The Bronze Age cemetery was very similar to that excavated at the nearby Kirkburn site, but on a rather smaller scale. It broadly comprised a large central burial surrounded by smaller satellite burials. The cemetery demonstrated a variety of burial rites, including cremation and inhumation. Of particular note was the large boulder that sat within the upper fill of the central burial. Several high-status items were recovered from the graves, including a stone wristguard and a bronze dagger of the Butterwick type.

The site also demonstrated clear evidence of Northumbrian settlement within the southwestern part of Scotland. Northumbrian settlement is clearly visible within the archaeological record of south-east Scotland at sites such as Sprouston, Doon Hill and Castle Rock, Dunbar, but in the south-west, away from the important monastic sites at Whithorn and Hoddom, it has been largely inferred from the historical records of the time, combined with the presence of Anglian placenames and the recovery of Anglian carved crosses and other sculpture. 


\section{ACKNOWLEDGEMENTS}

The excavations at Lockerbie Academy were carried out during the winter of 2006 . Conditions were often very adverse and on a number of occasions deep snow had to be removed from the site. The author would like to thank the following people for their hard work and dedication under what were very often difficult working conditions: Helena Gray, Ian Hill, Sarah Lynchaun, Gemma Midlane and Phil Richardson. The project was funded by Dumfries \& Galloway Council.

Radiocarbon-dating for the site was carried out by the Scottish Universities Environmental Research Centre (SUERC). The calibrated age ranges were determined from the University of Oxford Radiocarbon Accelerator Unit calibration program $(\mathrm{OxCal}$ v.10). The Collared Urn was conserved by Will Murray, Scottish Conservation Studio.

Illustrations are the work of Leeanne Whitelaw, Karen Clarke and Craig Evenden of CFA Archaeology Ltd, with the illustration of the dagger by
Marion O'Neil, and the microscope photographs supplied by National Museums Scotland. Alison Sheridan thanks Lore Troalen for having analysed the wristguard, Rob Ixer for having reported on its raw material, and Ann Woodward and John Hunter for permission to publish this information.

Thanks also to Jane Brann, Rhona Wells and John Cuthbertson of Dumfries \& Galloway Council and Bruce Glendinning of CFA Archaeology for their continued support throughout the project, and to Sue Anderson, Andy Dunwell, Alison Sheridan and Ian Ralston for their help and advice on this publication. Andrew Tester, Suffolk C.C. Archaeological Service, supplied useful information on Anglian timber-built structures in England. Dr Hilary Murray, Murray Archaeological Services Ltd, kindly provided a draft of the report on Warren Field, Crathes. Additionally, this paper has benefited from the comments of two anonymous referees. 


\section{REFERENCES}

Adamson, D 1970-72 'The Hearth Tax', Transactions of the Dumfriesshire \& Galloway Natural History \& Antiquarian Society, 47-9, 147-77.

Alcock, L 2003 Kings and Warriors, Craftsmen and Priests in Northern Britain AD 550-850. Edinburgh (=Soc Antiq Scot Monogr).

Anderson, S forthcoming 'The fired clay', in A Tester; S Anderson; R Carr \& I Riddler A High Status Middle Saxon Settlement on the Fen Edge: Staunch Meadow, Brandon, Suffolk. Bury St Edmunds: East Anglian Archaeology.

Anon 1871 Transactions of the Dumfriesshire \& Galloway Natural History \& Antiquarian Society, 1st ser, 6, 7-8.

Armit, I; Murphy, E; Nelis, E \& Simpson, D (eds) 2003 Neolithic Settlement in Ireland and Western Britain. Oxford: Oxbow.

Ashmore, P J 1989 'Excavation of a beaker cist at Dornoch Nursery, Sutherland', Proc Soc Antiq Scot, 119, 63-71.

Ashmore, P 1996 Neolithic and Bronze Age Scotland. Edinburgh: Historic Scotland.

Ashmore, P J 2007a 'Radiocarbon dates from the Pict's Knowe, Holywood and Holm', in J Thomas 248-59.

Ashmore, P J 2007b 'Appendix 9. Calibrated radiocarbon determinations from Holm, Holywood and the Pict's Knowe', in J Thomas, 307-10.

Barclay, A 2009 'New evidence for mid-late Neolithic burial from the Colne Valley, West London', PAST No. 63, Nov 2009, 4-6.

Barclay, G; Brophy, K \& MacGregor, G 2002 'Claish, Stirling: an early Neolithic structure in its context', Proc Soc Antiq Scot, 132, 65-137.

Bishop, A H 1919 'Note on a burial after cremation', Transactions of the Dumfriesshire \& Galloway Natural History \& Antiquarian Society, 3rd Series, 5 (1918-19), 44-8.

Bishop, R 2007 'What contributions did huntergathering and agriculture have for the Neolithic palaeo-economy of Lockerbie Academy?' Unpublished BSc Dissertation, University of Durham.

Boase, W N 1918 'Flax and flax fibre cultivation', Scottish Journal of Agriculture, 1, 140-7.

Boardman, S 1997 'The charred plant remains from Mills Mount', in S T Driscoll \& P A Yeoman Excavations within Edinburgh Castle in 198891, 191-9. Edinburgh (=Soc Antiq Scot Monogr Ser, 12).

Brindley, A 2007 The Dating of Food Vessels and Urns in Ireland. Galway: department of Archaeology, National University Ireland (=Bronze Age Studies 7).
Britnell, R 2004 Britain and Ireland 1050-1530: Economy and Society. Oxford: Oxford University Press.

Brooke, D 1991 'The Northumbrian settlements in Galloway and Carrick: an historical assessment', Proc Soc Antiq Scot, 121, 295-327.

Brophy, K 2007 'From Big Houses to Cult Houses: Early Neolithic timber halls in Scotland', Proceedings of the Prehistoric Society, 73, 75-96.

Brown, E; Howard-Davis, C \& Brennand, M 2007 'The early prehistoric landscape', in F Brown; C Howard-Davis; M Brennand;A Boyle; T Evans; S O'Connor; A Spence; R Heawood \& A Lupton The Archaeology of the A1(M) Darrington to Dishforth DBFO Road Scheme, 17-41. Lancaster: Oxford Archaeology North.

Carter, S \& Tipping, R 1993 'The prehistoric occupation of Carradale, Kintyre', Glasgow Archaeological Journal, 17, (1991-2), 39-52.

Cameron, A; Johnston, A \& Stones, J 1996 'Excavation at two sites in Old Aberdeen', Proc Soc Antiq Scot, 126, 911-27.

Carr, R D; Tester, A \& Murphy, P 1988 'The MiddleSaxon settlement at Staunch Meadow, Brandon', Antiquity, 62, 371-7.

Clapham, A J 1986 'The origin, domestication, dispersal and cultivation of flax, Linum usitatissimum', Plant Domestication and Dispersal: Unpublished Course Paper.

Clark, J G D 1932 'The date of the plano-convex flint-knife in England and Wales', Antiquaries Journal, 12, 158-62.

Clarke, D L 1970 Beaker Pottery of Great Britain and Ireland. Cambridge: Cambridge University Press.

Close-Brooks, J 1980 'Excavations in the Dairy Park, Dunrobin, Sutherland 1977', Proc Soc Antiq Scot, 110 (1978-80), 328-45.

Cormack, W F 1963 'Burial site at Kirkburn, Lockerbie', Proc Soc Antiq Scot, 96 (1962-3), 107-35.

Cormack, W F 1981 'A corn-drying kiln at Airykick, Port William', Transactions of the Dumfriesshire \& Galloway Natural History \& Antiquarian Society, 56, 91-9.

Cowie, T G; Masters, L J M \& Harman, M 1981 'An urn burial from Burnfoot Plantation, Dowglen Hill, Westerkirk', Transactions of the Dumfriesshire \& Galloway Natural History \& Antiquarian Society, 3rd Series, 56, 31-7.

Cowie, R \& Whytehead, R 1989 'Lundenwic: the archaeological evidence for Middle Saxon London', Antiquity, 63, 706-18.

Cressey, M \& Sheridan, J A 2003 'The excavation of a Bronze Age cemetery at Seafield West, near 
Inverness, Highland', Proc Soc Antiq Scot, 133, $47-84$.

Cross, S 2003 'Irish Neolithic settlement architecture - a reappraisal', in I Armit; E Murphy; E Nelis \& D Simpson (eds) Neolithic Settlement in Ireland and Western Britain, 195-202. Oxford: Oxbow.

Dalrymple, D 1776 Annals of Scotland, 338-9. London: J Murray.

Driscoll, S T 1997 'A Pictish settlement in north-east Fife: the Scottish Field School of Archaeology excavations at Easter Kinnear', Tayside \& Fife Archaeological Journal, 3, 74-118.

Fairweather, A D \& Ralston, I B M 1993 'The Neolithic timber hall at Balbridie, Grampian Region, Scotland: the building, the dates, the macrofossils', Antiquity, 67, 313-23.

Fenton, A 1999 Scottish Country Life. East Lothian: Tuckwell Press.

Finlayson, B 1990 'Lithic explotiation during the Mesolithic in Scotland', Scottish Archaeological Review, 7, 41-57.

Finlayson, B; Finlay, N \& Mithen, S 2001 'The cataloguing and analysis of the lithic assemblages', in S J Mithen (ed) Hunter-Gatherer Landscape Archaeology: The Southern Hebrides Mesolithic Project 1988-98, 61-72. Cambridge (=McDonald Institute Monogr).

Fitzpatrick, A P 2002 "The "Amesbury Archer": a well-furnished Early Bronze Age burial in southern England', Antiquity, 76, 629-30.

Fokkens, H; Achterkamp, Y \& Kuijpers, M 2008 'Bracers or bracelets? About the functionality and meaning of Bell beaker wristguards', Proceedings of the Prehistoric Society, 73, 109-40.

Gerloff, S I M 1975 The Early Bronze Age Daggers in Great Britain and a Reconsideration of the Wessex Culture, Prähistorische Bronzefunde, VI(2), München: C.H. Beck'sche Verlagsbuchhandlung.

Gibson, A 1989 'Medieval corn-drying kilns at Capo, Kincardineshire and Abercairny, Perthshire', Proc Soc Antiq Scot, 118, 219-29.

Green, H S 1980 The Flint Arrowheads of the British Isles: a detailed study of material from England and Wales with comparanda from Scotland and Ireland. Oxford (=Brit Archaeol Rep, Brit Ser, $75)$.

Greig, J 1991 'The British Isles' in W van Zeist; K Wasylikowa \& K Berne (eds) Progress in Old World Palaeoethnobotany: a retrospective view on the occasion of 20 years of the International Work Group for Palaeoethnobotany. Rotterdam: Balkema.

Harbison, P H 1976 Bracers and V-perforated Buttons in the Beaker and Food Vessel Cultures of Ireland. Bad Bramstedt (=Archaeologia Atlantica Research Report, 1).

Harding, D W 2004 The Iron Age in Northern Britain: Celts and Romans, Natives and Invaders. London: Routledge.

Hastie, M 2003 'Assessment of samples', in J
Morrison Research and Training Excavation in the Manse Field, Whithorn, Dumfries \& Galloway. Unpublished Archive Report, Headland Archaeology Ltd.

Hayden, C 2007 'White Horse Stone and the earliest Neolithic in the South East', South-East Research Framework Resource Assessment Seminar (unpublished).

Henshall, A S 1968 'Scottish dagger graves', in J M Coles \& D D A Simpson (eds) Studies in Ancient Europe, 173-95. Leicester: Leicester University Press.

Hill, P 1996 Whithorn and St Ninian: the Excavation of a Monastic Town, 1984-91. Stroud: Sutton.

Holden, T G 2006 'The Botanical Evidence' in C Lowe Excavations at Hoddom, Dumfriesshire: An enclosed high status settlement of the later First Millennium AD. Edinburgh: Society of Antiquities of Scotland.

Holden, T G \& Boardman, S 2000 'The macroplant assemblage' in A Crone (ed) The History of a Scottish Lowland Crannog: Excavations at Buiston, Ayrshire 1989-90. Edinburgh (=Scottish Trust for Archaeology Monograph, 4), 151-5.

Hope-Taylor, B 1977 Yeavering: An Anglo-British Centre of Early Northumbria. London (=Dept Environment Archaeol Rep (HMSO), 7).

Hope-Taylor, B 1980 'Balbridie . . . and Doon Hill', Current Archaeology 72, 18-19.

Huggins, P J 1991 'Anglo-Saxon timber building measurements: recent results', Medieval Archaeol, 35, 6-28.

Johnson, $\mathrm{M}$ \& Cameron, $\mathrm{K}$ forthcoming 'A Bronze Age cremation cemetery at Skilmafilly, near Maud, Aberdeenshire, and other prehistoric sites in Aberdeenshire. Excavations 2001', Scottish Archaeological Internet Reports.

Jones, G forthcoming 'Evidence for the importance of cereals in the Neolithic charred plant remains from the Neolithic settlement at Lismore Fields, Buxton', in D Garton The Excavation of a Mesolithic and Neolithic settlement area at Lismore Fields, Buxton, Derbyshire.

Kenney, J 2008 Recent Excavations at Parc Bryn Cegin, Llandygai, near Bangor, North Wales. Unpublished Excavation Report, Gwynedd Archaeological Trust.

Kenworthy, J B 1976 'A reconsideration of the "Ardiffery" finds', Proc Soc Antiq Scot, 108, 80-93.

Kinnes, I 1985 'Circumstance not context: the Neolithic of Scotland as seen from outside', Proc Soc Antiq Scot, 115, 15-57.

Lane, R 2005 'Daub', in C A Spall \& N J Toop (eds) Blue Bridge Lane \& Fishergate House, York. Report on Excavations: July 2000 to July 2002. Archaeol Planning Consultancy Ltd online monogr: http://www.archaeologicalplanningconsultancy.co.uk/mono/001/rep_build_daub.html

Laing, L R 1969 'Timber halls in Dark Age Britain - some problems', Transactions of the Dumfries- 
shire \& Galloway Natural History \& Antiquarian Society, 3rd ser, 46 (1969), 110-27.

Lewis, J \& Terry, J 2004 'The excavation of an early Bronze Age cemetery at Holly Road, Leven, Fife', Tayside \& Fife Archaeological Journal, $10,23-53$.

Longworth, I H 1984 Collared Urns of the Bronze Age in Britain and Ireland, Cambridge: Cambridge University Press.

Losco-Bradley, S \& Kinsley, G 2002 Catholme: An Anglo-Saxon Settlement on the Trent Gravels in Staffordshire. Nottingham: Trent and Peak Archaeological Unit.

Loveday, R 2008 'Where have all the Neolithic houses gone? Turf - an invisible component', Scottish Archaeological Journal, 28.2 (2006), 81-104.

Lowe, C E 2006 Excavations at Hoddom, Dumfriesshire: an Early Ecclesiastical Site in South-West Scotland. Edinburgh: Society of Antiquaries of Scotland.

MacGregor G \& McLellan K 2007 'A burning desire to build: excavations at Eweford West and Pencraig Hill (3950-3380 BC)', in O Lelong \& G MacGregor The Lands of Ancient Lothian. Interpreting the Archaeology of the A1, 15-45. Edinburgh: Society of Antiquaries of Scotland.

Marshall, A \& Marshall, G 1991 'A survey and analysis of the buildings of Early and Middle Anglo-Saxon England', Medieval Archaeology $35,29-43$.

Masters, L 1973 ‘The Lochhill long cairn', Antiquity, 47, 96-100.

Maynard, D 1993 'Neolithic pit at Carzield, Kirkton, Dumfriesshire', Transactions of the Dumfriesshire \& Galloway Natural History \& Antiquarian Society, 68, 25-32.

Mays, S A 1998 The Archaeology of Human Bones. London: Routledge.

Mays, S A 1999 'Cremated bone from CEU excavations, and unpublished bone from earlier work', in N R Brown, The Archaeology of Ardleigh, Essex: Excavations 1955-1980. Chelmsford (=East Anglian Archaeology 90).

McKinley, J I 1994 The Anglo-Saxon Cemetery at Spong Hill, North Elmham Part VIII: the Cremations. Norwich (=East Anglian Archaeology 69).

McKinley, J I 2004 'Compiling a skeletal inventory: cremated human bone', in M Brickley \& J I McKinley (eds) Guidelines to the Standards for Recording Human Remains. Reading (=IFA Paper No 7).

Mercer, R J \& Midgley, M S 1997 'The Early Bronze Age cairn at Sketewan, Balnaguard, Perth \& Kinross', Proc Soc Antiq Scot, 127, 281-338.

Monk, M A 1990 'The archaeobotanical evidence for field-crops in early historic Ireland', in J M Renfrew (ed) New Light on Early Farming: Recent Developments in Palaeoethnobotany, 315-28. Edinburgh: Edinburgh University Press.
Morrison, A 1968 'Cinerary urns and pygmy vessels in South-West Scotland', Transactions of the Dumfriesshire \& Galloway Natural History \& Antiquarian Society, 3rd ser, 45 (1967-8), 80ff, 101, 116, nos 101-4.

Murray, H \& Murray, C 2004 'Warren Field, Crathes (Banchory-Ternan parish): Neolithic timber structure; pit alignment', Discovery \& Excavation in Scotland, $5,11$.

Murray, H \& Murray, C 2006 Warren Field, Crathes: Summary of project results, 2006 season. Unpublished report, Murray Archaeological Services.

Murray, H K, Murray, C \& Fraser, S M 2009 A Tale of the Unknown Unknowns: A Mesolithic Pit Alignment and a Neolithic Timber Hall at Warren Field, Crathes, Aberdeenshire. Oxford: Oxbow.

Needham, S 1996 'Chronology and periodisation in the British Bronze Age', Acta Archaeologica 67, $121-40$.

Needham, S P 2005 'Transforming Beaker Culture in North-West Europe: Processes of Fusion and Fission', Proceedings of the Prehistoric Society, 71, 171-217.

Northover, J P 1980 'The analysis of Welsh Bronze Age metalwork', in H N Savory Guide Catalogue to the Bronze Age Collections, appendix. Cardiff: National Museum of Wales.

Northover, J P 2003a 'The bronze dagger from the log coffin: the metal of the dagger', in M Cressey \& A Sheridan 'The excavation of a Bronze Age cemetery at Seafield West, near Inverness, Highland', Proc Soc Antiq Scot, 133, 58-62.

Northover, J P 2003b 'The dagger: metallurgical analysis', in L Baker, J A Sheridan \& T G Cowie "An Early Bronze Age "dagger grave" from Rameldry Farm, near Kingskettle, Fife', Proc Soc Antiq Scot, 133, 98-9.

Northover, J P 2005 'The Early Bronze Age metalwork', in G Lambrick \& T G Allen Gravelly Guy, Stanton Harcourt, Oxfordshire: the development of a prehistoric and Romano-British Community, 88-90. Oxford (=Thames Valley Landscapes Monogr, 21).

Pauketat, T R \& Alt, S 2005 'Agency in a postmold? Physicality and the archaeology of culturemaking, Journal of Archaeological Method \& Theory, 12, 213-36.

Perry, D R 2000 Castle Park Dunbar: Two Thousand Years on a Fortified Headland, Edinburgh (=Soc Antiq Scot Monogr Ser, 16).

Peterson, R \& Roberts, J 2007 'Prehistoric ceramics', in $\mathrm{J}$ Thomas, $132-5$ \& 221-2.

Piggott, S 1948 'The excavations at Cairnpapple Hill, West Lothian', Proc Soc Antiq Scot, 82 (1947-8), 68-123.

Piggott, S \& Powell, T G E 1949 'The excavation of three Neolithic chambered tombs in Galloway, 1949', Proc Soc Antiq Scot, 83 (1948-9), 103-61.

Pollard, T 1997 'Excavation of a Neolithic settlement and ritual complex at Beckton Farm, Lockerbie, 
Dumfries \& Galloway', Proc Soc Antiq Scot, 127 (1997), 69-121.

Pollock, D 1985 'The Lunan Valley Project, medieval rural settlement in Angus', Proc Soc Antiq Scot, 115, 357-99.

Rae, W 1880 'Notice of an urn and bronze blade found at Shuttlefield, Lockerbie', Proc Soc Antiq Scot, 14 (1879-80), 280-2.

Ralston, I B M 1982 'A timber hall at Balbridie Farm: the Neolithic settlement of North-East Scotland', Aberdeen University Review, 168 (1981-2), 238-49.

Reynolds, N 1980 'Dark Age timber halls and the background to excavations at Balbridie', Settlements in Scotland 1000 BC-AD 1000, Edinburgh (=Scott Archaeol Forum, 10).

Ritchie, A 1983 'Excavations of a Neolithic Farmstead at Knap of Howar, Papa Westray, Orkney', Proc Soc Antiq Scot, 113, 40-122.

Robinson M A 2000 'Further considerations of Neolithic charred cereals, fruits and nuts', in A S Fairburn (ed) Plants in Neolithic Britain and beyond, 85-90. Oxford: Oxbow Books.

Roe, F \& Woodward, A 2007 'The wristguard from Burial 2245', in Brown et al 2007, 298-304.

Ryder, M L 1964 'Report on hair and skin remains from Ashgrove Farm, Methil, Fife and other Bronze Age sites', in A S Henshall 'A daggergrave and other cist burials at Ashgrove, Methilhill, Fife', 174-6, Proc Soc Antiq Scot, 97 (1963-4), 166-79.

Scott, L 1951 'Corn drying kilns', Antiquity, 100, 196.

Sheridan, J A 1997 'Pottery', in D A Johnston 'Biggar Common, 1987-93: an early prehistoric funerary and domestic landscape in Clydesdale, South Lanarkshire', Proc Soc Antiq Scot, 127, 202-23.

Sheridan, J A 2002 'Pottery and other ceramic finds', in G J Barclay; Brophy K \& G MacGregor 'Claish, Stirling: an Early Neolithic site in its context', Proc Soc Antiq Scot, 132, 79-88.

Sheridan, J A 2003 'New dates for Scottish Bronze Age cinerary urns: results from the National Museums of Scotland Dating Cremated Bones Project', in A Gibson (ed) Prehistoric Pottery: People, Pattern and Purpose. Oxford (=Brit Archaeol Rep, Int Ser, 1156).

Sheridan, J A 2007a 'From Picardie to Pickering and Pencraig Hill? New information on the "carinated Bowl Neolithic" in northern Britain', in A W Whittle R \& V A Cummings (eds), Going Over: the Mesolithic-Neolithic Transition in North-West Europe, 439-90. Oxford: Oxford University Press/British Academy (=Proceedings of the British Academy 144).

Sheridan, J A 2007b 'Pottery from Pencraig Hill', in A1 archive linked to O Lelong \& G MacGregor The Lands of Ancient Lothian. Interpreting the Archaeology of the A1. Edinburgh: Society of Antiquaries of Scotland.

Sheridan, J A 2007c 'Dating the Scottish Bronze
Age: "There is clearly much that the material can still tell us", in C Burgess; P Topping \& F M Lynch (eds) Beyond Stonehenge: Essays on the Bronze Age in Honour of Colin Burgess, 162-85. Oxford: Oxbow.

Sheridan, J A 2007d 'Scottish Beaker dates: the good, the bad and the ugly', in M Larsson \& M Parker Pearson (eds) From Stonehenge to the Baltic: Living with Cultural Diversity in the Third Millennium BC, 91-123. Oxford (=Brit Archaeol Rep, Int Ser, 1692).

Sheridan, J A 2009 'The pottery', in H K Murray et al.

Sheridan, J A \& Cowie, T G 2003 'Rameldry and Scottish dagger graves', in L Baker; J A Sheridan \& T G Cowie 'An Early Bronze Age "dagger grave" from Rameldry Farm, near Kingkettle, Fife', Proc Soc Antiq Scot, 133, 109-12.

Smith, I M 1991 'Sprouston, Roxburghshire: an early Anglian centre in the eastern Tweed Basin', Proc Soc Antiq Scot, 121, 261-94.

Smith, J 2006 'Early Bronze Age stone wrist-guards in Britain: archer's bracer or social symbol?', Archaeology Chaos, http://www.geocities.com/ archchaos1/article1/1.htm.

Statistical Accounts of Scotland 1791-99

Thomas, J (ed) 2007. Place and Memory. Excavations at the Pict's Knowe, Holywood and Holm Farm, Dumfries \& Galloway, 1994-8. Oxford: Oxbow.

Topping, P (ed) 1997 Neolithic Landscapes. Oxford (=Neolithic Studies Group Seminar Papers 2).

Ward, T 1995 'Daer Reservoir (Crawford Parish)', Discovery \& Excavation in Scotland 1995, 87.

Ward, T 1997 'Daer Reservoir (Crawford Parish)', Discovery \& Excavation in Scotland 1997, 75.

Ward, T 1998 'Daer Reservoir 1, Crawford', Discovery \& Excavation in Scotland 1998, 128.

Warren, G M 2007a 'Chipped stone tool industries of the earlier Neolithic in eastern Scotland', Scottish Archaeological Journal, 28, 27-47.

Warren, G M 2007b 'An archaeology of the Mesolithic in Eastern Scotland: deconstructing culture, constructing identity', in C Waddington \& K Pedersen (eds) Mesolithic Studies in the North Sea Basin and Beyond: Proceedings of a Conference Held at Newcastle in 2003, 137-150. Oxford: Oxbow.

Warren, G 2009 'Lithics', in H K Murray et al.

WEA 1980 'Recommendations for age and sex diagnoses of skeletons', Journal of Human Evolution, 9, 517-49.

Wickham-Jones, C J \& Collins, G H 1978 'The sources of flint and chert in northern Britain', Proc Soc Antiq Scot, 109, 7-21.

Woodman, P C; Finlay, N \& Anderson, E 2006 The Archaeology of a Collection: the Keiller-Knowles Collection of the National Museum of Ireland. Bray (=National Museum of Ireland Monograph Series 2).

Woodward, A; Hunter, J; Ixer, I; Roe, F; Potts, P J; Webb, P C; Watson, J S \& Jones, M C 2006 'Beaker 
age bracers in England: sources, function and use', Antiquity, 80, 530-43.

Woodward, A et al forthcoming Ritual in Early Bronze Age Grave Goods.
Wordsworth, J 1982 'Excavation of the settlement at 13-21 Castle Street, Inverness, 1979', Proc Soc Antiq Scot, 112, 322-91. 